Gustavo Afonso Rodrigues

\title{
UM SIMULADOR PARA MODELOS DESCRITOS EM UML
}

Dissertação apresentada à Escola Politécnica da Universidade de São Paulo para obtenção do título de Mestre em Engenharia. 


\section{Gustavo Afonso Rodrigues}

\section{UM SIMULADOR PARA MODELOS DESCRITOS EM UML}

Dissertação apresentada à Escola Politécnica da Universidade de São Paulo para obtenção do título de Mestre em Engenharia.

Área de concentração: Engenharia Elétrica - Sistemas Digitais

Orientador:

Prof. Dr. Edson Satoshi Gomi 
Este exemplar foi revisado e alterado em relação à versão original, sob responsabilidade única do autor e com a anuência de seu orientador.

São Paulo, 30 de setembro de 2009

Assinatura do autor

Assinatura do orientador

Ficha Catalográfica

Rodrigues, Gustavo Afonso

Um simulador para modelos descritos em UML / G.A. Rodrigues. - ed. rev. - São Paulo, 2009.

$92 \mathrm{p}$.

Dissertação (Mestrado) — Escola Politécnica da Universidade de São Paulo. Departamento de Engenharia de Computação e Sistemas Digitais.

1. UML 2. Projeto de software orientado a objeto 3. Ciclo de vida de desenvolvimento de software I. Universidade de São Paulo. Escola Politécnica. Departamento de Engenharia de Computação e Sistemas Digitais II. t. 


\section{Dedicatória}

Aos meus pais, à minha irmã, à minha avó e avô (i.m.), em quem me inspiro diariamente, aos meus amigos e à minha noiva, que sempre torcem por mim e me incentivam a seguir lutando pelos meus sonhos. Espero poder retribuir a todos o carinho e apoio irrestrito que recebi. 


\section{Agradecimentos}

Ao Prof. Dr. Edson Satoshi Gomi pelas diretrizes, sugestões e incentivo durante todo o tempo.

À minha família e noiva pelo apoio total e irrestrito durante todas as difíceis etapas que atravessei.

Aos meus colegas do laboratório KNOMA e companheiros de trabalho, sem os quais não teria chegado até aqui.

A todos que, direta ou indiretamente, colaboraram para a realização deste trabalho. 


\section{Resumo}

RODRIGUES, G. A. UM SIMULADOR PARA MODELOS DESCRITOS EM UML. 2009. 92 f. Dissertação - Escola Politécnica da Universidade de São Paulo, São Paulo, 2009.

O objetivo da pesquisa apresentada neste trabalho foi investigar como simular modelos descritos em Unified Modelling Language (UML) para sistemas de software especificados em nível de negócio. Um simulador de um modelo UML em nível de negócio pode ser uma ferramenta útil para um projetista que procura por erros ou modelos incompletos. Usando abordagens de desenvolvimento tradicionais, estes tipos de erros seriam encontrados apenas em estágios posteriores do ciclo de vida de desenvolvimento do sistema. Os principais resultados deste trabalho são a especificação de uma arquitetura de uma máquina virtual capaz de executar todas as ações descritas em um modelo UML, e o protótipo chamado ModSim, o qual executa um modelo UML recebido no formato $X M L$ Metadata Interchange (XMI).

Palavras-chave: UML, Model Driven Architecture (MDA), Simuladores. 


\section{Abstract}

RODRIGUES, G. A. A SIMULATOR FOR MODELS DESCRIBED IN UML. 2009. 92 f. Dissertation (Master's Degree) - Escola Politécnica da Universidade de São Paulo, São Paulo, 2009.

The main goal of the research presented in this Master Thesis was to investigate how to simulate UML based models for software systems specified on business level. A simulator of a UML model on business level can be a useful tool for a designer looking for errors or incomplete models. Using traditional development approaches, these kind of errors would be found only on lates stages of the system development. The main results of this work are the specification of an architecture of a virtual machine capable of executing all actions described in the UML model, and the prototype named ModSim, which executes a UML model received in XMI format.

Keywords: UML, MDA, Simulators. 


\section{Lista de Figuras}

2.1 Diagrama de classes no Método Booch (CAMPos, 2007). . . . . . . . . . 28

2.2 Diagrama de objetos OMT (CAMPOS, 2007) . . . . . . . . . . . . 29

2.3 Diagrama de estados OMT (CAMPos, 2007) . . . . . . . . . . . . . . 29

2.4 Exemplo de Diagrama de Casos de Uso. . . . . . . . . . . . . . . . . . . . 32

2.5 Exemplo de Diagrama de Classes. . . . . . . . . . . . . . . . . . . . . 34

2.6 Exemplo de Diagrama de Classes para geração de código-fonte. . . . . . . . 34

2.7 Exemplo de Diagrama de Objetos. . . . . . . . . . . . . . . . 36

2.8 Exemplo de diagrama de sequência, baseado em Mellor e Balcer (2002). . . 37

2.9 Exemplo de diagrama de colaboração, baseado em Mellor e Balcer (2002). . 38

2.10 Exemplo de diagrama de máquina de estados. . . . . . . . . . . . . . . 39

2.11 Exemplo de diagrama de atividade. . . . . . . . . . . . . . . 40

2.12 Diagrama de Pacotes. Baseado em Mellor e Balcer (2002). . . . . . . . . . 40

2.13 Diferentes usos para o diagrama de classes. . . . . . . . . . . . . . . . . 42

2.14 Exemplo de flexibilidade semântica em relacionamentos nos diagramas de classe. . . . . . . . . . . . . . . . . . . . . . . 4 42

2.15 Exemplo de flexibilidade semântica em diagramas de sequência, baseado em (CAMPOS, 2007). . . . . . . . . . . . . . . . . . 43

2.16 Exemplo de flexibilidade dos estereótipos. . . . . . . . . . . . . . . 44

2.17 Trecho de documento XMI. . . . . . . . . . . . . . . . . . . 47

2.18 Transformação de modelo(MDA) . . . . . . . . . . . . . . . . . . . . 49

2.19 Arquitetura xUML. . . . . . . . . . . . . . . . . . . . . 52

3.1 Fluxo de criação dos diagramas da UML. . . . . . . . . . . . . . . . . . . 59 
3.2 Diagrama de pacotes representando subsistemas. Baseado em Mellor e Balcer (2002) . . . . . . . . . . . . . . . . . . . . 60

3.3 Diagrama de caso de uso utilizado para derivar entidades externas. . . . . 61

3.4 Diagrama de classes em nível de negócio. . . . . . . . . . . . . . . . . 63

3.5 Diagrama de sequência semanticamente válido. . . . . . . . . . . . . . . 65

3.6 Diagrama de máquina de estados semanticamente válido. . . . . . . . . . . 67

3.7 Diagrama de atividade que pode ser interpretado pelo simulador. . . . . . . 69

3.8 Importação do modelo em XMI no ModSim. . . . . . . . . . . . . . . . . . 71

3.9 Tela de mapeamento de tipos de dados. . . . . . . . . . . . . . . . . . . . 74

3.10 Tela para a criação de objetos de exemplo. . . . . . . . . . . . . . . . . 75

3.11 Controle de execução do simulador. . . . . . . . . . . . . . . . . 76

3.12 Object Viewer durante uma simulação. . . . . . . . . . . . . . . . . . . . 77

3.13 Ambiente de simulação. . . . . . . . . . . . . . . . . . 78

3.14 Tela de entrada de dados gerada dinamicamente. . . . . . . . . . . . . . 79

$3.15 \log$ da simulação. . . . . . . . . . . . . . . . . . . . . . . . . 80

4.1 Diagrama de classes usado no experimento. . . . . . . . . . . . . . . 82

4.2 Diagrama de sequência usado no experimento. . . . . . . . . . . . . . 82

4.3 Diagrama de máquina de estado da clase ShoppingCart usado no experimento. 83 


\section{Lista de Tabelas}

2.1 Diagramas da UML . . . . . . . . . . . . . . . . . . . . 31

2.2 Documentação do caso de uso Abrir Conta Comum . . . . . . . . . . . . . 33

2.3 Conceitos em um modelo xUML, baseado em Mellor e Balcer (2002) . . . . 57

3.1 Semânticas para o diagrama de pacote . . . . . . . . . . . . . . . 60

3.2 Semânticas para o diagrama de casos de uso . . . . . . . . . . . . . . . . 62

3.3 Semânticas para o diagrama de classes . . . . . . . . . . . . . . . . 64

3.4 Semânticas para o diagrama de objetos . . . . . . . . . . . . . . . 64

3.5 Semânticas para o diagrama de sequência . . . . . . . . . . . . . 66

3.6 Semânticas para o diagrama de máquina de estados . . . . . . . . . . . . . 68

3.7 Semânticas para o diagrama de atividade . . . . . . . . . . . . . . . 69 


\section{Lista de Algoritmos}

1 Exemplo de código-fonte Java gerado a partir de uma diagrama de classes . 35

2 Exemplo de restrição geral de unicidade em OCL . . . . . . . . . . . . . 45

3 Exemplo da estrutura de controle "if" na OAL . . . . . . . . . . . . . . 55

4 Exemplo da estrutura de controle "for each" na OAL . . . . . . . . . . . . 55

5 Exemplo da manipulação de classes na OAL . . . . . . . . . . . . . . 55

6 Escrevendo e lendo atributos na OAL . . . . . . . . . . . . . 56

7 Gerando e recebendo eventos na OAL . . . . . . . . . . . . . . 56

8 Definição de ações do estado Adding Selection to Cart de ShoppingCart . . 70

9 Definição de ações do estado Canceling Entire Cart de ShoppingCart . . . 70

10 Estrutura dinâmica que representa uma classe . . . . . . . . . . . . . . . . 71

11 Estrutura dinâmica que representa uma entidade externa (ator) . . . . . . 72

12 Trecho de processamento da OAL na máquina virtual . . . . . . . . . . . 72

13 OAL para estado New Order . . . . . . . . . . . . . . . . . . 81

14 OAL para estado Adding Selection to Cart . . . . . . . . . . . . . . . . 83

15 OAL para estado Establishing Customer and Verifying Payment . . . . . . 83

16 OAL para estado Canceling Entire Cart . . . . . . . . . . . . . . . . 84 


\title{
Lista de Abreviaturas
}

\author{
ASL Action Specification Language \\ bUML Basic UML Subset \\ CASE Computer-Aided Software Engineering \\ DTD Document Type Definition \\ EJB Enterprise Java Beans
}

fUML Foundational UML Subset

MDA Model Driven Architecture

MDD Model Driven Development

MDE Model Driven Engineering

MER Modelo Entidade-Relacionamento

MOF Meta Object Facility

OAL Object Action Language

OCL Object Constraint Language

OMG Object Management Group

OMT Object Modeling Technique

OO Orientação a Objetos

OOSE Object-Oriented Software Engineering

PIM Plataform Independent Model

PSM Plataform Specific Model

QVT Query-Views-Transformations 
RDBMS Relational Database Management System

RFP Request For Proposal

SQL Structured Query Language

UML Unified Modelling Language

xUML Executable Unified Modelling Language

XMI XML Metadata Interchange

XML Extensible Markup Language

W3C World Wide Web Consortium 


\section{Conteúdo}

1 Introdução $\quad 16$

1.1 Motivação e Justificativa . . . . . . . . . . . . . . . . . . . . . . . . . . . . 19

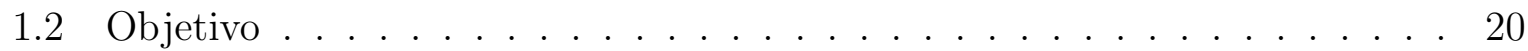

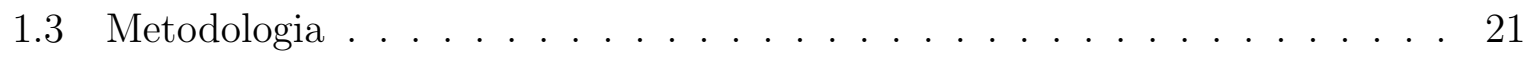

1.4 Estrutura do Texto . . . . . . . . . . . . . . . . . . . . . 22

2 Linguagem UML e Conceitos Relacionados 23

2.1 Histórico e Conceito da $\mathrm{OO} \ldots \ldots \ldots$. . . . . . . . . . . . 23

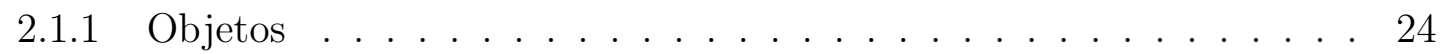

2.1.2 Classes . . . . . . . . . . . . . . . . . . 25

2.1 .3 Herança . . . . . . . . . . . . . . . . . . 25

2.1.4 Polimorfismo . . . . . . . . . . . . . . . . 25

2.1 .5 Abstração de Dados . . . . . . . . . . . . . . . . . 26

2.1.6 Encapsulamento....................... 26

2.1.7 Agregação . . . . . . . . . . . . . . . . . 26

2.2 Padrões de Projeto . . . . . . . . . . . . . . . . . . . . . 26

2.3 Métodos de Projeto Orientados a Objetos . . . . . . . . . . . 27

2.4 A UML . . . . . . . . . . . . . . . . . . . . 28

2.4.1 Contribuição de Booch . . . . . . . . . . . . . . . 28

2.4.2 Contribuição de Rumbaugh . . . . . . . . . . . . . . . . 29

2.4.3 Contribuição de Jacobson . . . . . . . . . . . . . . . . . 30

2.4.4 Contribuição da Rational . . . . . . . . . . . . . . . . . . 30 
2.4.5 Contribuição da OMG . . . . . . . . . . . . . . . . . . 30

2.4 .6 Propósito da UML . . . . . . . . . . . . . . . . . . 30

2.4.7 A Flexibilidade Semântica da UML . . . . . . . . . . . . . . . . . . 41

2.4.8 Object Constraint Language . . . . . . . . . . . . . . . . . . . . 45

$2.4 .9 \mathrm{XMI} \ldots \ldots \ldots \ldots \ldots \ldots \ldots$

2.5 Model Driven Architecture . . . . . . . . . . . . . . . . . . . . . 47

2.5.1 Mapeamento de Modelos . . . . . . . . . . . . . . . . . . . . . . 49

$2.5 .2 \mathrm{MOF} \ldots \ldots \ldots \ldots \ldots \ldots \ldots$

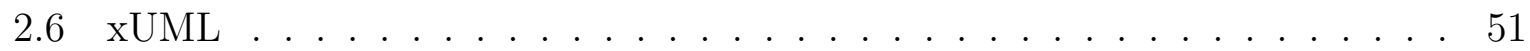

2.6.1 Especificação de Ações . . . . . . . . . . . . . . . . . . . . . . 53

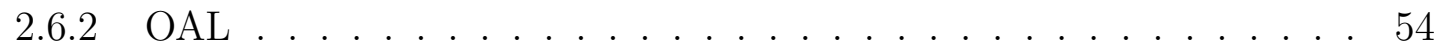

2.7 Propostas de $x U M L \ldots \ldots \ldots \ldots \ldots \ldots$

3 Especificação e Criação do ModSim $\quad 58$

3.1 Processo de criação dos modelos em nível de negócio . . . . . . . . . . 58

3.1 .1 Modelagem do domínio . . . . . . . . . . . . . . 58

3.1.2 Diagrama de casos de uso . . . . . . . . . . . . . . . . . . 61

3.1.3 Diagrama de classes . . . . . . . . . . . . . . . 62

3.1.4 Diagrama de objetos . . . . . . . . . . . . . . 63

3.1 .5 Diagrama de sequência . . . . . . . . . . . . . . . . 64

3.1.6 Diagrama de máquina de estados . . . . . . . . . . . . . 66

3.1.7 Diagrama de atividades . . . . . . . . . . . . . . 68

3.1 .8 Linguagem de Ação . . . . . . . . . . . . . . . . . . . . . . . . . . . 68

3.2 Simulador de modelos UML em nível de negócio . . . . . . . . . . . . . . . 69

3.2.1 Compilação do modelo descrito em XMI . . . . . . . . . . . . . 70

3.2.2 Dados complementares ao modelo UML . . . . . . . . . . . . . . 73

3.2 .3 Mecanismo de Interrupção . . . . . . . . . . . . . . . . . . . . . 76 
3.2.4 Object Viewer. . . . . . . . . . . . . . . . . . . 77

3.2 .5 Ambiente de Simulação . . . . . . . . . . . . . . . . . . . . . . 78

4 Resultados Obtidos em Simulações $\quad 81$

4.1 Artefatos de entrada . . . . . . . . . . . . . . . . 81

4.2 Simulação do evento startCart . . . . . . . . . . . . . . . . . . . 84

4.3 Simulação do evento checkOut . . . . . . . . . . . . . . . 85

4.4 Limitações . . . . . . . . . . . . . . . . . . . . . . . . . . 86

5 Considerações Finais $\quad 87$

5.1 Cumprimento dos Objetivos Propostos . . . . . . . . . . . . 87

5.2 Contribuições do Trabalho . . . . . . . . . . . . . . . . . . . 88

5.3 Trabalhos Futuros . . . . . . . . . . . . . . . . . . . . . . . . 89

$\begin{array}{ll}\text { Referências } & 90\end{array}$ 


\section{Introdução}

A modelagem é uma técnica bem aceita e de utilidade comprovada em diversas disciplinas da engenharia, desde uma casa que será construída com base em diversas plantas, passando por automóveis, aviões, dispositivos eletrônicos, entre outros. Dificilmente esses produtos de diferentes áreas de atuação seriam concebidos sem a utilização de modelos que pudessem garantir o sucesso ou identificar uma eventual falha que pode, então, ser corrigida antes de um estágio mais avançado, em que os custos e esforços de eventuais correções podem ser maiores.

Essa atividade também tem grande importância no desenvolvimento de sistemas e, por isso, é grande o interesse sobre o tema na engenharia de software, apesar da menor maturidade desta se comparada com outras disciplinas mais antigas da própria engenharia. (BEIERLEIN; FROHLICH; STEINBACH, 2004).

Desde as tradicionais linguagens de programação, passando do Assembly para o C e então para o Java, ou até mesmo em termos de métodos, em que a programação estruturada deu lugar para a OO, a cada nova geração se busca alcançar um nível de abstração mais alto. Pode-se definir abstração como as características essenciais de uma entidade, a visualização de algo excluindo as informações não relevantes em um determinado momento (BOOCH; RUMBAUGH; JACOBSON, 1999). Atualmente, alinhado com a tendência histórica de evolução do desenvolvimento de software, as pesquisas da área se concentram na tentativa de consolidação de um novo nível: o desenvolvimento baseado em modelos (MDD) (MILLER et al., 2003). A criação de modelos antes da produção efetiva do software se tornou uma técnica muito usada e aceita (HAUSMANN; KENT, 2003). Isso influenciado também pela iniciativa da Object Management Group (OMG) em formalizar o conceito da arquitetura MDA, usando padrões próprios e já conhecidos como a linguagem gráfica UML (OMG, 2007b).

O grande crescimento da Orientação a Objetos é também um forte motivador para se ter um método padronizado de modelagem de sistemas. Nos últimos anos, a linguagem UML com todos seus diagramas se tornou a principal ferramenta e pode ser utilizada 
durante todo o ciclo de vida de desenvolvimento de um software, desde sua arquitetura até a disposição física dos componentes gerados. Com o uso disseminado e possibilidade de aumentar a produtividade dos profissionais e a qualidade dos programas, diversas ferramentas Computer-Aided Software Engineering (CASE) surgiram e implementaram a capacidade de geração de código-fonte a partir dos diagramas da UML, antecipando a construção das primeiras linhas de código na plataforma final para as fases iniciais do ciclo de vida de desenvolvimento.

Em termos práticos, o código gerado por essas ferramentas representa apenas a estrutura da aplicação desejada (classes, assinatura de métodos e propriedades), desconsiderando a maioria dos detalhes de implementação e comportamento dinâmico do sistema. Para suprir a falta de informação entre a estrutura do programa gerada a partir do diagrama de classes e os algoritmos implementados em uma linguagem de programação, pode-se utilizar o conceito de restrições, que formam uma classe especial de anotações que impõem limitações adicionais a um modelo. As restrições podem ser especificadas no próprio diagrama, indicando algumas regras de negócio baseadas em pré e pós-condições. A linguagem de restrições, definida pela OMG, é a Object Constraint Language (OCL), que também é empregada na UML para expressar restrições de uma maneira declarativa e formal. Ainda assim, como dito anteriormente, os detalhes de implementação ainda não podem ser definidos por meio dos diagramas da UML e da linguagem OCL, como é originalmente definida. Esses detalhes deverão ser implementados por desenvolvedores de forma manual, portanto, mais suscetível a erros (JIANG; ZHANG; MIYAKE, 2007).

Atualmente são estudadas diversas iniciativas de utilização da modelagem, como uma linguagem de programação de alto nível de abstração para geração completa de códigofonte, porém, as ferramentas CASE e outras mais específicas não são necessariamente compatíveis em relação ao resultado estrutural e comportamental gerado, impedindo a interoperabilidade e tornando o processo de simulação, análise e codificação automatizada dependente da ferramenta. Dada a flexibilidade semântica da UML, ferramentas diferentes podem interpretar de maneiras distintas o mesmo modelo.

Como para o Model Driven Development (MDD), utilizar uma plataforma específica nas fases iniciais do projeto iria em direção contrária ao desejado, a linguagem UML se viabiliza como melhor candidata para servir de base fundamental para a programação baseada em modelos. Entretanto, os desafios que devem ser superados, como a falta de semânticas claras e bem definidas dos diagramas e elementos existentes, são impeditivos graves para a simulação de execução de um modelo ou até a geração de código automática. Para isso, a OMG formalizou suas pesquisas na área de arquiteturas baseadas em modelos, 
uma extensão do que existia até então (MILLER; MUKERJI, 2003).

A estratégia utilizada no MDD é baseada no conceito de transformações de modelos, tema fundamental hoje na ciência da computação e engenharia de software (TRATT, 2006). Escrever sistemas em linguagens de programação ajuda a garantir que as operações aplicadas sejam compatíveis com os dados. Entretanto, como as abordagens da transformação de modelos envolvem os metadados, por exemplo, dados que representam artefatos de software como programas, interfaces e modelos, entra-se no conceito da metaprogramação, em que programas são construídos para que possam escrever ou manipular outros programas (CZARNECKI; HELSEN, 2006).

Pelo seu potencial, pode-se considerar como fundação básica da MDA os modelos executáveis, que adicionam facilidades de execução e transformação à linguagem UML tradicional (FLINT; GARDNER; BOUGHTON, 2004). Conhecido também como Executable Unified Modelling Language (xUML), esses modelos abstraem tanto as linguagens de programação específicas quanto as decisões sobre a organização do software tal que a especificação construída possa ser distribuída em vários ambientes sem alteração. Isso se dá pelo fato do conceito de Plataform Independent Model (PIM) utilizado nessa abordagem, um modelo de uma solução que não se baseia em nenhuma plataforma específica, poder ser completamente construído utilizando a xUML (MELLOR; BALCER, 2002).

Trabalhos relacionados a execução e simulação de modelos podem ser divididos em duas correntes: a acadêmica e a corporativa. Os estudos acadêmicos foram iniciados em Riehle et al. (2001), um estudo que descreve uma máquina virtual UML com ênfase no modelo de memória e seu conjunto de instrução. Muito deste trabalho foi utilizado como base para definições de propostas da xUML.

$\mathrm{Na}$ área corporativa, muitos frameworks de execução de modelos foram definidos. Algumas ferramentas são capazes de executar modelos como o Rational Rose Technical Developer, Kennedy Carter Tools for xUML, Kabira Tools e BridgePoint.

Essas ferramentas possibilitam a definição de modelos que podem ser executados e algumas delas permitem a definição de templates de código-fonte para utilizar a geração de código automática para uma linguagem de programação específica, porém, as ferramentas não implementam funcionalidades de simulação da execução em nível de negócio com interação do usuário, intuito da aplicação criada e descrita nesta pesquisa.

Simular a execução de um modelo permite ao engenheiro de software verificar se o que foi descrito utilizando os diagramas da UML está de acordo com o esperado, avaliando o comportamento da aplicação durante a simulação. Isso é feito antes de decidir e sem 
se preocupar com qual plataforma destino será usada durante a distribuição do software (MOONEY; SARJOUGHIAN, 2008).

Assim, criar uma máquina virtual de interpretação de modelos UML é uma opção válida para o desenho de novos sistemas que podem ter sua completeza e correção verificadas quanto ao que foi descrito nos diagramas com grande antecedência. Espera-se, então, permitir ganhos com a qualidade, produtividade e menores custos no desenvolvimento do software.

A posterior transformação do modelo executável para uma plataforma destino também é importante, dado o leque de opções disponíveis de arquitetura de hardware e software, linguagens de programação e sistemas operacionais, porém, fora do escopo deste trabalho. Uma primeira pesquisa sobre este problema da geração de código na plataforma alvo foi tratado em Silva (2005), em que, a partir de modelos UML e restrições OCL é possível gerar código para as linguagens Java e Structured Query Language (SQL).

\subsection{Motivação e Justificativa}

A motivação deste trabalho foi a possibilidade de apresentar, baseado em estudos anteriores, uma nova maneira de tratar as fases iniciais do desenvolvimento de softwares simulando sua execução antes da definição de sua plataforma de destino. A criação de modelos UML em nível de negócio que possam ser simulados em um ambiente computacional não tiram a tarefa de implementação dos desenvolvedores, porém, esses modelos executáveis permitem entender o comportamento de um sistema logo em sua fase inicial, assim como uma verificação formal de aspectos importantes do mesmo, o que tem se mostrado difícil quando se utiliza apenas a UML (MOONEY; SARJOUGHIAN, 2008).

A linguagem UML é largamente utilizada pela comunidade de desenvolvimento de software, entretanto, os analistas ou engenheiros podem definir uma solução que pode até ser independente de plataforma, mas que podem ser interpretados de mais de uma maneira pela falta de rigor semântico, ou eventualmente podem até deixar de representar no modelo alguma informação imprescindível para a aplicação por não perceber essa necessidade no momento da modelagem do negócio e, assim, os desenvolvedores que se baseiam no modelo criado para construir o código-fonte na plataforma alvo nas fases seguintes devem adicionar detalhes funcionais e comportamentais que não são apresentados de forma explícita nos diagramas. Isso deveria ser evitado, deixando a implementação baseada apenas em padrões de projeto e melhores práticas relacionadas à linguagem de 
programação utilizada.

Cria-se então um problema de aderência entre um modelo (do analista ou engenheiro) e outro (o código-fonte do desenvolvedor). Manter os modelos sincronizados é uma tarefa difícil e importante que muitas vezes nos projetos de software tradicionais é ignorada, introduzindo erros de desenvolvimento e arquitetura da aplicação que só serão descobertas em fases avançadas do projeto (YATAKE; KATAYAMA, 2008).

Ao permitir que o analista modele o sistema em nível de negócio utilizando artefatos com semântica bem definida para representar a estrutura estática e comportamental de um sistema e assim simular sua execução, espera-se que não exista o gap entre os modelos idealizados e realmente implementados. O analista não deve se preocupar com detalhes especificamente computacionais, como a estrutura interna de uma linguagem de programação e apenas utilizar seu conhecimento do negócio em questão.

\subsection{Objetivo}

O objetivo deste trabalho consiste na especificação de um simulador que permita ao usuário verificar a completeza e correção de um modelo UML em nível de negócio em relação à sua semântica, ou seja, sem levar em consideração características de plataformas tecnológicas, analisar se o modelo realmente representa o que se deseja.

Os termos "completeza" e "correção" no contexto deste trabalho se referem a garantia de que o sistema que foi modelado em UML represente todas as funcionalidades e o comportamento de cada uma delas de acordo com o esperado, respectivamente. O simulador não irá analisar se o que está representado nos diagramas faz ou não sentido em relação ao objetivo do engenheiro ou analista que o fez, mas mostrará qual será o comportamento da aplicação que foi modelada, permitindo que os próprios autores do modelo identifiquem possíveis erros ou falta de definição. A verificação visa atingir apenas os requisitos funcionais que foram modelados, portanto eventuais requisitos não-funcionais não serão tratados por este simulador. Fundamentado em trabalhos anteriores, define-se uma estratégia de desenvolvimento baseado em modelos e sem preocupação com detalhes específicos de implementação, com foco em modelos em nível de negócio de um domínio específico.

Para atingir o objetivo citado, será criado um conjunto de extensões constituído da definição semântica dos elementos UML para alguns diagramas como o de casos de uso, classes, máquina de estados e sequência, o interpretador do XMI, mapeamento do modelo 
gráfico para estruturas de dados computacionalmente manipuláveis e a máquina virtual para simulação e possível futura transformação dos modelos de origem para uma linguagem de programação específica. Os mapeamentos necessários para a equivalência entre os conceitos de negócios e o detalhamento tecnológico também serão criados.

Antes de entrar no mérito da construção do simulador, serão apresentados conceitos técnicos e históricos importantes para a compreensão do trabalho. Também serão apontados os problemas da flexibilidade semântica que dificultam a execução dos diagramas UML convencionais, bem como a tentativa de resolver esses problemas com a introdução da arquitetura MDA e os modelos executáveis, mostrando a importância da programação baseada em modelos para a engenharia de software e a ciência da computação.

Além da pesquisa e organização das informações para a compreensão do tema, será apresentada uma prova de conceito em forma de protótipo de um simulador que auxilia a pesquisa e permite a experimentação dos conceitos citados. Assim, a definição dos requisitos desse protótipo, seu desenvolvimento, realização dos testes e a análise dos resultados obtidos também são parte deste trabalho.

\section{$1.3 \quad$ Metodologia}

A estratégia proposta para a realização do trabalho consiste no estudo da arquitetura MDA e da UML e definição dos complementos necessários para o desenvolvimento de uma extensão viável, baseada em modelos em nível de negócio de um domínio específico, simplificando o ciclo de vida da engenharia de software.

Para permitir a simulação e apuração de resultados em relação ao objetivo desejado, deve-se proceder com a implementação de uma ferramenta que deverá contar com a máquina virtual de simulação dos modelos com semânticas pré-definidas também nesta pesquisa. Essa ferramenta deverá ter a capacidade desejada de simulação dos modelos para possibilitar ao usuário verificar a coerência, completeza e correção semântica destes.

Para alcançar o objetivo proposto, pretende-se seguir os seguintes passos, tidos como metas intermediárias do trabalho:

- estudar o estado da arte dos conceitos envolvidos na pesquisa;

- definir as extensões e restrições da linguagem UML necessárias para basear a abordagem proposta, assim como a semântica de cada diagrama e de seus elementos;

- escolher uma ferramenta especialista de modelagem UML; 
- construir o processo de mapeamento entre modelos e estruturas de dados para permitir a execução da máquina virtual sob a entrada;

- construir a máquina virtual de simulação dos modelos para testes;

- analisar os resultados obtidos em relação ao objetivo do trabalho.

\subsection{Estrutura do Texto}

No capítulo 2 são apresentadas as definições relacionadas ao desenvolvimento orientado a objetos e a linguagem UML, seu histórico, componentes e estado da arte. Serão descritos também os detalhes conceituais necessários para o entendimento da solução proposta.

No capítulo 3 são demonstrados os conceitos, extensões e restrições realizadas para possibilitar a construção de uma máquina virtual UML, assim como a definição da semântica e arquitetura utilizada.

O capítulo 4 tem foco na demonstração da prova de conceito construída para implementar as técnicas definidas nos capítulos anteriores, bem como os testes e simulações realizados para a obtenção dos resultados da pesquisa, baseados em um estudo de caso.

No capítulo 5 são feitas as considerações finais e os resultados do trabalho são analisados contra seus objetivos. Além disso, são apresentadas sugestões para trabalhos futuros relacionados à linha de pesquisa. 


\section{Linguagem UML e Conceitos Relacionados}

A simulação de modelos neste trabalho está relacionada com a utilização da linguagem UML e, portanto, baseia-se na abordagem de projeto orientado a objetos.

O ciclo de vida de desenvolvimento de software é a sequência de tarefas que ocorrem durante a construção da aplicação. Essa sequência pode ser definida escolhendo um processo de desenvolvimento, como cascata, espiral, processo unificado, entre outros, e um método. Para este trabalho, o processo escolhido não tem relevância prática. No momento em que o modelo em nível de negócio for criado, o simulador pode ser utilizado. Já em relação ao método, as restrições da UML, como não poderia deixar de ser, exigem a utilização da abordagem orientada a objetos.

\subsection{Histórico e Conceito da Orientação a Objetos $(\mathrm{OO})$}

Nas últimas décadas, diversos métodos de desenvolvimento de software apareceram tentando otimizar algumas ou todas as fases do ciclo de vida de um software, variando desde o levantamento de requisitos até a manutenção. O método da Orientação a Objetos, com sua imensa popularidade e crescente número de softwares descritos como orientados a objetos nos últimos anos, tornou-se um padrão para arquitetura e desenvolvimento de sistemas (CAPRETZ, 2003).

Embora o termo OO tenha suas raízes na década de 70, algumas definições sobre o seu significado foram dadas. Para alguns, o conceito de objeto era apenas um novo nome para os já existentes tipos de dados abstratos. Para outros, classes e objetos eram uma forma concreta de tipos. Outros ainda definiam como uma maneira de organizar e compartilhar código-fonte em grandes sistemas. É difícil fornecer uma definição genérica, precisa e largamente aceita para o paradigma da OO. 
Usa-se neste trabalho a definição de Wegner (1987), que caracterizou a OO em termos de objetos, classes e herança. Objetos são entidades autônomas que tem um ou mais estados e respondem a mensagens. As classes arranjam objetos por meio de suas operações e atributos em comum e, portanto, de comportamento uniforme. Herança é definida como um mecanismo para compartilhamento de recursos em hierarquias de classes. Assim, $\mathrm{OO}=$ objetos + classes + herança. Essa caracterização se tornou a mais aceita pela comunidade de software.

Apesar das diferentes interpretações da OO, algo que todas têm em comum é o reconhecimento de que um objeto é o conceito primitivo, sendo ele o encapsulamento de dados protegidos junto às operações que atuam sobre a informação escondida (CAPRETZ, 2003).

O método orientado a objeto pode ser utilizado durante todo o processo de desenvolvimento. Durante a fase de análise, modela-se o negócio, suas características e regras aplicadas. Nessa fase já é possível gerar diagramas que podem ser simulados e verificados.

Algumas definições básica que completam o entendimento do paradigma orientado a objetos:

\subsubsection{Objetos}

Um objeto tem um conjunto de características, operações e se mantém em um estado que tem como intuito lembrar o efeito dessas operações. Pode-se contrastar com funções que não têm essa memória. O valores retornados de uma função são determinados pelos seus argumentos, e será sempre o mesmo se esses argumentos não mudarem. De maneira diferente, o valor retornado por uma operação em um objeto pode depender tanto dos argumentos quanto do estado em que o objeto se encontra.

O termo objeto foi formalmente aplicado pela primeira vez na linguagem Simula, e objetos existiam nessa linguagem para simular algum aspecto de realidade. A estrutura e comportamento de objetos similares são definidos em suas classes. Pode-se, então, citar objetos como instâncias de uma classe.

Em sistemas orientados a objetos, todas as informações são armazenadas dentro de objetos que podem ser manipulados, quando necessário, para efetuar uma operação específica (MOLLA, 2005). 


\subsubsection{Classes}

Uma classe representa um molde para diversos objetos e descreve como esses objetos são estruturados internamente. Objetos de uma mesma classe têm características e operações em comum e, portanto, comportamento uniforme (JACOBSON et al., 1992).

Em um ambiente OO, uma classe é uma especificação de atributos, métodos e herança para objetos. Uma vez que uma classe esteja definida, um número ilimitado de objetos que pertencem a essa classe podem ser criados.

\subsubsection{Herança}

Herança é o processo em que objetos de uma classe adquirem as propriedades de objetos de outra classe. No projeto orientado a objeto, o conceito de herança suporta a idéia de reusabilidade.

Uma definição bem aceita é dada em Rumbaugh et al. (1991), que diz que herança é o compartilhamento de atributos e operações entre classes baseado em um relacionamento hierárquico. Com a herança é possível adicionar novas características a uma classe existente sem modificar a classe anterior, uma maneira de derivar uma nova classe a partir de uma existente. A nova classe é chamada de subclasse, classe-derivada ou classe-filha enquanto a classe de onde as características foram herdadas é chamada de superclasse, classe-base ou classe-pai.

\subsubsection{Polimorfismo}

Polimorfismo tem o papel importante de permitir que objetos possuam diferentes estruturas internas, mas compartilhem a mesma interface externa.

Por meio do polimorfismo é possível ter diversas implementações diferentes atrás da mesma interface. Basicamente, objetos de classes diferentes, que estão relacionados por uma superclasse em comum, podem ser representados por um objeto da superclasse. Apesar de cada um dos objetos implementar operações de mesmo nome de maneiras diferentes, o objeto que os contém será capaz de diferenciar as operações de cada um em tempo de execução (MOLLA, 2005). 


\subsubsection{Abstração de Dados}

Abstração de dados significa representar apenas as características essenciais e não incluir os detalhes não relevantes para a resolução do problema. A abstração de dados permite que objetos possam ser tratados como caixas-pretas. Espera-se que eles tenham certo comportamento, mas não é necessário saber exatamente como isso será implementado internamente.

Relacionado a isso, tem-se a informação escondida, em que um objeto se comunica com outro por meio de suas interfaces públicas. O objeto pode manter informações e métodos particulares que podem ser alterados a qualquer momento sem afetar o outro objeto (MOLLA, 2005).

\subsubsection{Encapsulamento}

Encapsulamento é um dos princípios básicos da aboradagem orientada a objetos. A idéia de encapsulamento vem dos tipos de dados abstratos. É um mecanismo para realizar a abstração de dados e esconder informações. Ele esconde detalhes da especificação interna de um objeto e publica somente suas interfaces externas. Com o encapsulamento, os dados e métodos internos de um objeto podem ser alterados sem mudar a maneira como esse objeto é utilizado. Desta forma, novas classes especializadas reutilizáveis podem ser criadas. Booch, Rumbaugh e Jacobson (1999) define o encapsulamento como o processo de esconder todos os detalhes de um objeto que não contribuem para suas características essenciais.

\subsubsection{Agregação}

Agregação é um tipo de relacionamento em que os objetos são organizados em uma estrutura que mostra como um deles é composto por outros.

\subsection{Padrões de Projeto}

Um tópico importante em relação à Orientação a Objetos são os padrões de projeto, com termo mais difundido em sua tradução na língua inglesa, os Design Patterns. Eles foram introduzidos em 1994 e são cada vez mais utilizados pelos programadores. Os Design Patterns definem e documentam estruturas de projeto orientados a objetos que resolvem determinados problemas de modelagem em um certo contexto. Alguns desses problemas 
são muito comuns, porém, as melhores soluções para eles não são simples de ser encontradas. Os Design Patterns documentam essas soluções (BIDDLE; NOBLE; TEMPERO, 2003).

Determinados padrões se mostraram tão efetivos que são considerados melhores práticas em seus contextos específicos. Alguns dos padrões de projetos utilizados pela comunidade de OO são:

- transfer object - permite utilizar um objeto para transferir diversas informações independentes de uma só vez, com uso frequente na computação distribuída;

- state - permite que um objeto mude seu comportamento quando seu estado muda;

- iterator - permite o acesso e iteração a elementos de uma coleção, sem exposição de estruturas internas.

Com a aderência dos modelos construídos a práticas de mercado bem estabelecidas, evita-se transtornos relacionados à qualidade, padronização e produtividade dos envolvidos no desenvolvimento.

Para este trabalho, não se exige a utilização de nenhum dos Design Patterns durante a construção do modelo, até mesmo pela decisão de usar modelos de negócio como entrada. Porém, como será apresentado nos próximos capítulos, as restrições de modelagem da xUML e a máquina virtual de simulação utilizam esses padrões mesmo sem o conhecimento dos usuários do simulador. Além desses citados, existe uma série de outros padrões muito utilizados em projetos orientados a objetos. Para uma descrição mais detalhada sobre os diversos padrões de projeto existentes, sugere-se a leitura de Freeman e Freeman (2004).

\subsection{Métodos de Projeto Orientados a Objetos}

Muitos métodos foram propostos para o projeto orientado a objetos. Esses métodos representam uma coleção de técnicas e idéias formalizadas que podem ser usadas durante o desenvolvimento de um projeto orientado a objeto. Eles contêm recomendações para o desenvolvimento de um bom projeto e construção de componentes reutilizáveis e obter benefícios tais como: melhor gerenciamento de complexidade das funções do sistema, melhor mapeamento dos objetos do mundo real no ambiente computacional, maior produtividade motivada pela reutilização de componentes e facilidade na manutenção dos sistemas.

Na próxima seção - UML - são apresentados alguns desses métodos e como eles se uniram para criar a linguagem de modelagem mais utilizada na OO. 


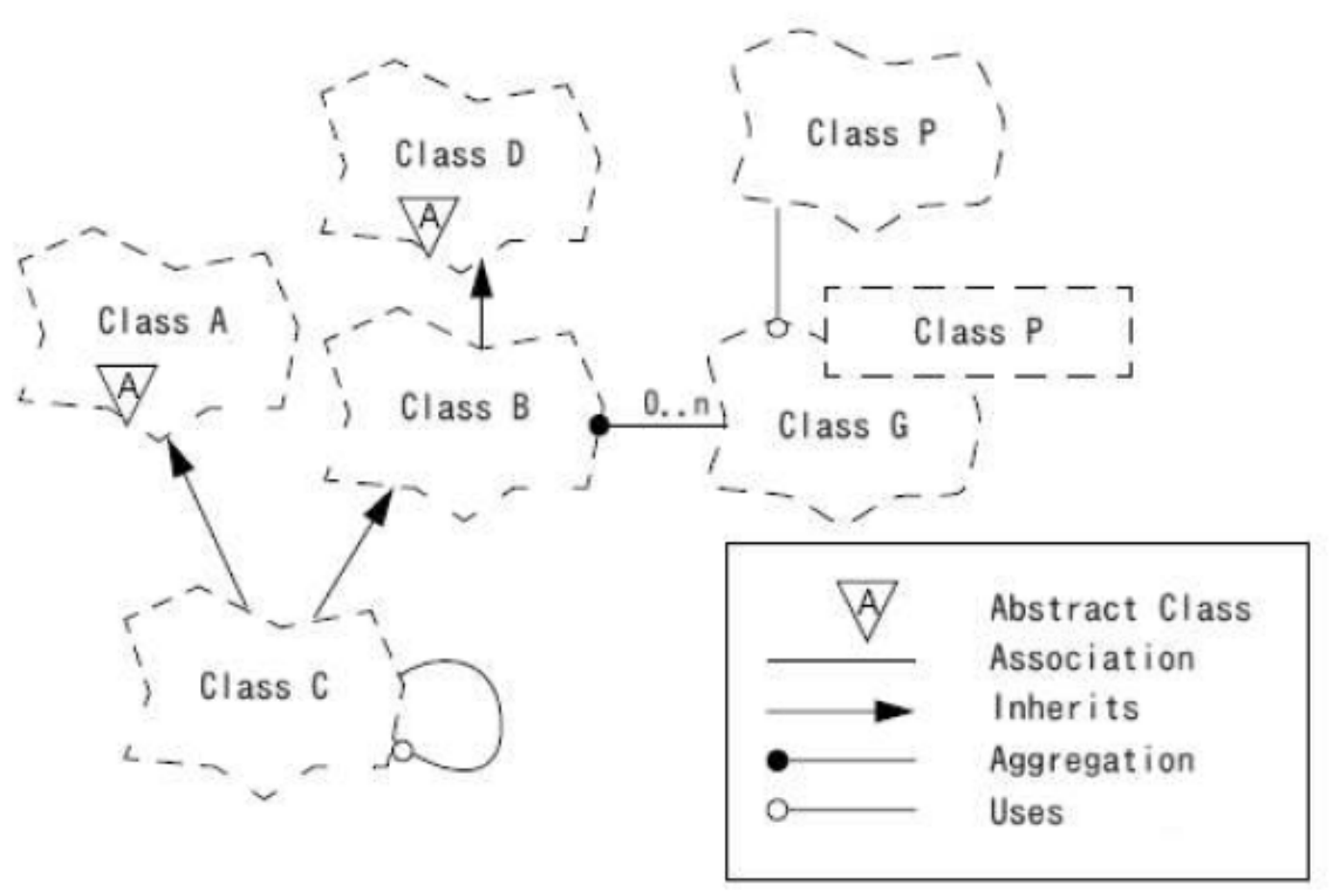

Figura 2.1: Diagrama de classes no Método Booch (CAMPOS, 2007).

\subsection{A UML}

O objetivo da linguagem UML é oferecer aos arquitetos, analistas de sistemas, engenheiros de softwares e desenvolvedores, ferramentas para análise, projeto e implementação de sistemas, além de permitir a modelagem de negócios e processos (OMG, 2007b).

As primeiras versões da UML tiveram origem em três dos principais e mais populares métodos orientados a objetos (Booch, Object Modeling Technique (OMT) e ObjectOriented Software Engineering (OOSE)) e incorporou diversas melhores práticas para linguagem de modelagem e descrição de arquitetura e programação orientada a objeto.

\subsubsection{Contribuição de Booch}

Ainda em sua antiga empresa, Rational Software, Gary Booch desenvolveu uma linguagem de modelagem de objetos e a chamou de Método Booch. Alguns dos símbolos utilizados na modelagem desse método ainda são encontrados na linguagem UML. A figura 2.1 mostra um exemplo de diagrama de classes representado pelo método Booch. 


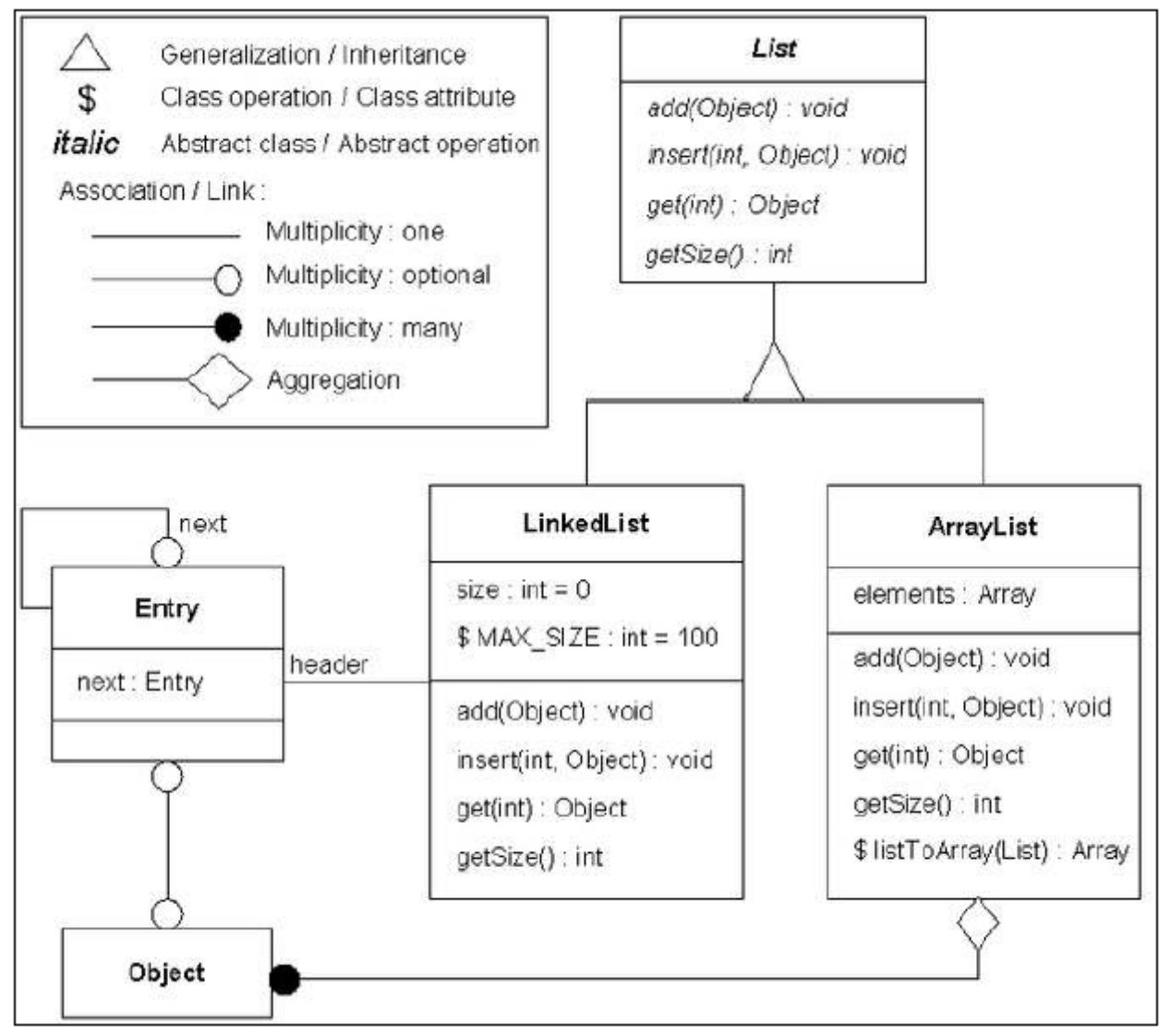

Figura 2.2: Diagrama de objetos OMT (CAMPOS, 2007).

\subsubsection{Contribuição de Rumbaugh}

A OMT é uma linguagem de modelagem desenvolvida em grande parte por James Rumbaugh no General Eletronic Research and Development Center. Pode-se observar diversas similaridades entre a OMT e a UML, como no diagrama de objetos apresentado na figura 2.2 e no diagrama de estados, na figura 2.3.

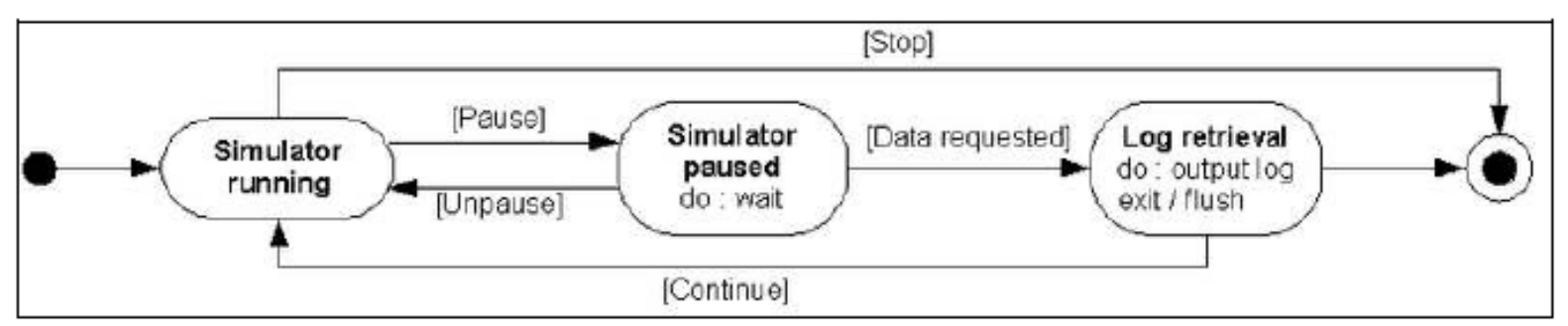

Figura 2.3: Diagrama de estados OMT (CAMPOS, 2007). 


\subsubsection{Contribuição de Jacobson}

A OOSE foi desenvolvida por Ivar Jacobson em 1992, enquanto trabalhava pela sueca Objectory AB. A principal contribuição da OOSE é o conceito dos casos de uso, que é, certamente, um dos principais artefatos da UML para representar os requisitos funcionais de uma aplicação.

\subsubsection{Contribuição da Rational}

A empresa Rational Software trabalhou na unificação das três abordagens citadas acima. A primeira versão efetiva da UML foi a 0.8, refletindo o trabalho de Booch e Rumbaugh. Na próxima versão, 0.9, seriam incluídas as contribuições de Ivar Jacobson. A Rational Software é atualmente um empresa do grupo IBM e desenvolve, entre outros produtos, ferramentas para modelagem de negócios, processos e aplicações.

\subsubsection{Contribuição da OMG}

OMG é um consórcio que trabalha em processos, modelagem e padrões orientados a objetos. Entre os membros do grupo estão empresas como a HP, IBM e Sun. Em 1996, a OMG liberou uma Request For Proposal (RFP) buscando uma linguagem para modelagem de objetos. A Rational foi a empresa que melhor se colocou nesse trabalho, fazendo a UML não só preencher os requisitos da RFP como também evoluir a partir da mesma. Atualmente, a UML 2.2 é a versão oficial aprovada pela OMG, embora novas versões já estejam em desenvolvimento.

\subsubsection{Propósito da UML}

A UML é uma linguagem de modelagem visual utilizada para especificar, construir e documentar os artefatos de sistemas de software. Pode ser usada com os principais métodos de objetos e componentes e ser aplicada a qualquer domínio de aplicação e plataforma de implementação (OMG, 2007b).

Modelagem se refere ao processo de gerar um modelo como uma representação abstrata de alguma entidade do mundo real. A UML permite criar modelos de um sistema de software analogamente a plantas arquitetônicas para a construção de uma casa. Não é tecnicamente ou até economicamente prático e viável desenvolver certos tipos de sistemas sem primeiro criar essa representação do que será construído. 
A modelagem permite que os profissionais envolvidos visualizem sistemas inteiros e tomem decisões de projeto de maneira mais clara sem os riscos técnicos, financeiros, ou de qualquer outro tipo, envolvidos na construção real de uma aplicação complexa (CERNOSEK; NAIBURG, 2004).

Segundo os autores da UML em Booch, Rumbaugh e Jacobson (1999) a modelagem de um sistema permite:

1. visualizar um sistema como ele é ou como ele deve ser;

2. especificar a estrutura ou comportamento de um sistema;

3. ter um molde que guia a construção de um sistema;

4. documentar as decisões que foram tomadas.

A partir da versão 2.0, a UML tem 13 diagramas definidos e permite a criação de perfis particulares para um determinado tema, como é o caso dos modelos executáveis. A tabela 2.1 descreve os diagramas.

\begin{tabular}{|l|l|}
\hline Diagrama & Descrição \\
\hline Classes & Estrutura interna dos objetos do sistema \\
\hline Objetos & Estrutura das instâncias das classes em tempo de execução \\
\hline Estrutura Composta & Estrutura interna e colaborações \\
\hline Componentes & Dependências entre componentes do sistema \\
\hline Implantação & Arranjo físico dos sistemas e componentes nos computadores \\
\hline Pacotes & Agrupamento lógico de classes e dependência entre grupos \\
\hline Atividade & Computações, workflows, fluxos de objetos e de controle \\
\hline Casos de uso & Comportamento do sistema para o usuário externo \\
\hline Máquina de estados & Possíveis estados de um objeto e suas transições \\
\hline Sequência & Tempo e ordem das mensagens entre objetos durante uma interação \\
\hline Interação Geral & Visualização do fluxo de controle \\
\hline Tempo & Dinâmica do tempo e mudança de estados \\
\hline Comunicação & Objetos e relações dentro de uma interação \\
\hline
\end{tabular}

Tabela 2.1: Diagramas da UML

A utilização de diversos diagramas tem como objetivo fornecer múltiplas visões do sistema que será modelado, analisando-o sob diversos aspectos e permitindo que cada diagrama complemente os outros (BLANKENHORN, 2004).

Cada diagrama analisa o sistema, ou parte dele, sob uma determinada óptica. Enquanto alguns dão ênfase à visão externa de forma mais geral, outros adicionam detalhes 


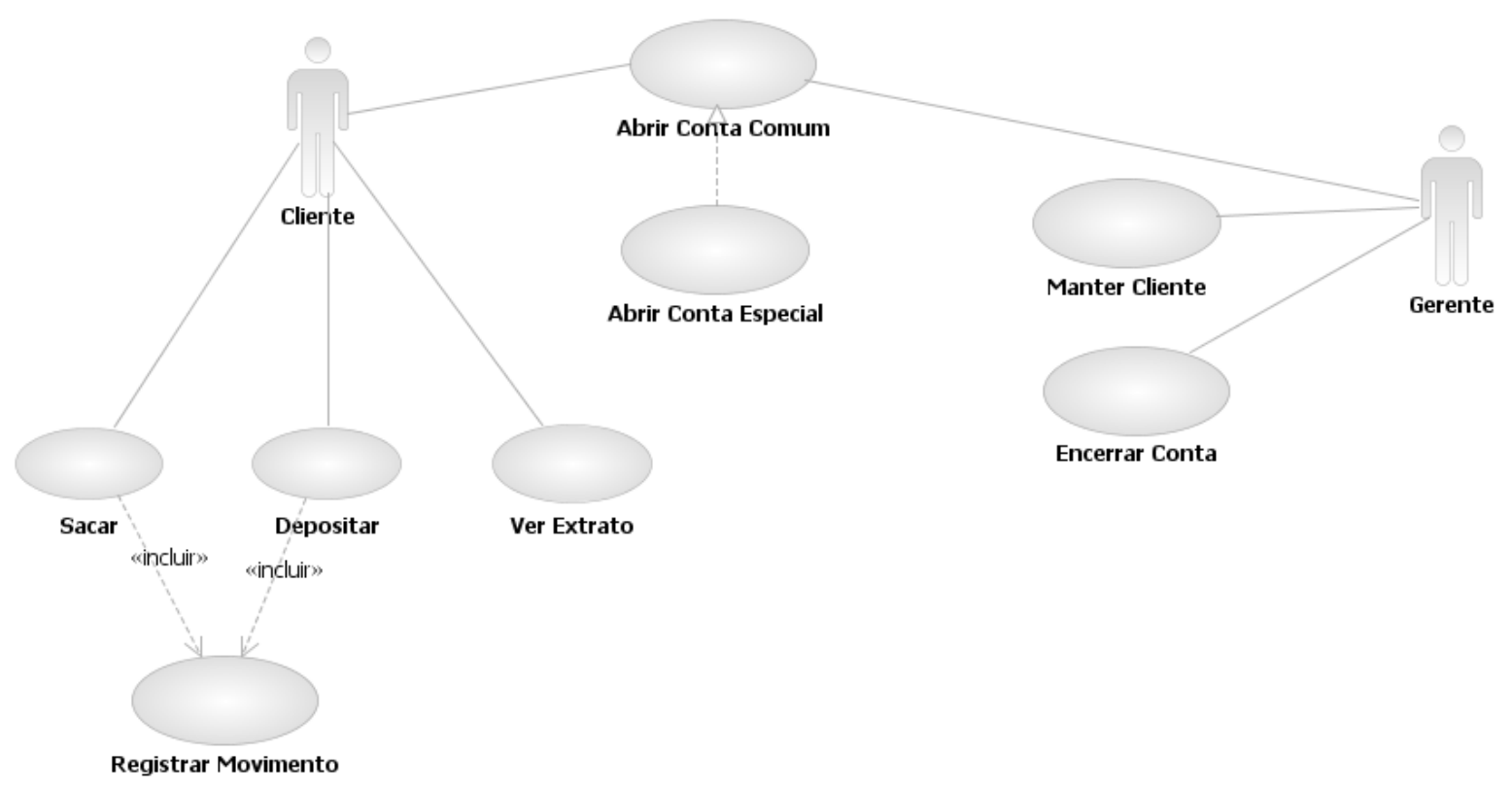

Figura 2.4: Exemplo de Diagrama de Casos de Uso.

mais técnicos ou características específicas do sistema ou de um processo qualquer, detalhando o tempo de processos críticos e estrutura dos objetos. Esses diagramas representam aspectos estáticos, dinâmicos ou comportamentais de um sistema, e alguns deles complementam outros para a visualização do sistema.

No processo de desenvolvimento de software, um dos primeiros diagramas utilizados é o diagrama de casos de uso. Ele auxilia na etapa de levantamento de requisitos de um sistema e os organiza em diferentes domínios. Um caso de uso especifica uma interação entre o sistema e um ou mais atores juntos com as atividades realizadas. Um ator é o papel desempenhado por uma entidade externa que precisa de algo da aplicação em uma ou mais interações com ela. O ator faz ou espera algo de um sistema e, por isso, é visto como uma fonte de estímulos externos que iniciam uma atividade (BLANKENHORN, 2004).

O diagrama de casos de uso é o diagrama mais informal da UML, apresentando uma linguagem simples e de fácil compreensão para que os usuários possam ter uma idéia geral de como o sistema irá se comportar.

Na figura 2.4 é apresentado um exemplo simples de diagrama de casos de uso.

Neste exemplo de uma aplicação bancária, clientes podem solicitar a abertura de uma conta, efetuar saques e depósitos, entre outros, enquanto os gerentes podem encerrar contas existentes, fazer manutenção no cadastro de um cliente etc.

Além da representação gráfica, cada caso de uso pode ter uma descrição textual. 
Documenta-se a definição de um caso de uso em termos de pré e pós-condições. Précondições definem o que deve ser verdadeiro para que o caso de uso possa ser realizado, e as pós-condições definem o que deve ser verdadeiro após a realização do caso de uso. Outras informações podem ser descritas como as regras de negócio aplicadas ao caso de uso (MELLOR; BALCER, 2002). Porém, como dito, os casos de uso são informais e essa descrição feita, utilizando linguagem natural, não permite o uso das informações para efeito da simulação.

Na tabela 2.2 é apresentada a documentação do caso de uso "Abrir Conta Comum":

\begin{tabular}{|c|c|}
\hline Nome do caso de uso & Abrir Conta Comum \\
\hline Caso de uso geral & (Utilizado em generalizações) \\
\hline Ator principal & Cliente \\
\hline Atores secundários & Funcionário \\
\hline Resumo & Etapas percorridas para abrir uma conta comum \\
\hline Pré-condições & O pedido de abertura precisa ser aprovado \\
\hline Pós-condições & É necessário realizar um depósito inicial \\
\hline Ações do ator & Ações do sistema \\
\hline \multicolumn{2}{|l|}{ 1. Solicitar abertura de conta } \\
\hline & 2. Consultar cliente por seu CPF ou CNPJ \\
\hline & 3. Gravar ou atualizar o cadastro do cliente \\
\hline & 4. Avaliar o pedido do cliente \\
\hline & 5. Aprovar o pedido \\
\hline \multicolumn{2}{|l|}{ 6. Escolher a senha da conta } \\
\hline & 7. Abrir conta \\
\hline \multicolumn{2}{|c|}{ 8. Fornecer valor a ser depositado } \\
\hline & 9. Registrar depósito \\
\hline & 10. Emitir cartão da conta \\
\hline & 11. Registrar depósito \\
\hline Restrições / Validações & Para abrir uma conta é preciso ser maior de 18 anos \\
\hline
\end{tabular}

Tabela 2.2: Documentação do caso de uso Abrir Conta Comum

Na fase de análise é criado o modelo conceitual do sistema. Elabora-se, então, o diagrama de classes representando entidades reais do negócio. Usa-se esse diagrama para modelar a visão estática de um sistema. Ele é composto por um conjunto de classes com seus atributos e métodos, interfaces, colaborações e seus relacionamentos, esses últimos que podem ser de dependência, generalização ou associação. Graficamente, um diagrama de classes é uma coleção de vértices e arcos (BOOCH; RUMBAUGH; JACOBSON, 1999). Um exemplo de diagrama de classe é apresentado na figura 2.5.

O diagrama de classes é certamente o diagrama mais utilizado da UML. É a partir desse modelo que diversas ferramentas CASE geram código-fonte de maneira automática 


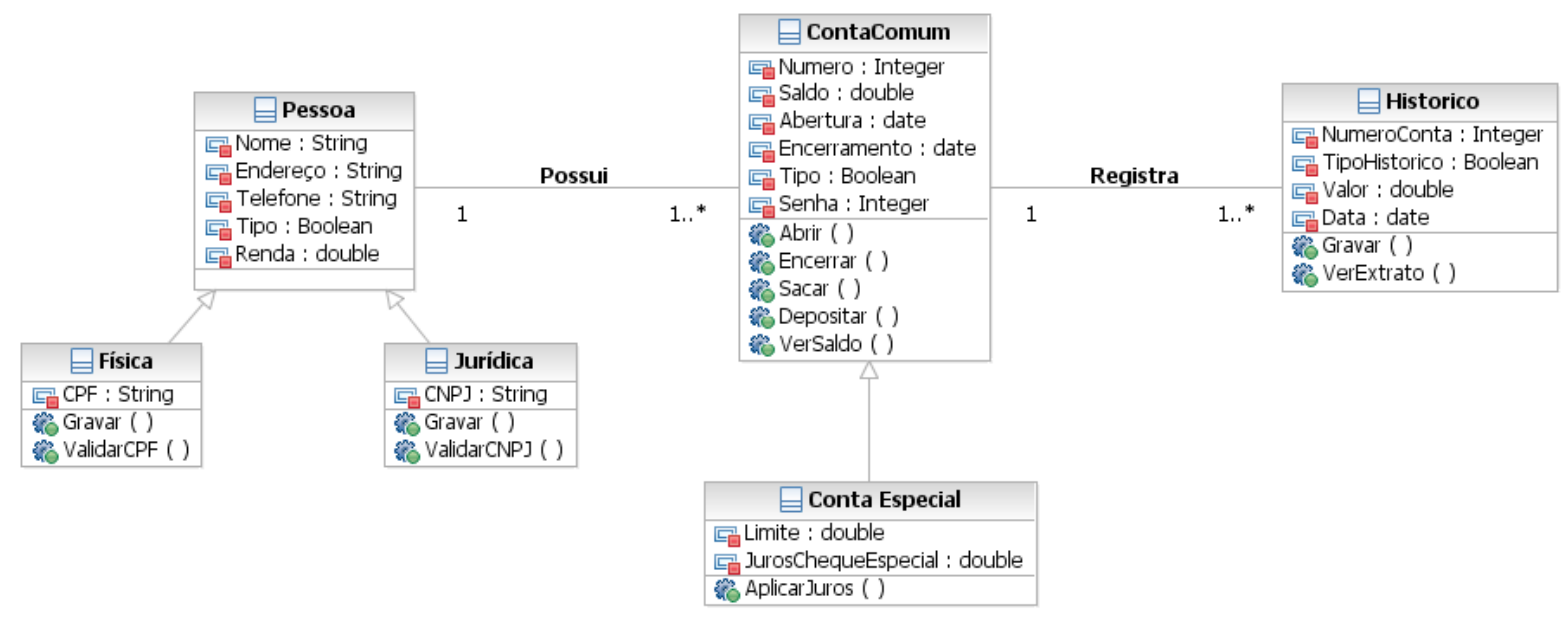

Figura 2.5: Exemplo de Diagrama de Classes.

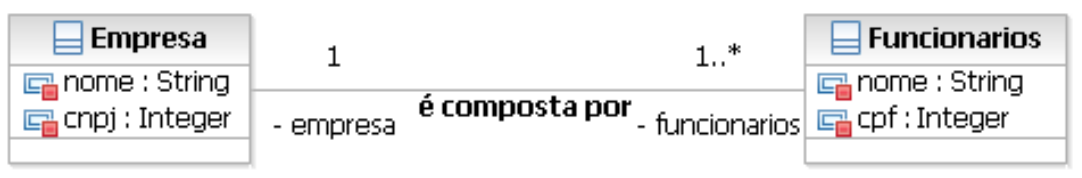

Figura 2.6: Exemplo de Diagrama de Classes para geração de código-fonte.

para auxiliar os desenvolvedores. Dada a característica estática desse diagrama, o códigofonte gerado normalmente envolve apenas a estrutura da aplicação em uma linguagem de programação orientada a objetos específica. Por exemplo, o algoritmo 1 representa o código-fonte em Java que poderia ser gerado a partir do diagrama de classes apresentado na figura 2.6.

Os diagramas de objetos estão associados aos diagramas de classes, dado que são complementos e bastante dependente destes. Esse diagrama fornece a visão dos valores armazenados por instâncias / objetos de uma diagrama de classes em um determinado momento da execução do sistema. A figura 2.7 mostra um diagrama de objetos (BOOCH; RUMBAUGH; JACOBSON, 1999).

Os diagramas de interação podem ser representados pelo diagrama de sequência e de comunicação (antigamente conhecido como diagrama de colaboração) e são usados para modelar aspectos dinâmicos de um sistema. Esses diagramas mostram a interação, consistindo de um conjunto de objetos e seus relacionamentos, incluindo as mensagens que podem ser trocadas entre eles.

Enquanto o diagrama de sequência dá ênfase na ordenação temporal das mensagens, o de comunicação enfatiza a organização estrutural dos objetos que enviam e recebem 


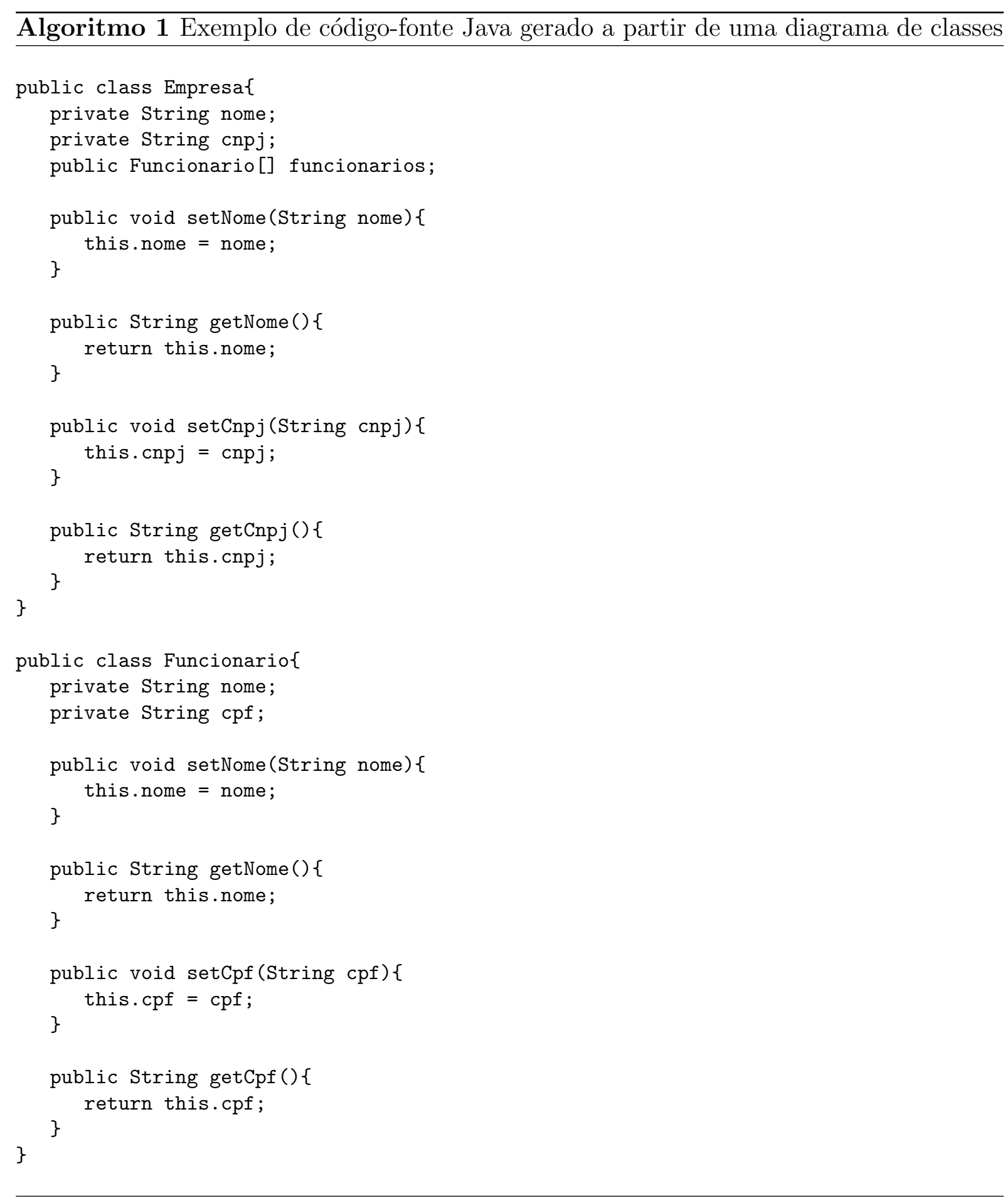




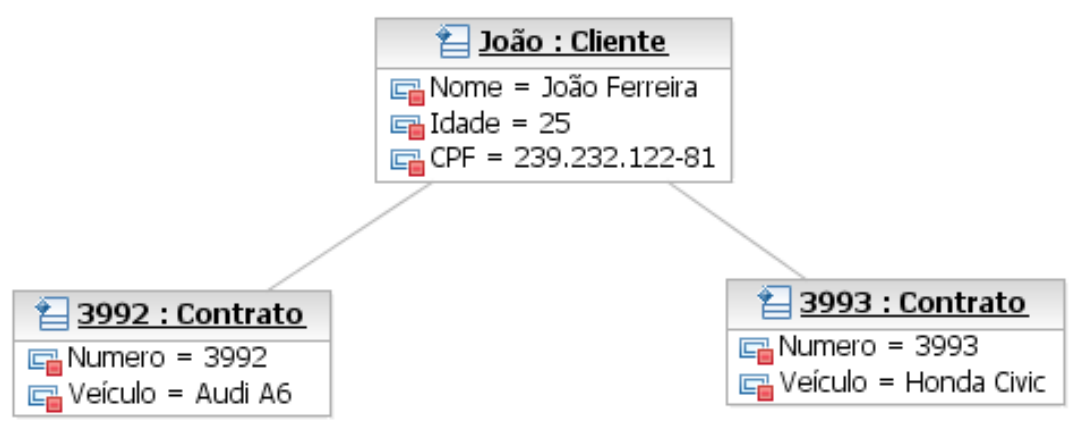

Figura 2.7: Exemplo de Diagrama de Objetos.

mensagens.

Em geral, os diagramas de interação são construídos a partir dos casos de uso que estão representados nos diagramas de mesmo nome e das classes definidas no diagrama de classes para determinar os objetos envolvidos em um processo. Esses diagramas geralmente identificam o evento gerador do processo modelado, bem como o ator responsável pelo estímulo externo (OMG, 2007b).

Como ambos derivam da mesma informação no metamodelo da UML, diagramas de sequência e comunicação são semanticamente equivalentes. Assim, é possível converter um para o outro sem perder qualquer informação, entretanto, isso não significa que ambos diagramas irão visualizar a mesma perspectiva (BOOCH; RUMBAUGH; JACOBSON, 1999), como apresentado nas figuras 2.8 e 2.9, utilizadas no estudo de caso deste trabalho.

A maioria das ferramentas CASE de modelagem permite a geração automática do diagrama de comunicação a partir de um diagrama de sequência existente.

Os diagramas de máquina de estados, que nas versões anteriores eram conhecidos como diagramas de gráfico de estados ou simplesmente diagramas de estados, também são usados para modelar aspectos dinâmicos de um sistema. Eles modelam o ciclo de vida dos objetos e são compostos por estados que representam um estágio no ciclo de vida de uma instância de uma classe; eventos que indicam que uma progressão está ocorrendo; transições que definem qual é o novo estado adquirido quando um objeto em um dado estado recebe um evento específico; e procedimentos que devem acontecer quando um objeto está em determinado estado (MELLOR; BALCER, 2002).

Confirmando mais uma vez a flexibilidade semântica dos elementos e diagramas da UML, o diagrama de máquina de estados também pode ser utilizado para representar os estados de um caso de uso ou mesmo estados gerais de um subsistema ou de um sistema 


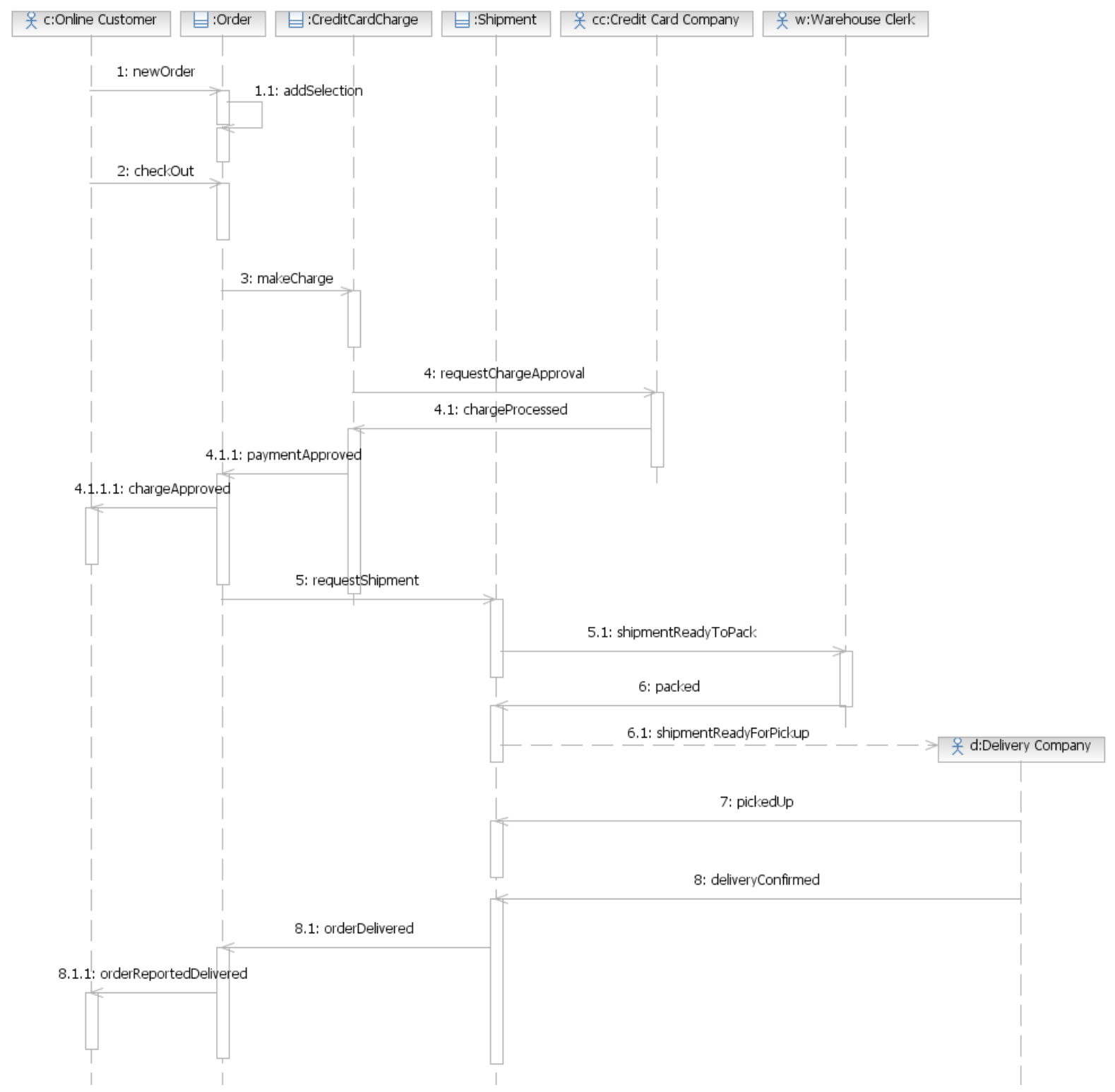

Figura 2.8: Exemplo de diagrama de sequência, baseado em Mellor e Balcer (2002). 


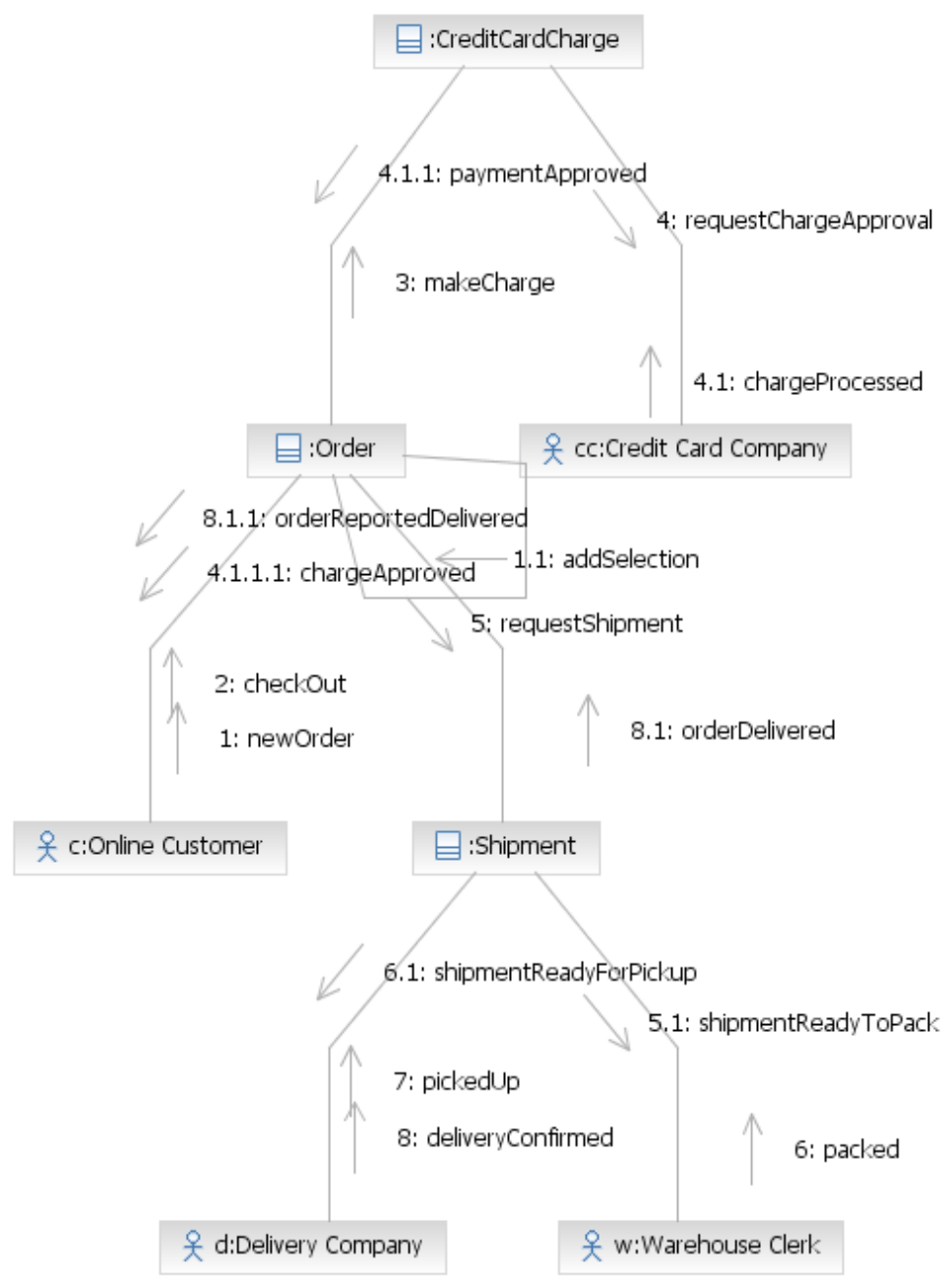

Figura 2.9: Exemplo de diagrama de colaboração, baseado em Mellor e Balcer (2002). 


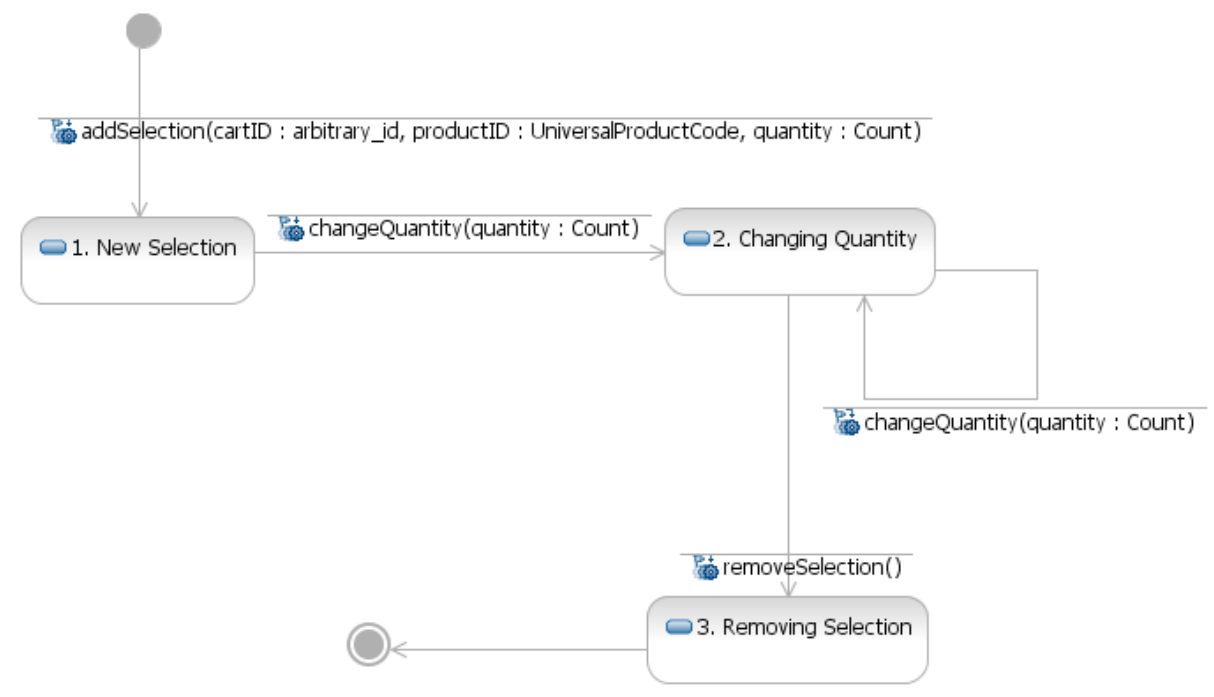

Figura 2.10: Exemplo de diagrama de máquina de estados.

completo.

Um exemplo de diagrama de máquina de estados é apresentado na figura 2.10.

Ainda nas fases de análise e projeto, outro diagrama utilizado é o diagrama de atividade, antigamente considerado um tipo especial do diagrama de máquina de estados, mas que a partir da versão 2.0 é um diagrama independente. Seu objetivo é mostrar o fluxo de uma atividade para outra dentro de um sistema. Esses diagramas são especialmente importantes na modelagem do fluxo de controle entre objetos, casos de uso ou processos do negócio.

Um exemplo de diagrama de atividade é ilustrado na figura 2.11.

O diagrama de atividade pode ser usado também para representar os passos a serem percorridos para a conclusão de uma tarefa específica, muitas vezes representada por um método com certo grau de complexidade.

Para representar e organizar os subsistemas encontrados em um sistema, utiliza-se os diagrama de pacotes. Esse diagrama pode ser usado de maneira independente ou relacionado a outros diagramas ou elementos. Assim, um pacote pode conter uma classe, um diagrama de sequência, de atividade etc (MOONEY; SARJOUGHIAN, 2008).

Um diagrama de pacote utilizado para representar os subsistemas de uma aplicação é apresentado na figura 3.2 .

Alguns dos 13 diagramas disponíveis na versão 2.0 da UML dão ênfase a fases posteriores das tratadas neste trabalho, como construção ou implantação. Entre estes está o 


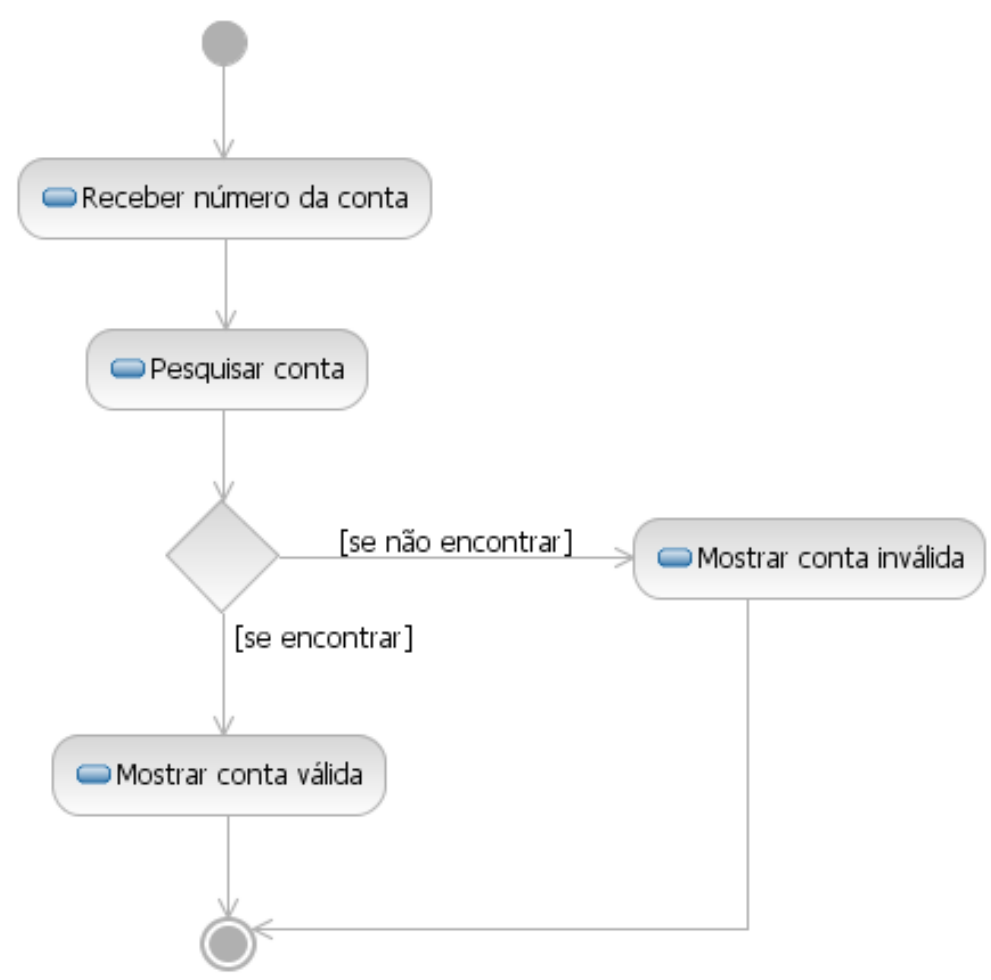

Figura 2.11: Exemplo de diagrama de atividade.

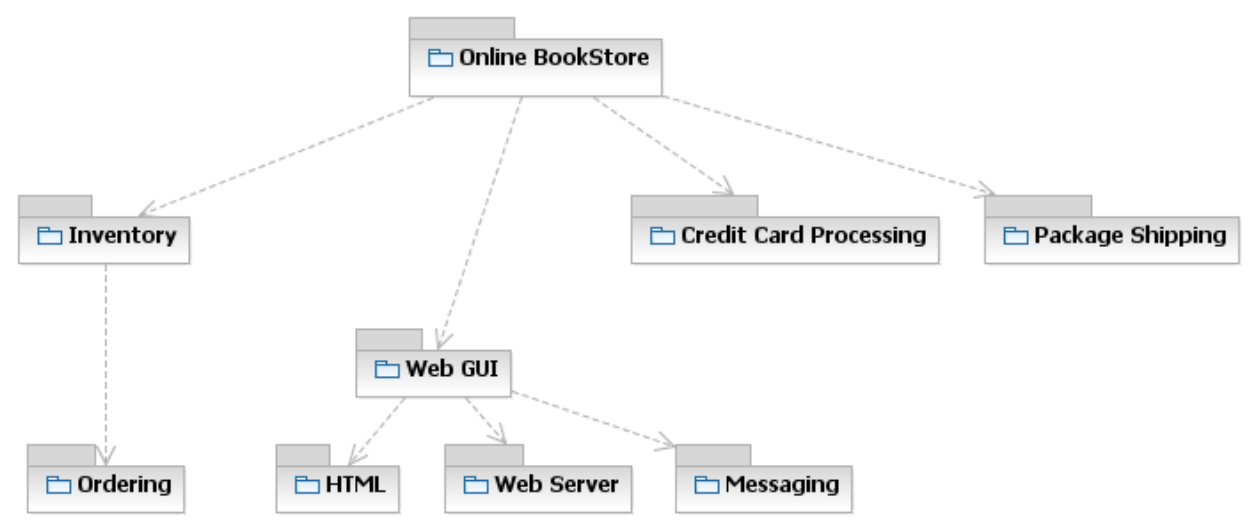

Figura 2.12: Diagrama de Pacotes. Baseado em Mellor e Balcer (2002). 
diagrama de componentes, vinculado geralmente à linguagem de programação utilizada para desenvolver o sistema. Ele representa os componentes do sistema em termos de módulos de código-fonte, bibliotecas, formulários, módulos executáveis etc.

O outro diagrama é o de implantação, que determina as necessidades de hardware do sistema, as características físicas como servidores, estações, protocolos etc.

Os diagramas de componentes e de implantação estão relacionados e podem ser apresentados de maneira independente ou em conjunto, porém, para o objetivo deste trabalho, não serão utilizados.

Por fim, também na versão 2.0 foram adicionados três novos diagramas: diagrama de estrutura composta, que descreve a estrutura interna de um classificador, como uma classe ou componente; diagrama de interação geral, que é uma variação do diagrama de atividade e fornece uma visão geral dentro de um sistema ou processo de negócio; e o diagrama de tempo, que descreve a mudança de estado ou condição de um objeto durante um tempo. Esses diagramas, por serem mais recentes, têm sua utilização ainda restrita e muito específica e também não são utilizados para o objetivo deste trabalho (OMG, 2007b).

\subsubsection{A Flexibilidade Semântica da UML}

A impossibilidade de executar um modelo UML tradicional está diretamente relacionada com a falta de semânticas concretas, organizadas e bem-definidas na linguagem. A história por trás da UML descrita anteriormente ajuda a entender o motivo da falta de clareza semântica que a afeta. Com várias contribuições — adicionando cada uma delas alguns aspectos de suas técnicas para a linguagem de modelagem unificada - é esperado que alguns de seus diagramas possam ter diferentes usos e interpretações.

Muitos projetos de pesquisa trabalham na definição de semânticas mais precisas para os elementos da UML padrão, porém, reduzindo sua flexibilidade.

Nessa seção são apresentados alguns dos problemas semânticos existentes e que tornam difícil a programação baseada em modelos e sua simulação usando a linguagem UML padrão.

\subsubsection{Problemas Semânticos do Diagrama de Classes}

A figura 2.13 mostra como o diagrama de classes pode ser usado em momentos distintos do ciclo de vida de desenvolvimento de software, por exemplo, nas fases de análise e 


\begin{tabular}{||l||l||}
\hline \multicolumn{1}{|c|}{ Análise } & \multicolumn{1}{c|}{ Projeto } \\
\cline { 1 - 1 } Order & \multicolumn{1}{c|}{ Order } \\
\hline $\begin{array}{l}\text { Placement Date } \\
\text { Delivery Date } \\
\text { Order Number }\end{array}$ & $\begin{array}{l}\text { - deliveryDate: Date } \\
\text { - orderNumber: int } \\
\text { - placementDate: Date } \\
\text { - taxes: Currency } \\
\text { - total: Currency }\end{array}$ \\
\hline $\begin{array}{ll}\text { Calculate Total } \\
\text { Calculate Taxes }\end{array}$ & $\begin{array}{l}\text { \# calculateTaxes(Country, State): Currency } \\
\text { \# calculateTotal(): Currency } \\
\text { getTaxEngine() \{visibility=implementation\} }\end{array}$ \\
\hline
\end{tabular}

Figura 2.13: Diferentes usos para o diagrama de classes.

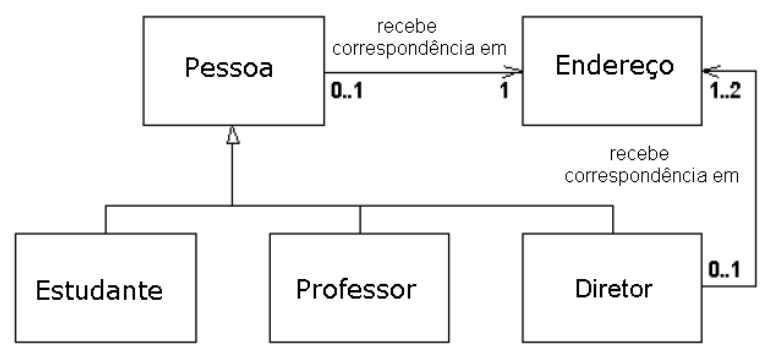

Figura 2.14: Exemplo de flexibilidade semântica em relacionamentos nos diagramas de classe.

projeto. Embora isso ofereça flexibilidade ao engenheiro de software, torna difícil definir uma semântica precisa.

A figura mostra como a fase de análise usa expressões menos formais para definir suas características e operações, enquanto na fase de projeto é utilizado um maior formalismo, assim, o engenheiro pode utilizar o diagrama de classes de diferentes maneiras, tornando difícil a derivação de padrões computacionais.

Similarmente, a semântica flexível nos relacionamentos entre classes e suas cardinalidades torna impossível obter uma consistência computacional em alguns modelos UML. A figura 2.14 apresenta um diagrama de classes de alto nível com relacionamentos e cardinalidades. Observa-se que os relacionamentos não são identificados de forma única, dificultando a aplicação de restrições nos mesmos.

\subsubsection{Problemas Semânticos do Diagrama de Sequência}

O diagrama de sequência pode ser utilizado para representar as interações envolvidas em um cenário de caso de uso. Esse diagrama também seria um bom candidato para auxiliar a execução de um modelo UML, no entanto, variações semânticas de como certos 


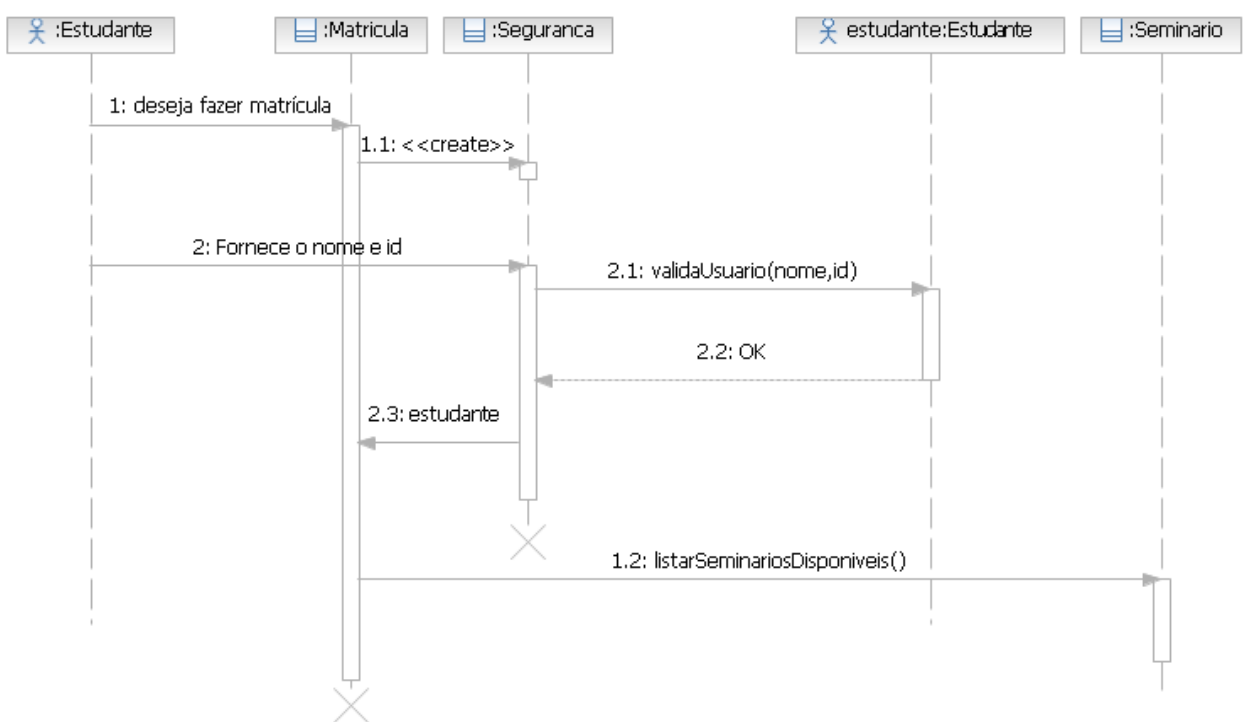

Figura 2.15: Exemplo de flexibilidade semântica em diagramas de sequência, baseado em (CAMPOS, 2007).

componentes do diagrama podem ser usados não permitem tal execução. A figura 2.15 mostra um exemplo de diagrama de sequência.

Apenas neste exemplo é possível notar alguns problemas semânticos. Quando um ator "estudante" chama a operação "deseja fazer matrícula" do objeto "Matricula", está descrito com uma expressão informal. Entretanto, o objeto "Seguranca" chama a operação "validaUsuario" no objeto que representa um estudante de maneira mais consistente com a programação orientada a objetos.

Outro ponto de variação semântica é o uso opcional de valores de retorno nas chamadas de métodos. Por exemplo, o método "validaUsuario" retorna "OK", enquanto o método "listarSeminariosDisponiveis" não retorna nada.

\subsubsection{Problemas Semânticos dos estereótipos}

Os estereótipos oferecem uma maneira rápida e flexível de introduzir elementos de modelagem definidos pelo usuário a UML. A versatilidade dos estereótipos é evidente no seu uso em diferentes diagramas e elementos. De fato, alguns desses elementos fazem parte da UML padrão. Entretanto, a UML não tem restrições sobre como um estereótipo pode ser usado e isso introduz ainda mais dificuldades semânticas para a execução de um modelo. Um exemplo extremo de como os estereótipos podem ser usados de forma válida é apresentado na figura 2.16.

Embora na prática nenhum engenheiro ou analista crie um modelo como o da figura, 


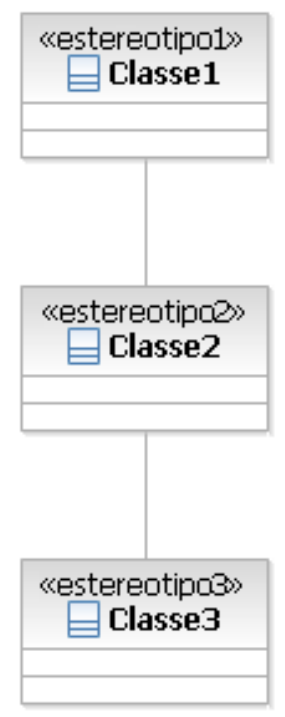

Figura 2.16: Exemplo de flexibilidade dos estereótipos.

não há nada na UML padrão que previna isso de acontecer. Pode-se criar ilimitados estereótipos sem violar qualquer regra de modelagem.

\subsubsection{Diversos usos para um único diagrama}

Uma característica relevante em relação à semântica da UML é a possiblidade de utilizar um mesmo diagrama com objetivos diferentes como já citado. Por exemplo:

- diagrama de atividade: representação das ações de um método, fluxo de um processo de negócio, casos de uso etc.

- diagrama de máquina de estado: representação dos estágios do ciclo de vida de um objeto, representação dos estados de um subsistema ou sistema inteiro.

\subsubsection{Falta de formalismo}

A falta de formalismo para expressar as atividades na documentação de um caso de uso, nos diagramas de interação, as condições e ações dos diagramas de atividades e máquina de estados, entre outros, também tornam muito difícil a simulação de um modelo sem determinar algumas restrições de uso e extensões que serão interpretadas na máquina virtual. 


\subsubsection{Object Constraint Language}

A OCL é uma linguagem definida pela OMG para expressar restrições em diagramas da UML. Ela não é uma linguagem de programação, mas, sim, uma linguagem de especificação formal que tem por objetivo descrever objetos e suas relações (MILLER; MUKERJI, 2003).

As restrições em relação ao comportamento são definidas em OCL utilizando pré e pós-condições que auxiliam na definição semântica de um modelo UML, incorporando regras de negócio que não tinham como ser formalmente descritas. Entretanto, a OCL em si não é suficiente para a execução de um modelo, dada sua incapacidade para tratar ações comportamentais de um sistema (JIANG; ZHANG; MIYAKE, 2007).

Para definir uma restrição de unicidade de instâncias formalmente, pode-se usar a OCL conforme o algoritmo 2.

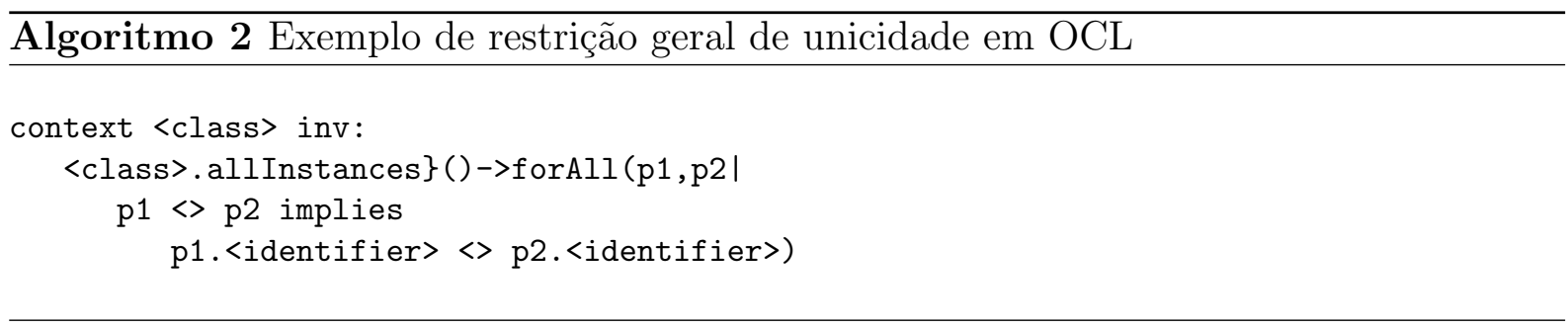

A primeira linha define o contexto da restrição, a classe na qual a restrição será aplicada, e o fato de que a restrição é a definição de uma invariante, ou seja, uma condição que deve ser verdadeira para todas as instâncias daquela classe a qualquer momento (JIANG; ZHANG; MIYAKE, 2007).

A segunda linha itera sobre todas as instâncias da classe usando duas variáveis: $p 1$ e p2. A palavra-chave allInstances é um operador pré-definido que encontra todas as instâncias da classe associada, e o símbolo de "seta" indica que a operação seguinte atua sobre a coleção.

As terceira e quarta linhas introduzem uma implicação e a invariante. Para duas instâncias quaisquer da classe, $p 1$ e p2, que não são iguais, o atributo identificador dessas duas não deve ser o mesmo.

Essas expressões são escritas como funções lógicas que retornam "verdadeiro" se a restrição é respeitada e "falso" se ela for violada.

Segundo Mellor e Balcer (2002), a OCL e as linguagens de ação podem ser utilizadas em conjunto, porém, como todas as definições de restrições feitas em OCL podem também ser representadas em uma linguagem de ação específica, é preferível usar a linguagem de 
ação também para isso.

Uma alternativa possível é a definição de uma linguagem de ação baseada na OCL. Alguns estudos como o de Haustein e Pleumann (2004) contribuem com essa abordagem.

\subsubsection{XMI}

XMI é um documento Extensible Markup Language (XML) definido e mantido pela OMG. Foi criado para ser um mecanismo para a troca de informações contidas em um modelo entre as várias ferramentas que suportam a UML. Algumas importantes indústrias da área de desenvolvimento de software orientado a objetos, incluindo IBM e Unisys, propuseram um novo padrão que combina os benefícios do XML para definição, validação e compartilhamento de documentos com os benefícios da UML (KIELLAND, 2005).

XML é um padrão aberto e consolidado da World Wide Web Consortium (W3C), definido como um formato de dados para troca de documentos estruturados na internet. O objetivo do XMI é permitir a troca de objetos definidos pela OMG como UML e Meta Object Facility (MOF), representando esses objetos como elementos e atributos XML referenciados com o uso de identificadores.

Antes da definição do XMI não havia nenhum padrão definido pela indústria, assim cada ferramenta tinha seu próprio formato proprietário.

O XMI também pode ser usado para produzir Document Type Definition (DTD) e Schemas XML automaticamente a partir de modelos UML e MOF, oferecendo uma descrição XML para esses artefatos (MILLER; MUKERJI, 2001).

A figura 2.17 apresenta um trecho de um documento XMI utilizado neste trabalho.

A primeira linha do arquivo indica que o documento é do tipo XML, assim como sua versão e codificação de caracteres. As linhas seguintes apresentam os dados estruturados que representam um modelo UML contendo os seus diagramas e elementos. A sexta linha mostra uma tag packagedElement que representa uma classe do modelo chamada Product. Pode-se notar a atribuição de um identificador único para esse elemento. A oitava linha mostra a representação do atributo ProductID da classe representado pela tag ownedAttribute. Outras informações úteis, como a visibilidade e tipo de dado, estão disponíveis para um atributo.

Para cada elemento de um modelo da linguagem UML padrão existe um mapeamento possível na estrutura de dados criada no documento XMI, fato importante que permite 
? $2 x m 1$ version="1,0" encoding="UTF-8" ?>

<uml:Package xmi:version=" 2.1" xmlns:xmi="http://schema.omg.org/spec/XMI/2.1" xmlns:xsi="http://ww.w3.org/2001/Xul Sch

<package Import xmi : type=" uml:PackageImport" xmi : id="_BsvYEOvHEd6DGYYzu8x-HQ" >

<importedPackage xmi:type="uml:Model" href="http://schema.omg.org/spec/unl/2.1.1/uml. xml\#_0"/>

$</$ package Import $\rangle$

<packagedE lement xmi: type="uml: class" xmi:id="_BsvYFEVHEd6DGYyzu8x-HQ" name="Product"

<generalization xmi:type=" unl:Generalization" xmi: $i d="$ BsvYFUvHEd6DGYYzu8x-HQ" general="_BsvZIUvHEd6DGYYzu8x-HQ"/> cownedattribute xmi:type="uml:Property" xmi:id="_BswFkVHEd6DGYYzu8x-HQ" name="productID" visibility="private" typ $\langle x m i:$ Extension extender="http://ww. eclipse.org/emf/2002/Ecore" >

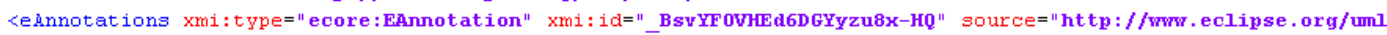
$</$ xmi: Extension>

$<$ ownedittribute>

<ownedattribute xmi:type="uml:Property" xmi:id=" BsvYGEVHEd6DGYYzu8x-H0" name="currentlyÃailable" visibility="pri 〈type xmi:type="uml:PrimitiveType" href="http: $/ /$ schema.omg.org/spec/unl $/ 2.1 .1 /$ unl. mll\#Boolean" $/>$

$<$ /ownedattribute>

<ownedattribute xmi:type="uml:Property" xmi:id="_BswGUVHEd6DGYYzu8x-HQ" name="productKame" visibility="private"> 〈type xmi:type="uml:PrimitiveType" href="http://schema.omg.org/spec/unl/2.1.1/unl.xml\#String"/>

$<$ /ownedsttribute $>$

<ownedAttribute xmi:type="uml:Property" xmi:id="_BsvYGkVHEd6DGYYzu8x-HQ" name="copyright" visibility="private" typ <ownedattribute xmi:type="uml:Property" xmi:id="_BsyYGovHEd6DGYYzu8x-HQ" name="unitPrice" visibility="private" typ <ownedattribute xmi:type="uml:Property" xmi:id=" BsvYHEVHEd6DGYyzu8x-HQ" name="description" visibility="private">

<type xmi:type="unl:PrimitiveType" href="http://schema.omg.org/spec/urL/2.1.1/uml. xml\#String"/>

$<$ /ownedsttribute>

<ownedattribute xmi:type="uml:Property" xri:id="_BswYHuvHEd6DGYYzu8x-HQ" name="website" visibility="private" type= <ownedattribute xmi:type="uml:Property" xmi:id="_BsvYHkVHEd6DGYyzu8x-HQ" name=" shoppingCart" visibility="private"

<upperValue xmi:type="uml:LiteralUnlimitedHatural" xmi:id=" BsyYHOVHEd6DGYYzu8x-HQ" value=" *"/>

<lowerValue xmi:type="unl:LiteralInteger" xmi:id="_BswYIEVHEd6DGYYzu8x-HQ" / >

$</$ ownedattribute $>$

Figura 2.17: Trecho de documento XMI.

que a prova de conceito construída neste trabalho possa receber como entrada um modelo criado em qualquer ferramenta de modelagem UML disponível no mercado que conte com a funcionalidade de exportação desse tipo de documento.

Deve-se notar entretanto uma restrição importante nos documentos XMI: a ordenação das trocas de mensagens entre os componentes do diagrama de sequência não é representada neste documento. Como alternativa para tratar essa restrição, pode-se utilizar a numeração das mensagens - o que algumas ferramentas CASE fazem como padrão. Nesse trabalho a numeração das mensagens não foi adotada para deixar isso a critério do engenheiro, então no protótipo, o usuário deve informar a ordem em tempo de simulação se ela não estiver explícita em outros elementos como máquina de estados ou operações das classes.

\subsection{Model Driven Architecture}

A MDA é uma iniciativa anunciada pela OMG em 2001 e que vem passando por um processo de evolução durante os anos. Atualmente, muitos fornecedores criam produtos para suportar a MDA e a programação baseada em modelos. Segundo Stephen Mellor em Miller et al. (2004), basicamente a MDA fala sobre a construção de uma especificação em uma linguagem abstrata e sua tradução em sistema, com foco em uma palavra: "Modelo". Separar a especificação da operação de um sistema dos detalhes de como ele usará as 
funcionalidades de uma plataforma destino (MILLER; MUKERJI, 2003).

MDA consiste em uma abordagem para:

- especificar um sistema independentemente da plataforma que irá o suportar;

- especificar plataformas;

- escolher uma plataforma específica para o sistema;

- transformar a especificação genérica do sistema em uma para determinada plataforma específica.

Os três objetivos principais da MDA, todos levados em consideração na proposta deste trabalho, são: portabilidade, interoperabilidade e reusabilidade.

Em Ambrogio (2005), essa arquitetura é definida como uma estratégia de desenvolvimento de software composta por modelos de sistema. Logo, ela fornece modelos para a especificação das várias partes que compõem um sistema completo. Essa filosofia busca sustentar a capacidade de abstração do conceito de implementação de um sistema das funcionalidades do mesmo. Para isso, propõe modelar todas as características do sistema independentemente da plataforma e depois gerar a implementação para uma arquitetura específica.

Com essa definição, a arquitetura MDA permite que se especifique os modelos independentes da plataforma de execução e implementação, depois selecione e marque os elementos desse modelo para serem transformados para uma das plataformas específicas necessárias. Após isso, uma transformação de um modelo independente de plataforma para as plataformas selecionadas pode ser feita manualmente ou automaticamente.

O processo para transformar um modelo independente de plataforma em um modelo específico para uma plataforma envolve as fases de mapeamento e transformação. Na fase de mapeamento os modelos que são independentes de plataforma devem ser selecionados e marcados para uma determinada plataforma, que é especificada em algum momento no projeto do sistema. Essas marcações podem ser definidas com o uso de padrões e linguagens padronizadas pela OMG, como a linguagem OCL.

No caso da arquitetura MDA, a transformação de modelos pode ser definida como o processo de converter um modelo em outro do mesmo sistema. O PIM e outras informações são combinados pela transformação para produzir um Plataform Specific Model (PSM), como demonstrado na figura 2.18 . 


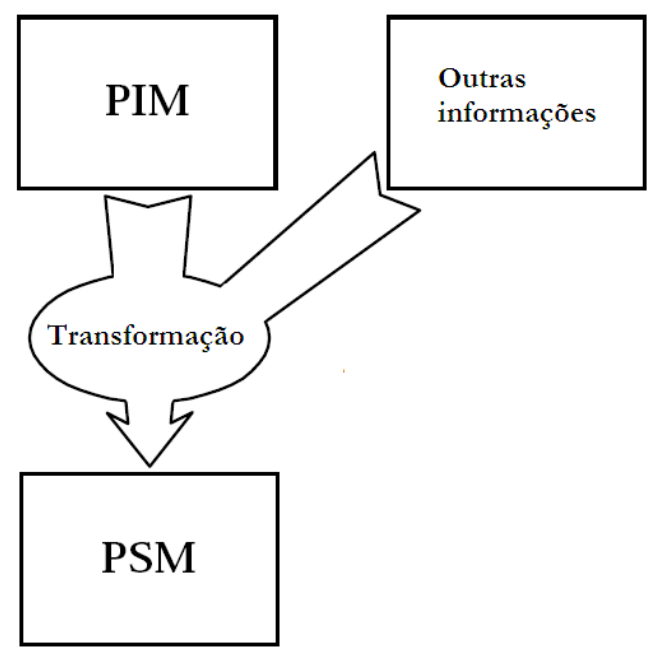

Figura 2.18: Transformação de modelo(MDA).

Como citado anteriormente, existem diversas estratégias na transformação de modelos para se realizar tal transformação. Seja qual for, ela produz, a partir de uma modelo independente de plataforma, um modelo específico para uma plataforma em particular.

\subsubsection{Mapeamento de Modelos}

Uma característica-chave de toda a abordagem da MDA é a noção de mapeamento. Um mapeamento é um conjunto de regras e técnicas utilizadas para modificar um modelo de forma a chegar em outro modelo. Mapeamentos são utilizados para transformar:

- PIM para PIM: essa transformação é utilizada quando os modelos são aprimorados, filtrados ou especializados durante o ciclo de vida de desenvolvimento sem precisar de alguma informação dependente de plataforma. Um dos mais óbvios mapeamentos é a transformação de modelo de análise para projeto. Transformações PIM para PIM normalmente estão relacionadas a refinamento de modelo.

- PIM para PSM: essa transformação é utilizada quando o PIM está suficientemente refinado para ser projetado para o ambiente de execução. A projeção é baseada nas características da plataforma. Partir de um modelo de componente lógico para um modelo de componente comercial existente (como Enterprise Java Beans (EJB) para a plataforma Java) é um tipo de mapeamento PIM para PSM.

- PSM para PSM: essa transformação é necessária para a realização e distribuição de componentes. Por exemplo, o empacotamento de componentes é feito selecionando serviços e preparando suas configurações. Uma vez empacotados, a entrega dos 
mesmos pode ser feita especificando os dados de inicialização, máquinas alvo, configuração etc. Mapeamento PSM para PSM é geralmente relacionado ao refinamento de modelo dependente de plataforma.

- PSM para PIM: essa transformação é necessária para abstração de modelos de implementações existentes em uma tecnologia em particular em um modelo independente de plataforma. Esse processo frequentemente lembra um processo de extração que é difícil de ser totalmente automatizado. De qualquer forma, ele pode ser suportado por ferramentas. Idealmente, o resultado desse mapeamento será compatível com o mapeamento PIM para PSM correspondente.

Para efetuar essa conversão de um modelo independente de plataforma para outro dependente de plataforma, caracterizada como sendo uma fase de mapeamento e transformação de modelos, a MDA sugere uma série de etapas para isso:

- escolha de uma plataforma;

- marcação dos modelos para essa plataforma;

- transformação do modelo para a plataforma específica.

Na primeira etapa deve-se escolher a plataforma que implementará o sistema. Em seguida, o processo de mapeamento dos modelos PIM pode ter início, onde se podem colocar marcas, que são especificações de instâncias de modelos, associadas com o mapeamento, com os valores de parâmetros requeridos. Nesse processo pode ser indicado, por exemplo, que para a plataforma móvel do Java (J2ME), uma classe deve implementar determinada interface, algo como CommandListener (para tratar os comandos do teclado de um dispositivo). Marcado o modelo, ele pode ser transformado, utilizando uma ferramenta CASE que conheça a plataforma escolhida.

Foi a partir da iniciativa da MDA que estudos relacionados a execução de modelos ganharam força nos meios acadêmicos e corporativos. Essas propostas são consideradas possíveis realizações práticas e efetivas por trás da arquitetura conceitual da MDA (FLINT; GARDNER; BOUGHTON, 2004).

\subsubsection{MOF}

O padrão MOF oferece um framework para a gestão de metadados independentes de plataforma para a abordagem MDA, em que a notação de classes da UML é utilizada 
para representar os metamodelos MOF. Estes, são representações gráficas de relações que podem ser estabelecidas entre elementos descritos por metadados. Este framework e o conjunto de serviços de metadados oferecidos pela MOF habilitam a interoperabilidade da iniciativa MDA (MILLER; MUKERJI, 2003).

\section{$2.6 \mathrm{xUML}$}

Embora ainda não seja um padrão da OMG, a xUML utiliza como notação elementos da linguagem UML tradicional e assim pode ser qualificado como um perfil desse padrão. Entretanto, a OMG liberou uma RFP entitulada Foundational Subset for Executable UML Models, sendo essa basicamente uma chamada para definir as fundações e semânticas da xUML (FLINT; GARDNER; BOUGHTON, 2004).

Os objetivos da especificação criada a partir dessa RFP são:

- permitir a definição de uma série de ferramentas que suportam a construção, verificação, transformação e execução de modelos computacionalmente completos.

- para atingir esse objetivo, a especificação deve usar um subconjunto computacionalmente completo de artefatos da UML 2.0 e define as semânticas de execução desse subconjunto.

- computacionalmente completo significa que o subconjunto deve ser suficientemente expressivo para permitir a definição de modelos que podem ser executados em um computador.

Algumas implementações de xUML têm sido sugeridas, e esta pesquisa se baseia nesses trabalhos para descrever uma extensão voltada aos negócios, em um nível mais alto de abstração em relação ao detalhamento técnico computacional, porém, independente de plataforma, que possa ser simulado por meio de uma máquina virtual.

A figura 2.19 apresenta uma descrição da arquitetura da xUML, usando a notação UML.

As áreas-chaves dessa arquitetura, segundo Mooney e Sarjoughian (2008), são:

- O Foundational UML Subset (fUML) é um subconjunto executável da UML padrão que pode ser usado para definir, operacionalmente, as semânticas dinâmica e estática de linguagens de modelagem como a UML padrão ou seus subconjuntos e extensões. 


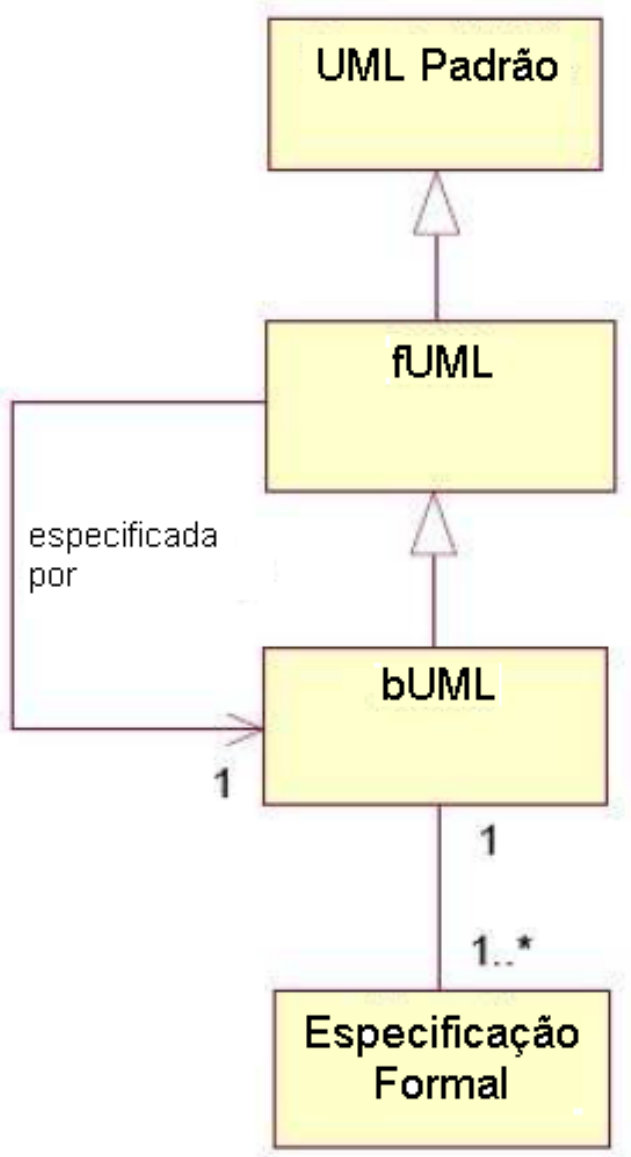

Figura 2.19: Arquitetura xUML. 
Por exemplo, as semânticas dos diagramas de máquina de estados da UML podem ser especificadas como um programa escrito em fUML.

- O Basic UML Subset (bUML) é um subconjunto do fUML que tem uma definição de semânticas matematicamente formais correspondente e é usada para especificar as semânticas do fUML. A idéia é fornecer uma base para o tratamento formal de programas fUML.

- Uma biblioteca de modelo de tempo de execução que contém definições de classes auxiliares usadas pelos serviços em tempo de execução.

Os vários componentes na especificação da xUML apontam claramente para a definição das semânticas da UML assim como a definição de uma máquina virtual para executar o modelo.

\subsubsection{Especificação de Ações}

As ações que podem ser utilizadas em alguns diagramas UML são como código-fonte, porém em um nível de abstração mais alto, sem se importar com a estrutura do software ou implementação. Essa linguagem de ação é também conhecida como Action Specification Language (ASL).

As semânticas dessa linguagem — mas não a sintaxe — são definidas pela OMG. A padronização aconteceu na versão oficial 1.5 da UML.

Assim, com a definição da xUML, diversas linguagens de ação foram criadas. Entre as primeiras estão: $S M A L L, T A L L$, a $i U M L$ e a Object Action Language (OAL). Outras tantas são encontradas atualmente, porém, como a OMG somente define as semânticas para as ações, sem padronizar uma linguagem efetivamente (sintaxe concreta), não existem nelas a interoperabilidade e independência de plataforma desejada. Por isso, foi liberada pela OMG uma RFP (OMG, 2007a), em que se espera definir uma linguagem de ação única.

Os requisitos dessa RFP é que as seguintes semânticas de ações já definidas sejam respeitadas (HAUSTEIN; PLEUMANN, 2004):

- Estruturas de Controle: usadas para repetições e estruturas de decisão;

- Ações de Escrita e Leitura: usadas para acessar valores das propriedades dos objetos e para criar ou excluir instâncias; 
- Ações de Computação: transformar um conjunto de valores de entrada para produzir um conjunto de valores de saída sem efeitos colaterais em outras partes do sistema;

- Ações de Coleção: permitir a aplicação de uma ação a um conjunto de elementos de dados;

- Ações de Mensageria: disparar ações assíncronas e síncronas, tais como transições de máquina de estados ou chamadas a métodos com um valor de retorno;

- Ações Composicionais: iterações e condicionais sobre o modelo;

- Ações de Salto: permitir desvios do principal caminho do fluxo de controle, similar ao comando break de diversas linguagens de programação.

Mesmo com as propostas solicitadas na RFP citada, até então não foi definida uma sintaxe padrão de ASL.

Utiliza-se para fins de demonstração neste trabalho uma variação simplificada da ASL, conhecida como OAL, que será descrita na próxima seção, porém a sintaxe da linguagem de ação utilizada no modelo pode ser facilmente alterada no simulador para permitir uma maior abrangência de uso.

\subsubsection{OAL}

A OAL (BRIDGEPOINT, 2003) é usada para definir as semânticas para o processamento que ocorre em uma ação. Uma ação pode ser associada com alguns elementos da modelagem, por exemplo:

- estados;

- funções;

- operações de classes;

- atributos matematicamente dependentes.

Embora tenha sido projetada para modelos usados pela ferramenta BridgePoint UML Suite, a linguagem descrita aqui pode ser utilizada para definir a semântica de ações para qualquer modelo UML em qualquer ferramenta.

Essa linguagem suporta: 
- lógica de controle;

- acesso aos dados descritos pelo diagrama de classes;

- acesso aos dados fornecidos por eventos que iniciam ações;

- geração de eventos;

- acesso a timers e a data e hora corrente.

Os algoritmos apresentados abaixo mostram exemplos da sintaxe utilizada para definição de ações neste trabalho, porém, para maiores detalhes sobre a sintaxe da OAL, indica-se a leitura do manual de referência da linguagem em BridgePoint (2003).
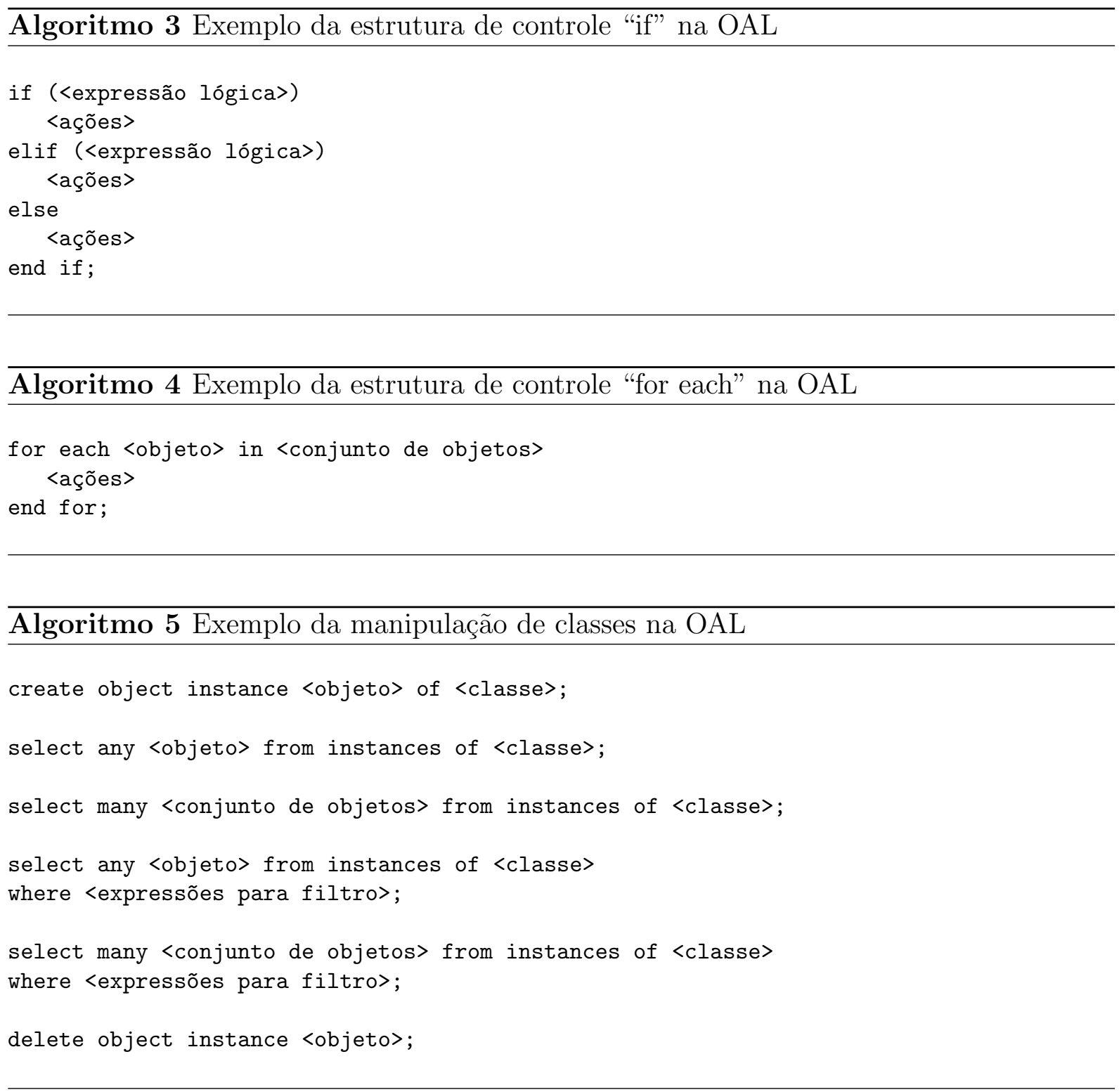

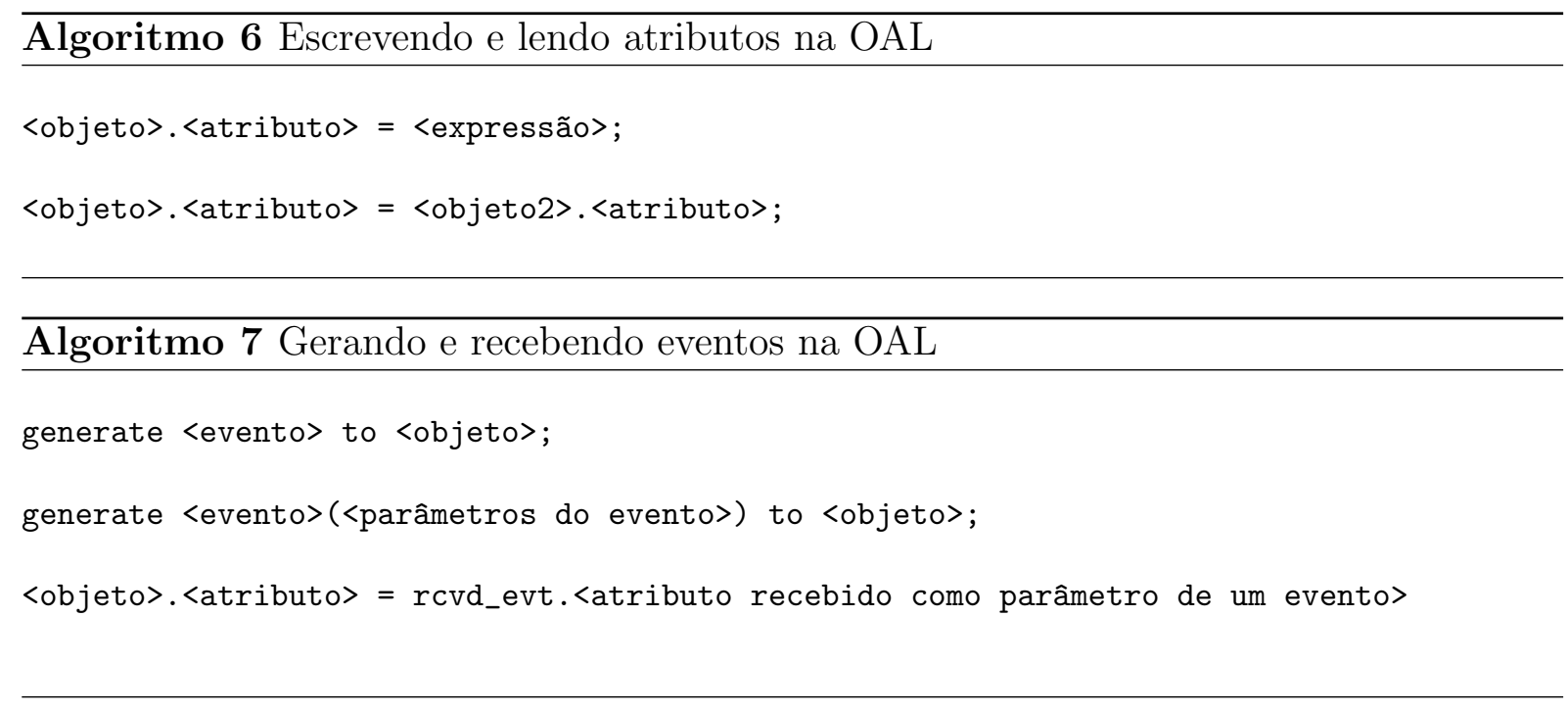

\subsection{Propostas de $\mathrm{xUML}$}

A abordagem mais popular e bem aceita para modelos executáveis até hoje é a descrita em Mellor e Balcer (2002). Basicamente, essa proposta visa encontrar abstrações necessárias para construir o modelo preciso de um domínio, capturando o comportamento das partes que o compõe.

Esse modelo é composto de:

- diagramas de classe;

- máquinas de estado;

- especificação de ações.

O primeiro modelo identifica, classifica e abstrai o mundo real ou hipotético e organiza a informação em uma estrutura formal. Utiliza-se o diagrama de classes da UML para expressar esse modelo.

Depois, os objetos (instâncias das classes) podem ter ciclos de vida (comportamento durante o tempo) que são abstraídas como máquinas de estados. Essas máquinas são definidas para as classes e representadas com a utilização dos diagramas de máquina de estados da UML.

O comportamento do sistema é baseado na alteração de estágios no ciclo de vida dos objetos em resposta a eventos. Cada máquina de estado tem um conjunto de procedimentos e um deles é realizado quando o objeto muda de estado, estabelecendo, assim, o novo estado. 
Cada procedimento é composto por um conjunto de ações. Cada ação é uma unidade primitiva de computação, como uma seleção, atribuição, decisão etc. A UML definiu há pouco tempo uma semântica para as ações, porém, não existe notação ou sintaxe padrão para ela.

Esses três modelos - o modelo de classe, as máquinas de estado para as classes e os procedimentos dos estados — formam uma definição completa do assunto sob estudo. A tabela 2.3 descreve os conceitos na xUML.

\begin{tabular}{|l|l|l|l|}
\hline Conceito & Chamado & Modelado como & Representado como \\
\hline $\begin{array}{l}\text { o mundo é composto } \\
\text { de coisas }\end{array}$ & dados & $\begin{array}{l}\text { classes } \\
\text { atributos } \\
\text { associações } \\
\text { restrições }\end{array}$ & $\begin{array}{l}\text { diagrama de } \\
\text { classes UML }\end{array}$ \\
\hline $\begin{array}{l}\text { as coisas têm ciclos } \\
\text { de vida }\end{array}$ & controle & $\begin{array}{l}\text { estados } \\
\text { eventos } \\
\text { transições } \\
\text { procedimentos }\end{array}$ & $\begin{array}{l}\text { diagrama de } \\
\text { máquina de estados }\end{array}$ \\
\hline $\begin{array}{l}\text { as coisas fazem outras } \\
\text { coisas em cada estágio }\end{array}$ & algoritmo & aços & linguagem de ação \\
\hline
\end{tabular}

Tabela 2.3: Conceitos em um modelo xUML, baseado em Mellor e Balcer (2002)

Essa abordagem, no entanto, não tem foco nos modelos em nível de negócio - ela auxilia principalmente na fase de projeto de um sistema - e alteraria bruscamente a forma de trabalho de engenheiros ou analistas, que geralmente têm como ponto central de seus modelos os diagramas de classes e não o diagrama de máquina de estados, como sugerido nesse método.

Além disso, utiliza-se apenas dois diagramas da UML tradicional, restringindo demais os artefatos disponíveis para representar o sistema em nível de negócio. Por exemplo, diversos projetos têm a modelagem estática da aplicação representada pelos diagramas de classes enquanto o modelo dinâmico, ou seja, o comportamento da aplicação, definido por diagramas de sequência. Trabalhar com um pequeno subconjunto de diagramas pré-selecionados pode restringir o uso da abordagem por pessoas que não têm grande familiaridade com esses diagramas.

Outras iniciativas menos populares são variações da proposta de Mellor e Balcer e, portanto, apesar de servirem como base para algumas das definições do simulador apresentado neste trabalho, não são utilizadas durante o processo tradicional de modelagem de sistemas orientados a objetos. 


\section{Especificação e Criação do ModSim}

A proposta de definição semântica para alguns elementos da linguagem UML utiliza alguns dos pontos fortes de iniciativas existentes de xUML, porém, adiciona novas possibilidades de representação de modelos em nível de negócio para os engenheiros e analistas.

O projeto da solução para a utilização do protótipo capaz de simular os modelos será apresentado com a seguinte abordagem: primeiro, o processo que o autor do modelo UML deve seguir para criar um modelo xUML de acordo com a proposta sugerida. Após a demonstração de uso de cada diagrama, as semânticas definidas para este e para seus elementos serão também descritas. Por fim, os detalhes técnicos da prova de conceito criada para simulação desse modelo - mapeamentos, estrutura e funcionalidades — serão apresentados.

\subsection{Processo de criação dos modelos em nível de negócio}

A sugestão de processo para criar modelos em nível de negócio que podem ser simulados não precisa ser seguida exatamente como descrito. Alguns diagramas ou elementos são imprescindíveis para permitir a simulação e serão descritos nas próximas seções na ordem em que eles possivelmente apareceriam durante a modelagem de um sistema tradicional.

A figura 3.1 exibe o fluxo tradicional de criação dos diagramas que serão descritos a seguir.

\subsubsection{Modelagem do domínio}

Iniciando a partir dos requisitos fornecidos para o sistema, um modelo é construído por meio da identificação dos domínios que são relevantes.

Pode-se construir um modelo xUML para cada assunto ou domínio em um sistema, 


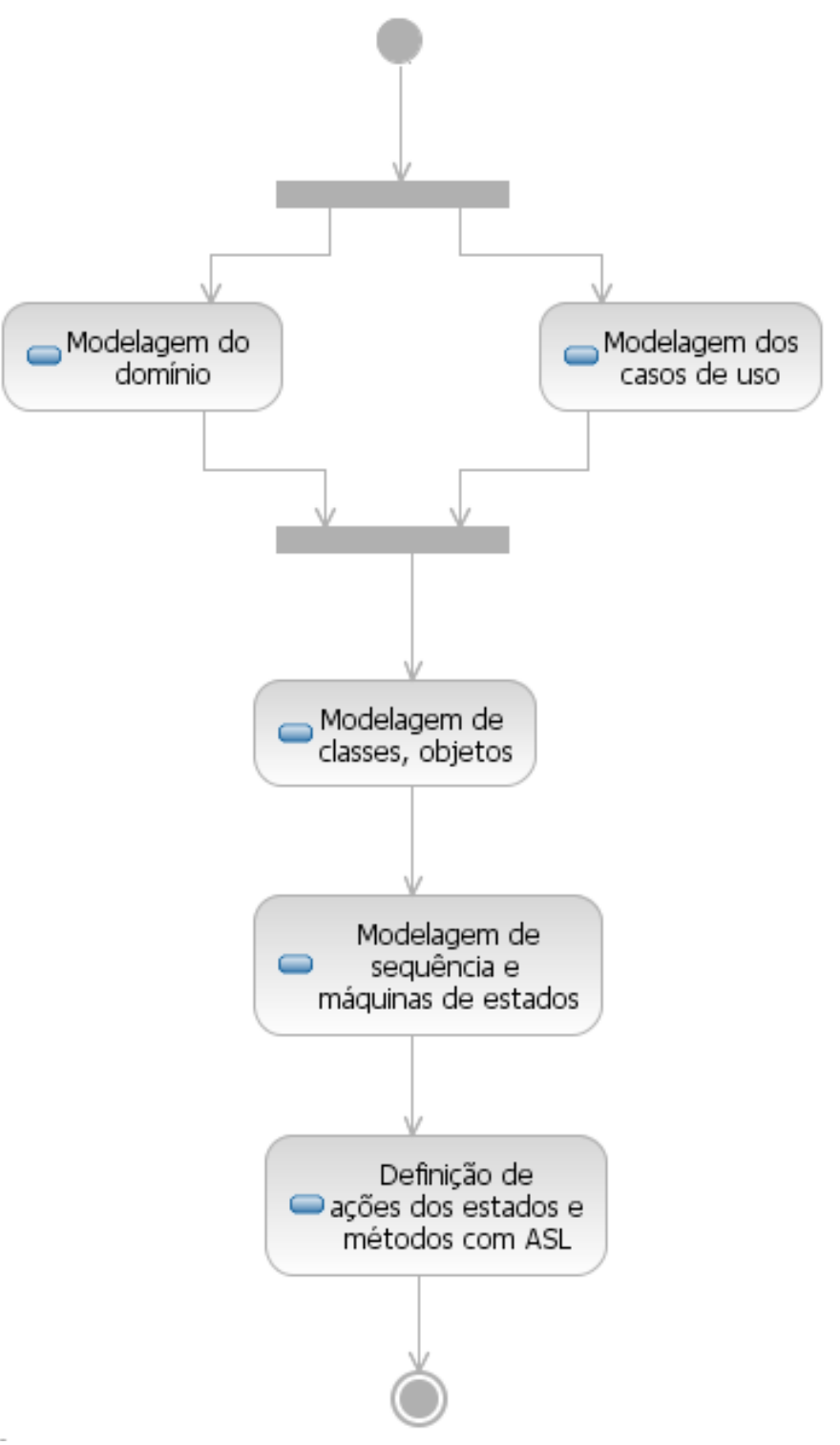

Figura 3.1: Fluxo de criação dos diagramas da UML. 


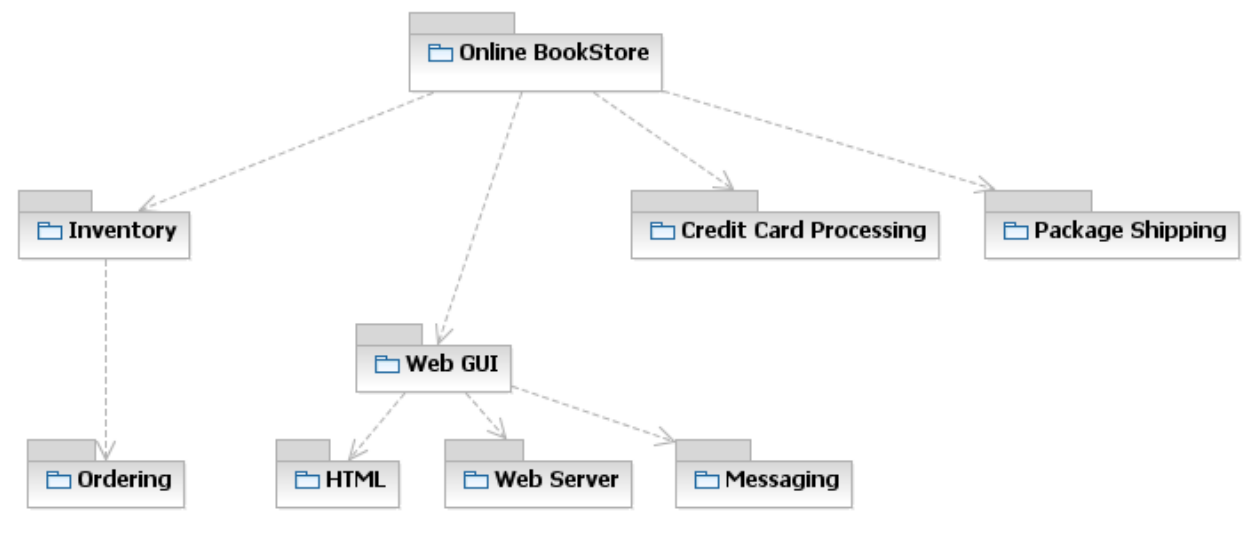

Figura 3.2: Diagrama de pacotes representando subsistemas. Baseado em Mellor e Balcer (2002).

criando assim um conjunto de subsistemas que serão tratados de maneira independente. O processo de particionamento do mundo real em domínios, que segundo Mellor e Balcer (2002) são mundos autônomos habitados por entidades conceituais, é chamado de identificação de domínio.

Representa-se os domínios e os relacionamentos entre eles em um diagrama de pacote, como apresentado na figura 3.2.

Com esse diagrama o autor pode decidir simular apenas um dos subsistemas que compõem seu modelo, simplificando assim o processo. Para isso, ele deve organizar todos os outros diagramas e elementos em relação aos subsistemas pré-definidos.

Se os subsistemas não forem modelados, a máquina virtual irá considerar todos os diagramas e elementos em sua simulação.

Definições semânticas para o diagrama de pacotes são apresentadas na tabela 3.1

\begin{tabular}{|l|l|}
\hline Semântica definida & Descrição \\
\hline Elemento "Pacote" & $\begin{array}{l}\text { Deve ser utilizado como divisão de subsistemas } \\
\text { e conter os outros diagramas do modelo }\end{array}$ \\
\hline
\end{tabular}

Tabela 3.1: Semânticas para o diagrama de pacote

As relações de dependência desse diagrama não têm efeito prático para o simulador, dado que estas são representadas também em outros diagramas. 


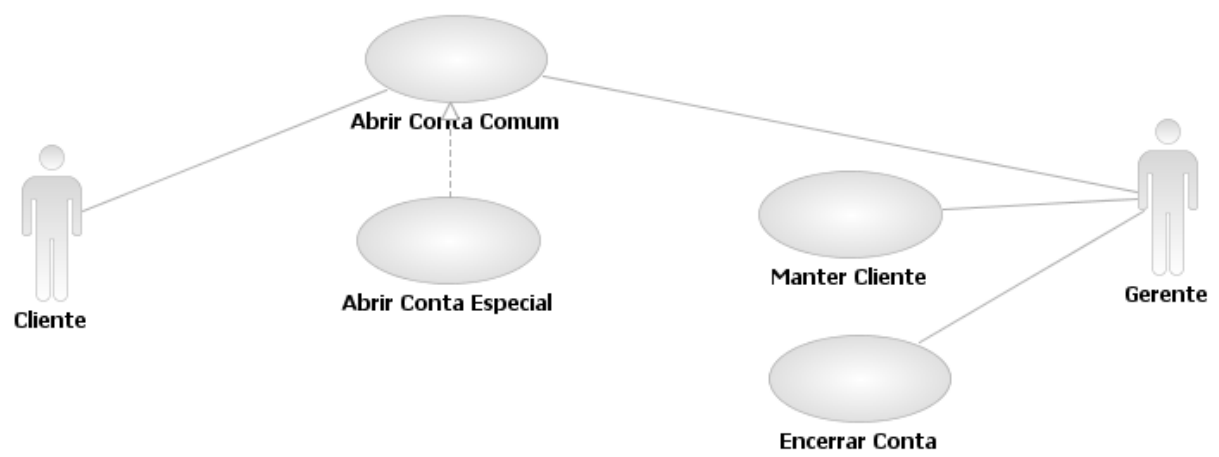

Figura 3.3: Diagrama de caso de uso utilizado para derivar entidades externas.

\subsubsection{Diagrama de casos de uso}

Durante a fase de modelagem dos casos de uso, os aspectos funcionais ${ }^{1}$ do sistema são definidos e as interações entre entidades externas ao sistema podem ser identificadas.

Apesar da utilidade inquestionável desse diagrama para os modelos UML, toda a informação adicional contida neles não é considerada no simulador. O motivo disso é a natureza informal da documentação utilizada nos casos de uso, que torna impossível derivar qualquer padrão computacional sem obrigar o uso de um formalismo sintático. Como as informações sobre o comportamento do sistema e interação entre atores e funcionalidades também estarão descritas em outros diagramas, não há prejuízo para o processo de simulação.

Ainda assim, a partir de um diagrama como o da figura 3.3, pode-se derivar a existência de duas entidades externas que estão de alguma forma relacionadas com funcionalidades que serão modeladas em outros diagramas. Esse é o melhor diagrama para representar a existência dessas entidades.

As entidades externas são responsáveis pelos estímulos iniciais em uma simulação. No exemplo citado existem duas entidades externas (atores):

- Cliente;

- Gerente.

Sugere-se que os diagramas de caso de uso continuem a ser construídos com sua documentação, pois eles podem ser utilizados como artefatos de apoio para casos de teste que podem ser verificados pelo simulador.

\footnotetext{
${ }^{1}$ Apenas os requisitos funcionais são suportados pelo simulador.
} 
Definições semânticas para o diagrama de casos de uso são apresentadas na tabela 3.2

\begin{tabular}{|l|l|}
\hline Semântica definida & Descrição \\
\hline Elemento "Ator" & $\begin{array}{l}\text { Será considerado entidade externa geradora de } \\
\text { estímulos para iniciar um processo de simulação }\end{array}$ \\
\hline
\end{tabular}

Tabela 3.2: Semânticas para o diagrama de casos de uso

\subsubsection{Diagrama de classes}

Depois da definição dos casos de uso, pode-se abstrair as classes que serão utilizadas para representar a estrutura do sistema em questão.

No modelo executável proposto, a partir desse diagrama são derivadas as informações sobre as classes, suas propriedades e métodos. Além disso, dados sobre os relacionamentos entre as classes e suas cardinalidades também são utilizados para garantir que a simulação represente tais restrições.

É a partir desse diagrama que são criados os objetos que são executados na memória virtual do simulador. Uma vez criada a instância de uma classe no simulador, seus atributos e operações estão disponíveis para execução.

Os atributos são representados por tipos de dados em nível de negócio, assim, o autor do modelo não deve trabalhar com tipos computacionais como int, double, char etc., mas, sim, com tipos de dados que fazem parte do domínio estudado. No caso de uma livraria, o número de identificação de um livro pode ser do tipo "ISBN". Um atributo que armazena o valor de um pedido pode ser definido com um tipo de dado "Dinheiro".

Pode-se observar a figura 3.4 para verificar a utilização dos tipos de dados em nível de negócio. Este diagrama, apesar de não ter operações definidas, está de acordo com a definição semântica apresentada abaixo.

Como o objetivo é simular modelos em nível de negócio, a sintaxe utilizada para descrever os nomes das classes, métodos e propriedades não é restrita. Pode-se utilizar a linguagem natural com todos os caracteres, inclusive espaços em branco. ${ }^{2}$

Para resolver a questão das relações de generalização(herança) no diagrama de classes, durante sua tradução para as estruturas internas do simulador, as subclasses já serão carregadas com as informações das superclasses.

\footnotetext{
${ }^{2}$ No caso de eventual extensão desse simulador com atividades de compilação, essas descrições informais devem ser manipuladas para gerar elementos sintáticos válidos nas linguagens de programação.
} 


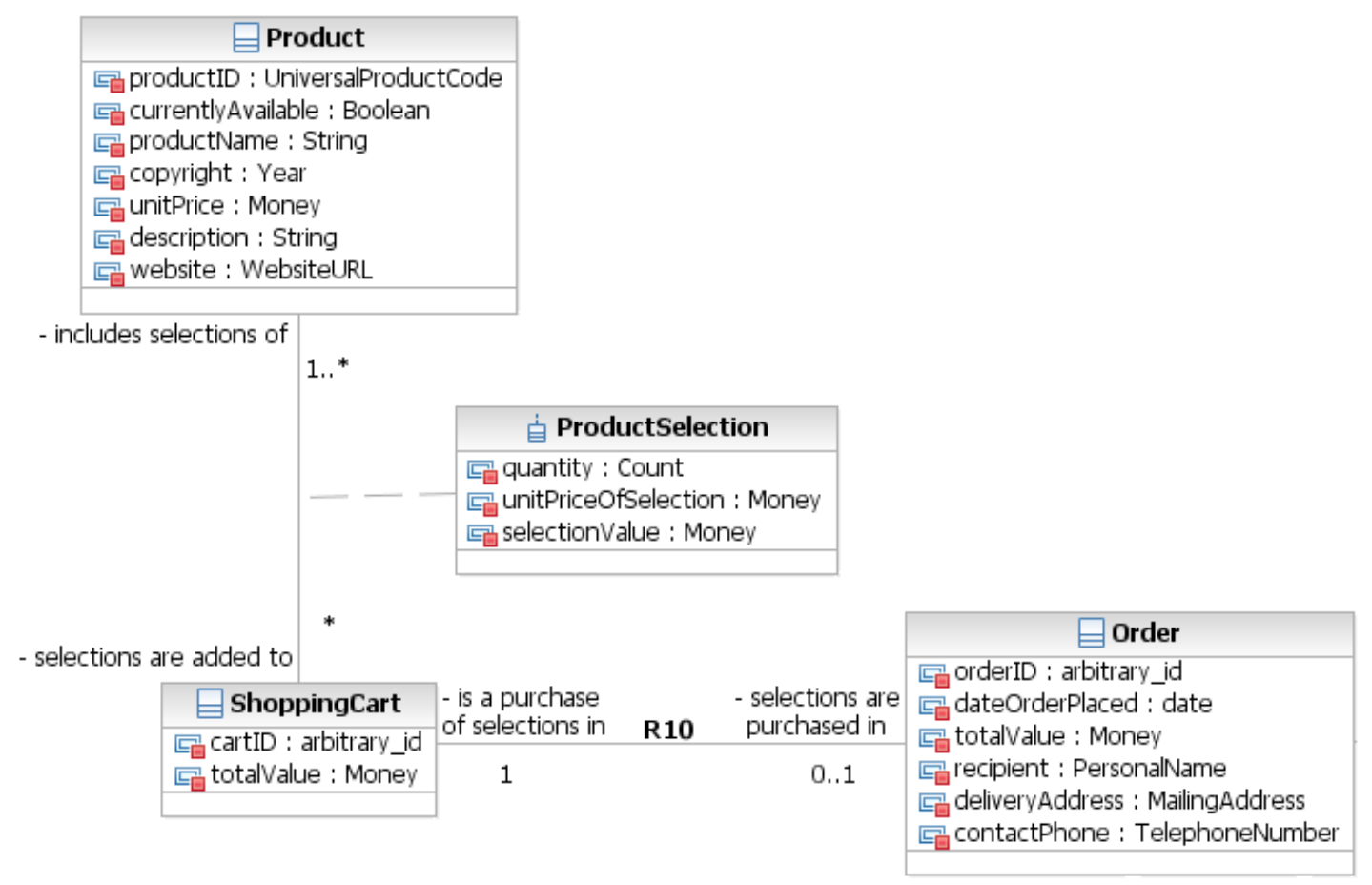

Figura 3.4: Diagrama de classes em nível de negócio.

Motivado ainda pela utilização de modelo em nível de negócio, os elementos que representam interfaces não são considerados pelo simulador.

Definições semânticas para o diagrama de classes são apresentados na tabela 3.3

\subsubsection{Diagrama de objetos}

Os diagramas de objetos permitem a definição de instâncias de uma classe. Se o modelo contiver este diagrama, os objetos nele descritos estarão disponíveis durante a simulação do modelo. Além disso, o simulador permite a adição de exemplos de instâncias manualmente e aleatoriamente, se necessário.

Estes objetos são utilizados para o usuário não ter que passar por diversas funcionalidades da aplicação caso queria apenas simular um ponto específico do sistema. Assim, mesmo que um objeto específico não estiver disponível na memória da máquina virtual do protótipo no momento em que o usuário estiver simulando uma funcionalidade, pode-se usar um exemplo de objeto de determinada classe para permitir terminar a simulação com sucesso, sem se preocupar sobre como aquele objeto foi criado na memória. 


\begin{tabular}{|l|l|}
\hline Semântica definida & Descrição \\
\hline Relacionamentos & $\begin{array}{l}\text { Todos os relacionamentos entre classes devem ter } \\
\text { nomes únicos para serem identificados pelo simulador }\end{array}$ \\
\hline Cardinalidades & $\begin{array}{l}\text { As cardinalidades devem ser sempre definidas } \\
\text { para que o simulador controle as restrições de criação } \\
\text { de novos objetos }\end{array}$ \\
\hline Propriedades & $\begin{array}{l}\text { As propriedades das classes devem ser baseadas em } \\
\text { tipos de dados do negócio. Esses tipos podem ser criados } \\
\text { com a utilização do elemento "Tipo de Dado" da UML }\end{array}$ \\
\hline Oétodos & $\begin{array}{l}\text { Os métodos devem ter todos os parâmetros de entrada } \\
\text { e valor de retorno explícitos. Esses tipos também podem } \\
\text { ser baseados nos tipos de dados de negócio } \\
\text { As operações devem ser definidas com a utilização da } \\
\text { documentação da classe ou diagrama de atividades, } \\
\text { utilizando uma ASL. Outra opção é definir o método } \\
\text { como stub no ambiente de simulação }\end{array}$ \\
\hline
\end{tabular}

Tabela 3.3: Semânticas para o diagrama de classes

Definições semânticas para o diagrama de objetos são apresentados na tabela 3.4

\begin{tabular}{|l|l|}
\hline Semântica definida & Descrição \\
\hline Elemento "Instância" & $\begin{array}{l}\text { Só serão considerados os objetos que forem instâncias } \\
\text { de classes com semântica definida conforme a seção } \\
\text { anterior }\end{array}$ \\
\hline
\end{tabular}

Tabela 3.4: Semânticas para o diagrama de objetos

\subsubsection{Diagrama de sequência}

O diagrama de sequência é utilizado como representante dos diagramas de interação nesta proposta de xUML. Como o diagrama de comunicação pode ser gerado automaticamente a partir do diagrama de sequência e ambos contêm as mesmas informações, apenas um deles é necessário para representar o comportamento das classes. Desta forma, o diagrama de comunicação não é usado neste trabalho.

Espera-se que cada caso de uso definido no diagrama de mesmo nome tenha um diagrama de sequência relacionado. A existência das classes e entidades externas (atores) representadas nesse diagrama do modelo é fundamental para sua simulação. Sem isso, perde-se a referência de qual entidade externa inicia um processo de simulação baseado em operações ou eventos da máquina de estado.

Dos diagramas de sequência é possível derivar a troca de mensagens entre os objetos 


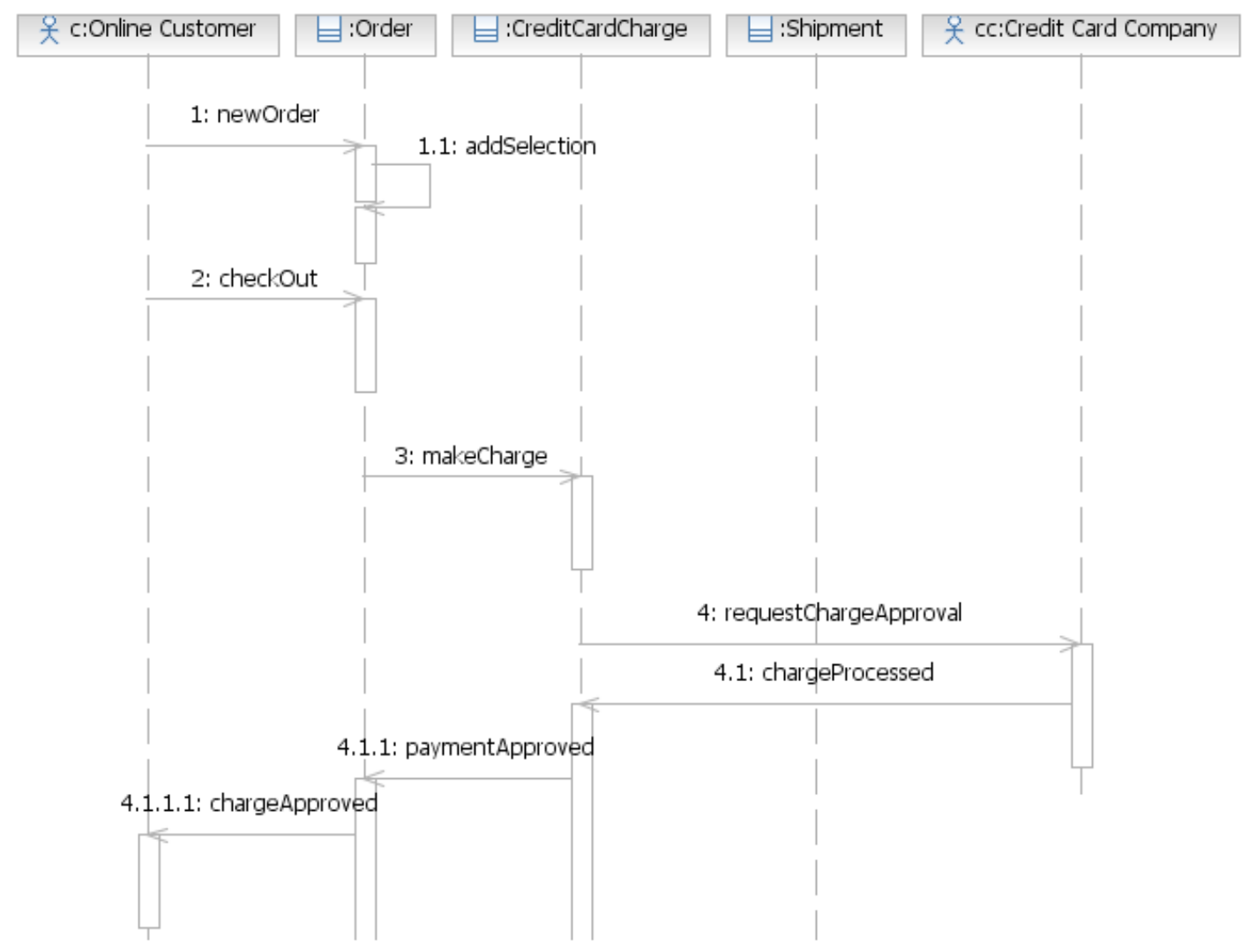

Figura 3.5: Diagrama de sequência semanticamente válido.

e entre atores e objetos. Dada sua natureza de ordenação das mensagens, pode-se utilizar essas informações para o fluxo da simulação de uma funcionalidade do sistema.

Na figura 3.5 é apresentado um diagrama de sequência semanticamente válido. Podese notar a troca de mensagens entre entidades externas e objetos que foram criados nos diagramas de casos de uso e de classes respectivamente. Neste diagrama as mensagens são baseadas em eventos e não em operações.

As trocas de mensagens devem sempre ser baseadas nas operações ou eventos existentes na máquina de estado de determinada classe.

Quando a troca de mensagem envolver uma entidade externa, o simulador usará tal informação para:

- gerar telas dinâmicas de entrada de dados, para que o usuário possa informar manualmente os parâmetros utilizados em uma operação ou evento se a troca de mensagem for a partir de uma entidade externa para um objeto;

- gerar telas de saída com respostas dadas pelo processo de simulação se a troca de mensagem for a partir de um objeto para uma entidade externa. 
No caso do diagrama de sequência, algumas definições semânticas devem ser respeitadas para sua utilização no simulador, como mensagens de retorno explícitas, quando existirem, e o uso de fragmentos para controle de decisão ou repetição.

Outro detalhe importante é que o fluxo de execução do modelo representado no diagrama de sequência pode ser sobreposto pelo fluxo apresentado em ações definidas com ASL nos métodos ou estados. Por isso, fica sob responsabilidade do autor manter a consistência de seus diagramas dentro do modelo, já que o simulador não pode identificar qual é o fluxo correto a ser seguido se existirem duas informações diferentes para um mesmo passo.

Definições semânticas para o diagrama de sequência são apresentadas na tabela 3.5

\begin{tabular}{|l|l|}
\hline Semântica definida & Descrição \\
\hline Mensagens & $\begin{array}{l}\text { Uma mensagem deve representar um método } \\
\text { existentes na classe do objeto ou um evento da } \\
\text { máquina de estado do mesmo }\end{array}$ \\
\hline Mensagens de retorno & $\begin{array}{l}\text { As mensagens de retorno devem ser explícitas } \\
\text { para completar a execução da operação ou evento }\end{array}$ \\
\hline Fragmentos & $\begin{array}{l}\text { Para representar estruturas de decisão ou repetição } \\
\text { é necessária a utilização dos fragmentos }\end{array}$ \\
\hline Classes & $\begin{array}{l}\text { Todas as classes devem existir no diagrama de } \\
\text { classes do modelo }\end{array}$ \\
\hline Atores & $\begin{array}{l}\text { Todos os atores devem existir no diagrama de } \\
\text { casos de uso do modelo }\end{array}$ \\
\hline
\end{tabular}

Tabela 3.5: Semânticas para o diagrama de sequência

\subsubsection{Diagrama de máquina de estados}

Após a definição do diagrama de classes, deve-se identificar quais objetos possuem ciclo de vida complexo o suficiente para justificar a sua modelagem. Isso deve ser feito utilizando máquinas de estado, como apresentado no capítulo anterior.

Desse diagrama são derivados os estados, eventos, transições e ações. Todos esses elementos são mapeados em estruturas dinâmicas utilizadas na simulação de um modelo.

Um exemplo de diagrama de máquina de estados com sintaxe válida está na figura 3.6. Neste caso não é apresentado fluxo de exceções, apenas os fluxos de processos esperados.

Os eventos devem ser definidos com os tipos de dados de negócio do modelo e que foram utilizados nos diagramas de classes. Durante a modelagem, os eventos são representados com elementos da UML conhecidos como "sinais". 


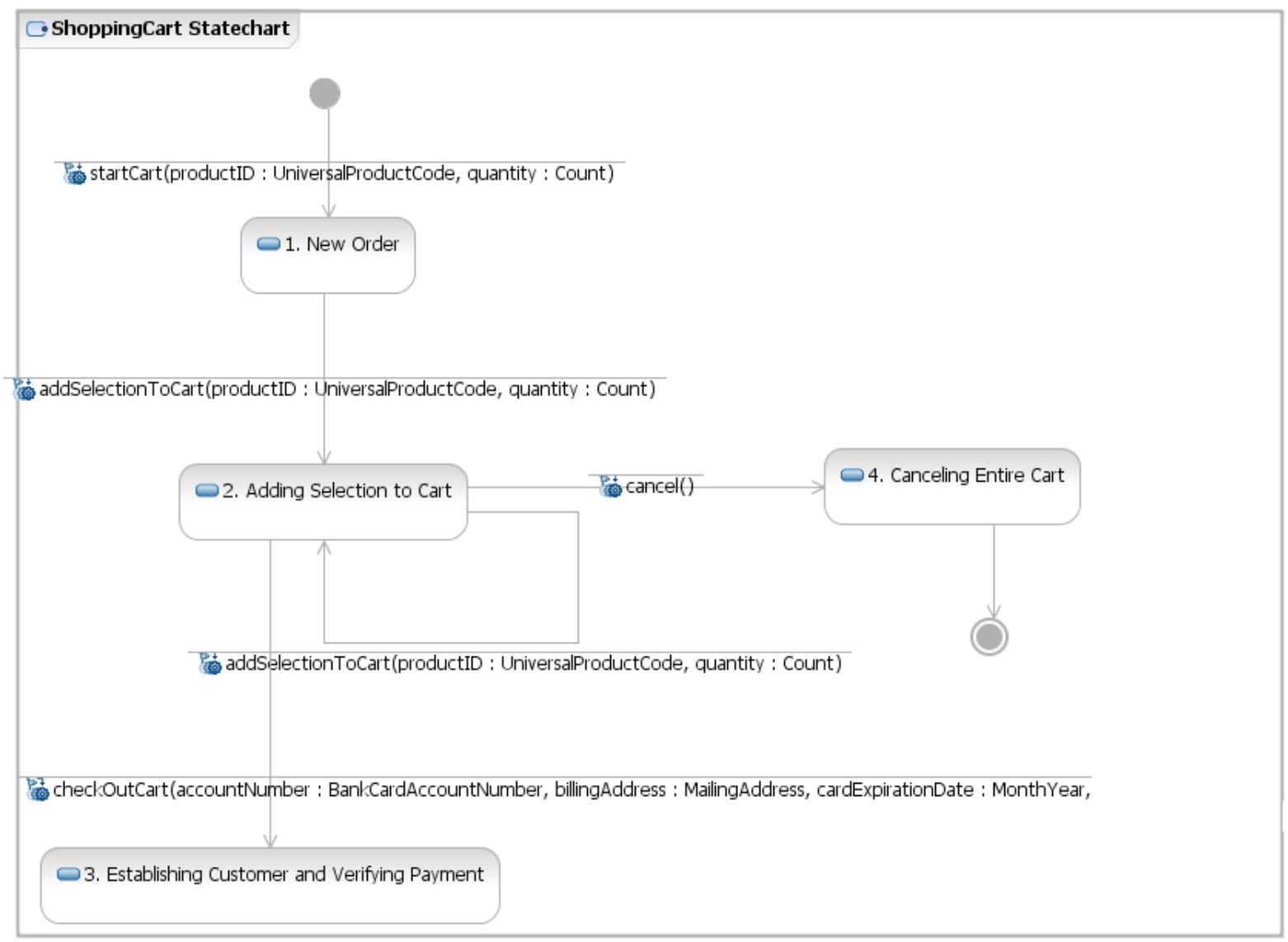

Figura 3.6: Diagrama de máquina de estados semanticamente válido. 
Os procedimentos de um estado são especificados com a utilização de uma ASL, assim como a definição dos métodos. Para permitir a interoperabilidade com a maioria das ferramentas de modelagem, essas ações devem ficar na documentação do estado, dado que boa parte das ferramentas CASE ainda não suportam as linguagens de ação. Exemplos de ações especificadas em uma ASL serão apresentados neste capítulo.

Definições semânticas para o diagrama de máquina de estados são apresentadas na tabela 3.6

\begin{tabular}{|l|l|}
\hline Semântica definida & Descrição \\
\hline Máquina de estado & $\begin{array}{l}\text { Uma classe deverá ter apenas uma máquina de estado } \\
\text { A máquina de estado deve obrigatoriamente ter } \\
\text { o estado inicial }\end{array}$ \\
\hline Evento & $\begin{array}{l}\text { Todo evento deve ser modelado como um "sinal" da UML } \\
\text { Os eventos devem definir explicitamente os parâmetros } \\
\text { e estes devem usar os tipos de dados de negócio definidos } \\
\text { no modelo }\end{array}$ \\
\hline Procedimentos & $\begin{array}{l}\text { Devem ser declarados utilizando o subconjunto de ações } \\
\text { básicas de uma ASL }\end{array}$ \\
\hline
\end{tabular}

Tabela 3.6: Semânticas para o diagrama de máquina de estados

\subsubsection{Diagrama de atividades}

Os diagramas de atividades podem ser utilizados nesta abordagem como uma representação gráfica das ações dos métodos ou eventos das máquinas de estados. Apesar disso, o subconjunto de ações da ASL ainda deve ser usado, pois o simulador não conseguiria identificar instruções definidas de maneira informal neste diagrama.

Os nós inicial, final, de ação e decisão são utilizados para representar uma operação ou procedimento de um estado. Os nós de ação devem contêr instruções ASL. Estes nós representam toda a notação necessária para a simulação do modelo em nível de negócio.

Um exemplo de diagrama de atividade interpretado pelo simulador está na figura 3.7

Definições semânticas para o diagrama de atividade são apresentadas na tabela 3.7

\subsubsection{Linguagem de Ação}

A especificação de ações que podem ser utilizadas nos métodos ou procedimentos de um estado utilizam a semântica definida em uma linguagem de ação. 


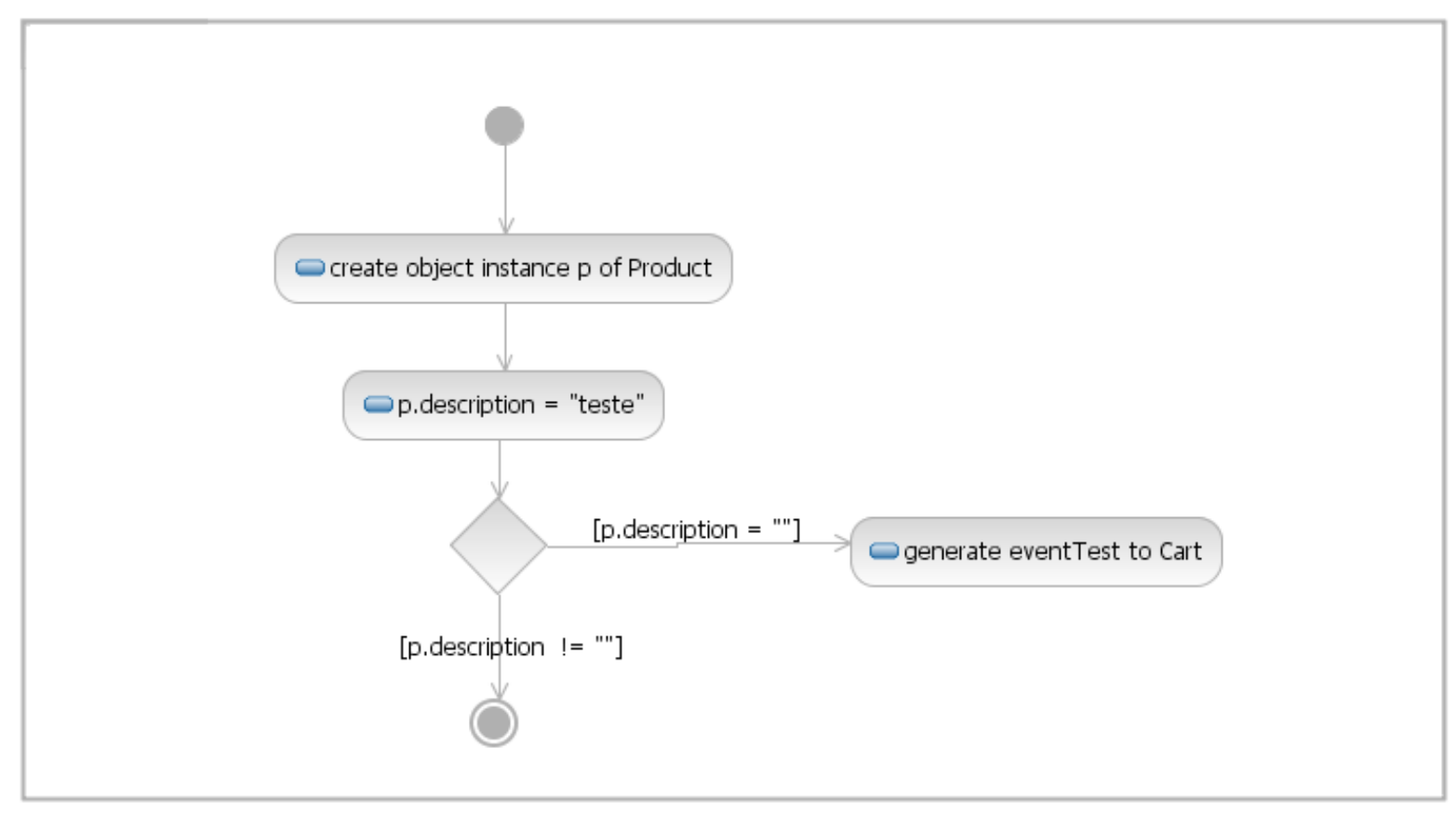

Figura 3.7: Diagrama de atividade que pode ser interpretado pelo simulador.

\begin{tabular}{|l|l|}
\hline Semântica definida & Descrição \\
\hline Linguagem das instruções & $\begin{array}{l}\text { Apenas o subconjunto de ações definidas na ASL } \\
\text { do simulador pode ser utilizado }\end{array}$ \\
\hline Parâmetros & $\begin{array}{l}\text { Os parâmetros de entrada devem ser } \\
\text { representados no diagrama com os mesmos nomes } \\
\text { que foram determinados nos métodos ou eventos }\end{array}$ \\
\hline Nó inicial e final & Devem ser criados obrigatoriamente \\
\hline Outros nós & $\begin{array}{l}\text { Apenas os nós de ação e de decisão serão } \\
\text { interpretados pelo simulador }\end{array}$ \\
\hline
\end{tabular}

Tabela 3.7: Semânticas para o diagrama de atividade

Na sua versão atual o ModSim suporta apenas um subconjunto de instruções de uma ASL, suficiente para a simulação de um modelo em nível de negócio. A sintaxe básica da ASL utilizada neste trabalho, a OAL foi apresentada no capítulo 2. Alguns exemplos do estudo de caso deste trabalho são descritos nos algoritmos 8 e 9 .

Apesar do simulador gerado neste trabalho utilizar a OAL, a alteração da sintaxe da linguagem de ação é muito simples e permite a aplicação seja estendida para novas linguagens, conforme necessário.

\subsection{Simulador de modelos UML em nível de negócio}

O ModSim foi desenvolvido utilizando a plataforma Java e tem três módulos básicos: 

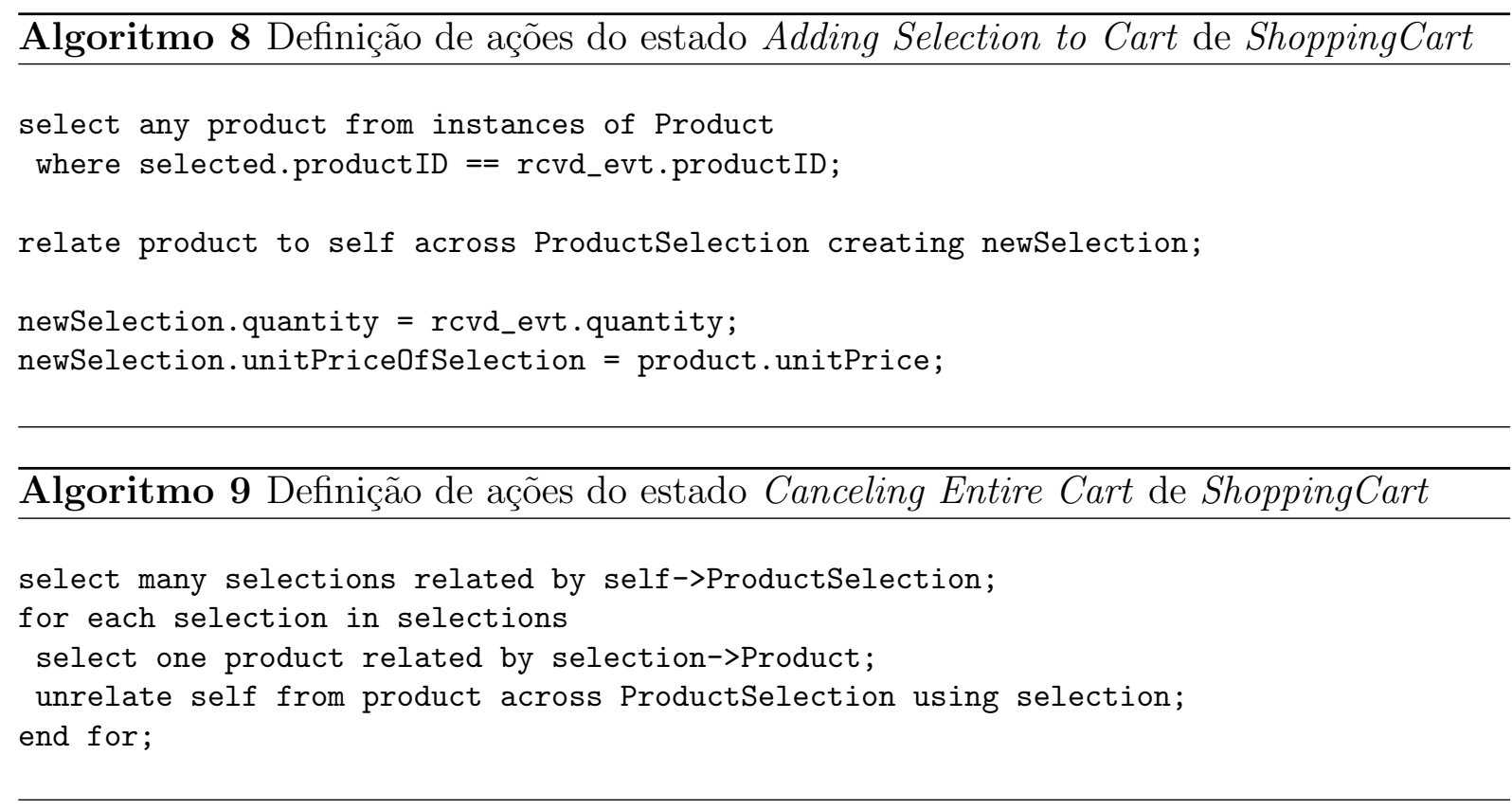

- leitura e compilação do arquivo XMI e mapeamento de elementos UML;

- definição de dados complementares ao documento XMI;

- simulação do modelo na máquina virtual.

\subsubsection{Compilação do modelo descrito em XMI}

Para começar a utilizar o ModSim, deve-se primeiramente gerar um modelo em XMI com o auxílio de uma ferramenta CASE. Isso feito, pode-se iniciar o ambiente de simulação e importar o arquivo que será processado por um parser separando todos os elementos relevantes para simulação em estruturas dinâmicas de classes.

A figura 3.8 apresenta a entrada de informações para a importação do modelo em XMI no ModSim. A tela inicial do simulador permite que o usuário selecione o arquivo desejado e mostra o código que será processado pelo parser que foi desenvolvido, antes do processamento.

Após o processamento do arquivo, diversas estruturas de dados dinâmicas são criadas para suportar a máquina virtual. Os algoritmos 10 e 16 mostram exemplos destas estruturas.

As ações definidas com a OAL também são processadas para gerar o comportamento esperado na máquina virtual. Um trecho do código que faz este processamento é apresentado no algoritmo 12 


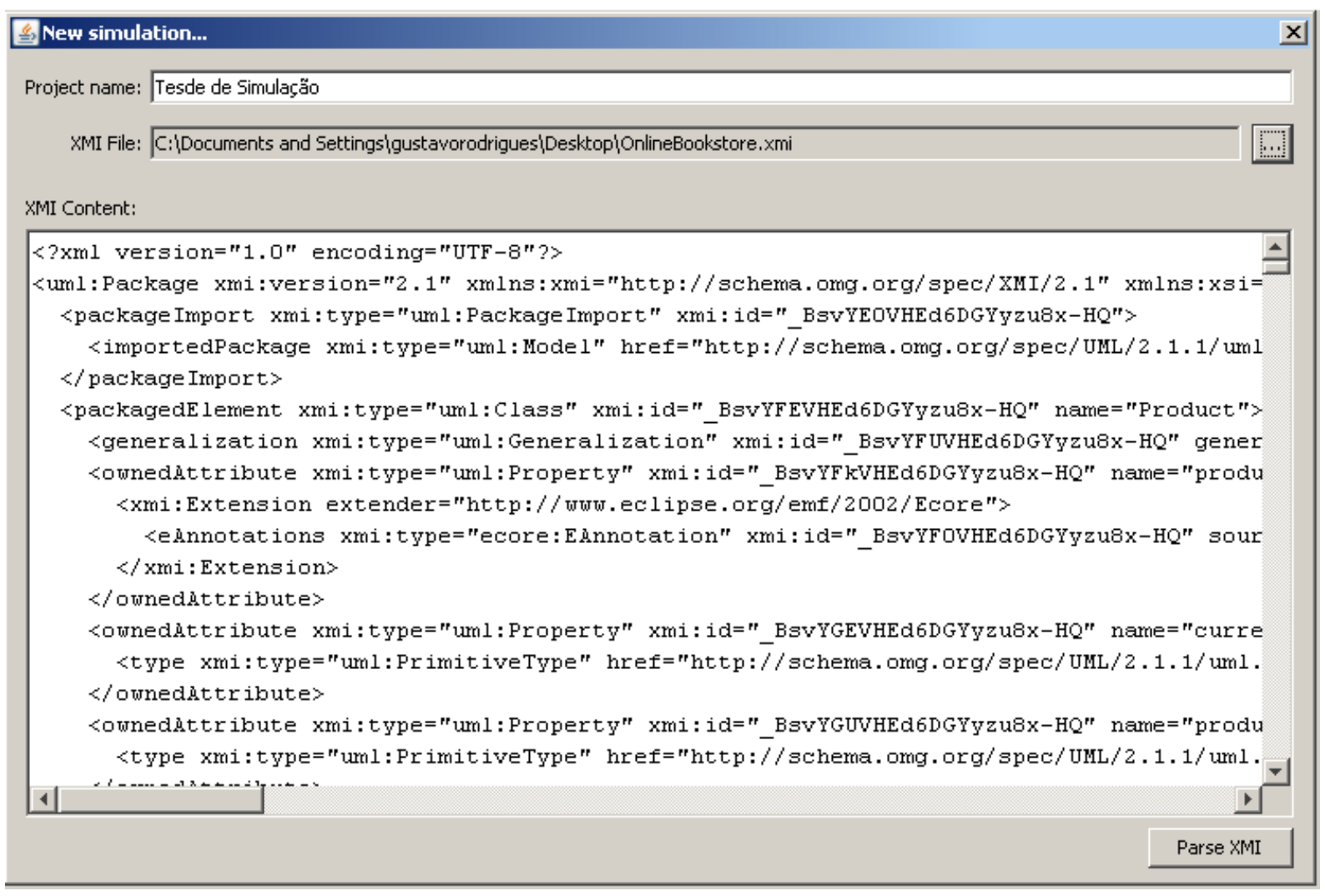

Figura 3.8: Importação do modelo em XMI no ModSim.

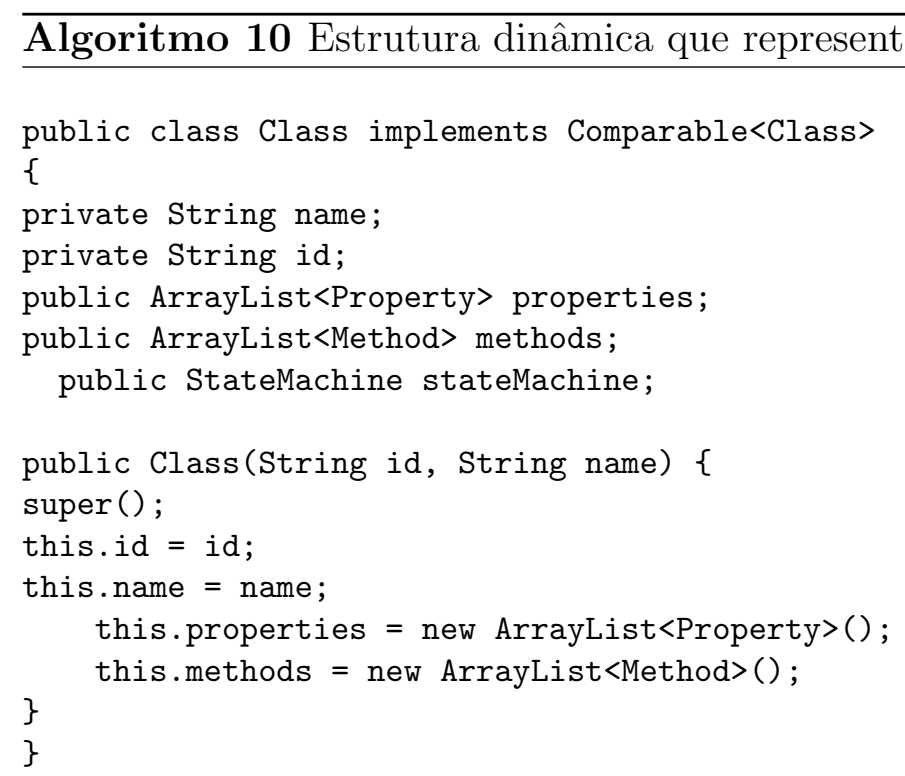



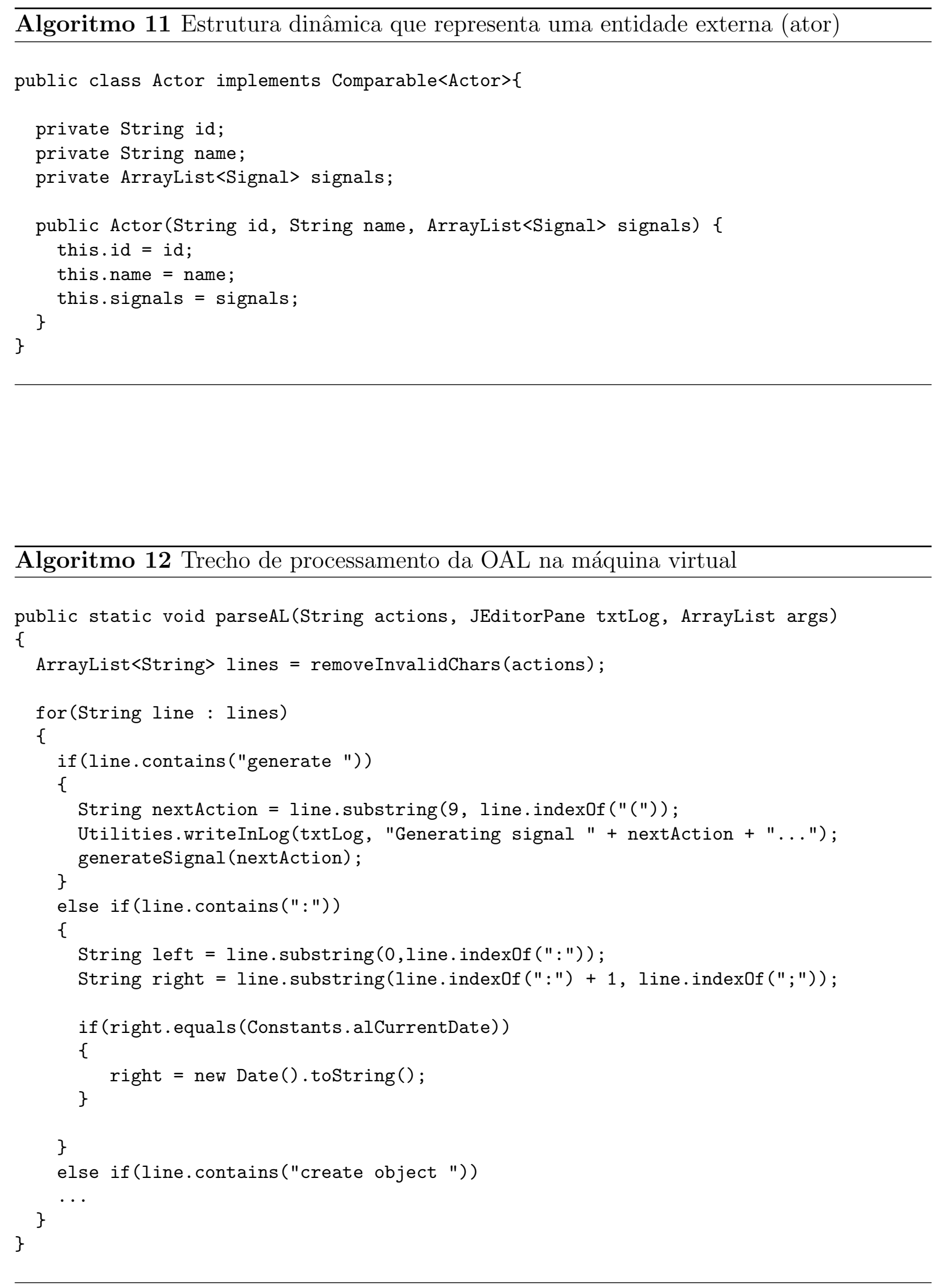
A compilação do XMI neste trabalho não utiliza os tradicionais critérios de précondições e pós-condições tradicionais dos compiladores. Basicamente é feito um mapeamento das entradas do documento para estruturas de dados como apresentado anteriormente. Não é feita a validação sintática dos elementos da UML. Tem-se como premissa desse trabalho que os modelos que serão simulados estejam sintaticamente corretos, apesar de citar como um possível trabalho futuro a adequação de um módulo de validação sintática no ModSim.

\subsubsection{Dados complementares ao modelo UML}

O documento XMI, utilizado como entrada para o ambiente de simulação, tem toda a informação sobre os diagramas e elementos representados no modelo UML. Porém, existem algumas definições que devem ser feitas pelo usuário antes de começar a simular um modelo.

Essas definições se dividem em três categorias:

1. tipo de dado computacional que representa cada tipo de dado de negócio do modelo;

2. exemplos de objetos que são carregados junto com a máquina virtual;

3. dados que podem ser retornados por métodos stub se estes forem utilizados.

Os tipos de dados em nível de negócio criados pelo autor do modelo devem ser mapeados para tipos computacionais para a correta simulação desse tipo de dado. Neste trabalho são permitidos os seguintes tipos computacionais:

- Numérico: neste caso, pode-se definir o intervalo aceitável e o número de casas decimais permitido;

- Texto: pode-se definir o número de caracteres permitido e a máscara do texto;

- Lógico: dados como yes/no, sim/não, on/off, 0/1. Nenhuma definição adicional é permitida;

- Date: define-se o formato da data por meio de máscaras.

Durante a simulação do modelo, se os parâmetros de entrada das operações ou sinais não forem respeitados, uma exceção da máquina virtual será gerada para o usuário.

Observe na figura 3.9 a tela de mapeamento dos tipos de dados e abaixo sua descrição: 


\section{Setup the project data}

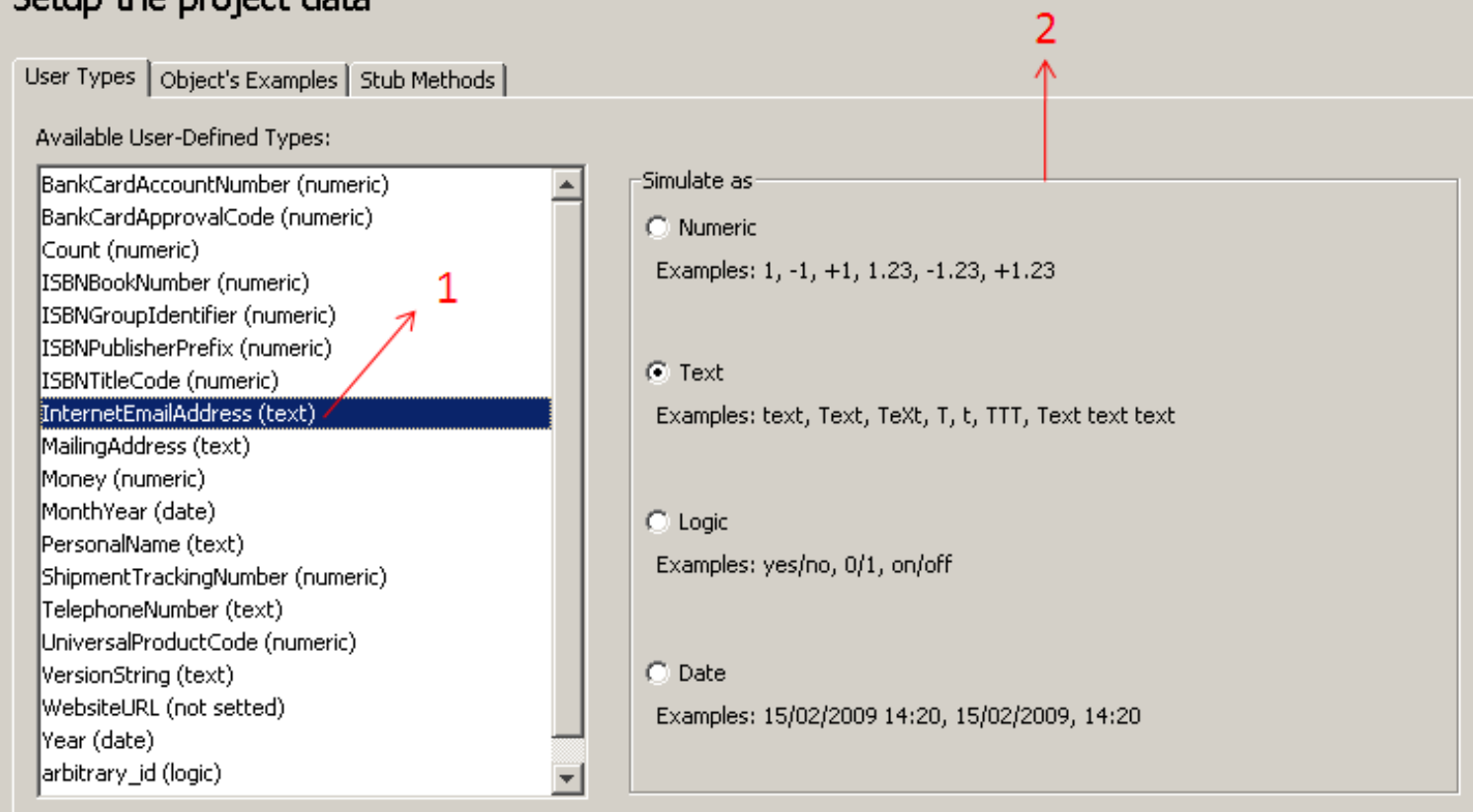

Figura 3.9: Tela de mapeamento de tipos de dados.

1. lista com todos os tipos de dados em nível de negócio definidos pelo usuário;

2. tipos computacionais disponíveis para a simulação.

Pode-se observar selecionado um tipo de dado de negócio chamado "InternetEmailAddress" 3 que está mapeado para o tipo "Text". Após escolher o tipo de dado da simulação, pode-se definir as características adicionais deste, conforme citado anteriormente.

Com o mapeamento de tipos de dados feito, o usuário deve então criar exemplos de objetos que serão carregados na memória da máquina virtual, assim que ela for carregada. O objetivo desse passo é permitir que o usuário não tenha que simular todo o sistema se desejar apenas verificar uma parte dele. Na simulação de uma livraria virtual, por exemplo, pode-se desejar que os objetos que representam livros já estejam criados e apenas simular a adição desses livros no carrinho de compras.

Os exemplos podem ser criados manualmente ou com dados aleatórios, se o usuário desejar.

A figura 3.10 apresenta a tela para criação dos objetos de exemplo.

\footnotetext{
${ }^{3}$ Endereço de e-mail
} 


\section{Setup the project data}

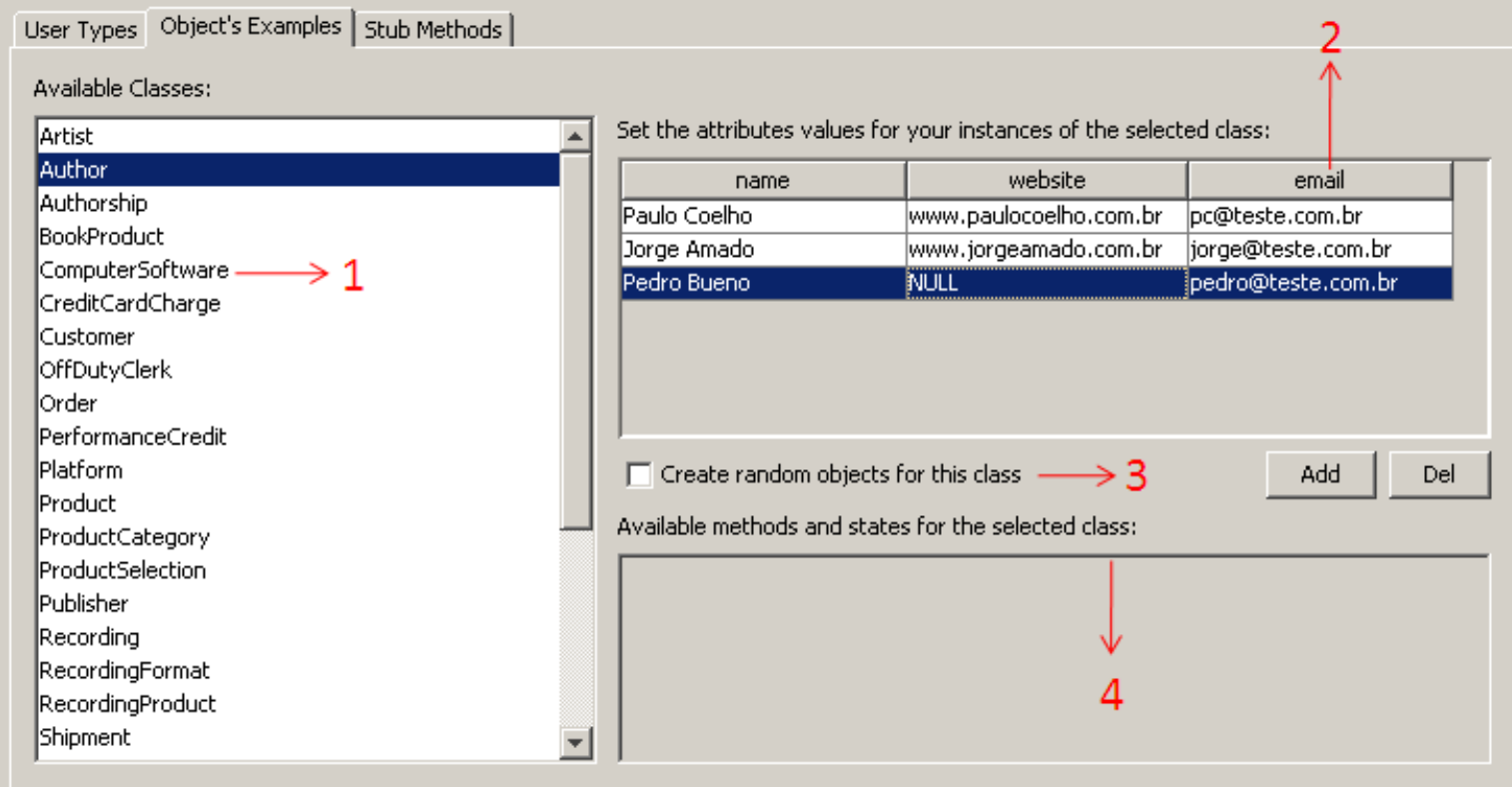

Figura 3.10: Tela para a criação de objetos de exemplo.

Nessa tela é possível observar:

1. as classes disponíveis no modelo de entrada;

2. os exemplos de instâncias criadas para a classe selecionada;

3. opção para criar objetos aleatórios de exemplo, caso não existam exemplos criados manualmente;

4. painel que apresenta métodos e estados disponíveis para a classe selecionada.

Se existir um diagrama de objetos no modelo, os exemplos das classes representadas nesse diagrama já estarão carregados na lista de exemplos, o que não impede a criação de novos objetos manualmente.

Por fim, o usuário definirá os métodos stub que não têm ação definida no modelo por meio dos diagramas de atividades ou especificação ASL. Para cada método selecionado, o usuário deve informar o conjunto de valores que deve ser retornado, no caso de uma chamada ao método. Em tempo de execução, esses valores serão utilizados de maneira aleatória pela máquina virtual. 


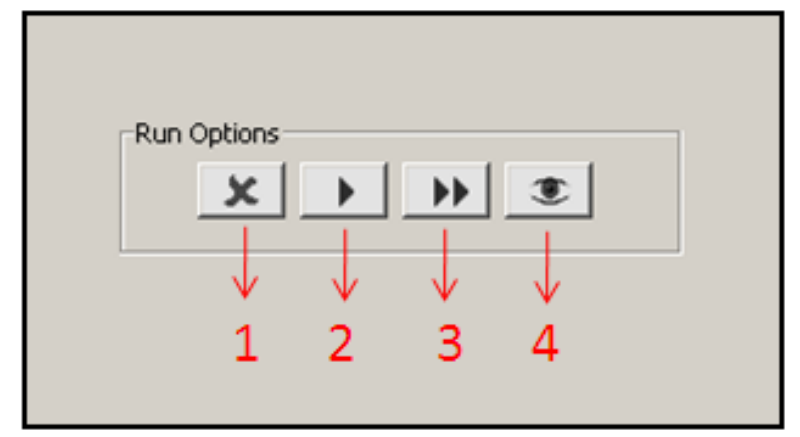

Figura 3.11: Controle de execução do simulador.

O método "defineTaxes" pode ter um conjunto de valores numéricos que será utilizado quando o mesmo for chamado. A configuração desses métodos stub deve ser feita com critério para a simulação ser mais próxima do comportamento real do sistema.

\subsubsection{Mecanismo de Interrupção}

Durante o processo de simulação de um modelo o fluxo de acontecimentos pode ser complexo. Estímulos iniciais realizados pelo usuário da aplicação, troca de mensagens (sinais e eventos) entre objetos para alteração de seus estados, manipulação de atributos e, de acordo com o que foi modelado, até eventos ou respostas podem ser enviadas para as entidades externas.

Para maior contole e melhor visualização desse fluxo, inclui-se no simulador um mecanismo de interrupção que permite que cada passo da execução seja controlado pelo usuário. Assim, em conjunto com a funcionalidade do Object Viewer ${ }^{4}$, pode-se acompanhar as mudanças de estado dos objetos que estão na memória virtual.

Se o usuário não quiser ou não precisar visualizar esse processo a cada passo, ele pode indicar ao simulador para que sejam executados todos os passos até a próxima interação com entidades externas (representadas pelo usuário), na qual a interrupção é inevitável.

O controle de execução do simulador é apresentado na figura 3.11. Abaixo, descreve-se a ação que cada um dos botões representa:

1. encerrar uma simulação;

2. executar apenas próximo passo da simulação;

3. executar todos os passos até a próxima interação com entidades externas, se houver;

\footnotetext{
${ }^{4}$ Visualizador de objetos que será apresentado durante o capítulo
} 


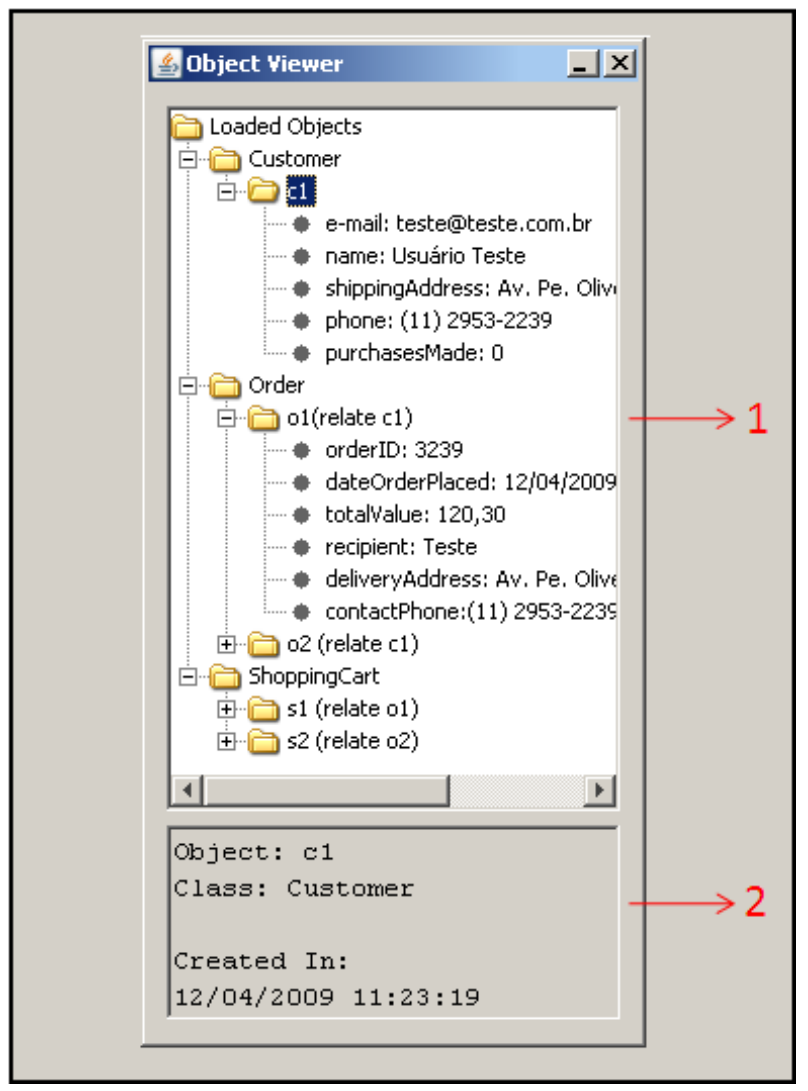

Figura 3.12: Object Viewer durante uma simulação.

4. abrir o Object Viewer.

\subsubsection{Object Viewer}

Para complementar e justificar a utilização de um mecanismo de interrupção, como o apresentado na seção anterior, foi criada uma interface que permite a visualização da memória virtual do simulador.

Todas as instâncias das classes existentes em um determinado momento ficam disponíveis para inspeção. Apresentam-se nessa interface os valores para os atributos dos objetos e a data de criação de cada um para maior controle do usuário. Após um objeto sair da memória virtual, ele não estará mais disponível no visualizador. Assim, o único registro da existência desse objeto será o log da simulação.

A figura 3.12 mostra a interface do Object Viewer durante uma simulação. Nela pode-se notar:

1. objetos carregados na memória virtual do simulador. Esses objetos são categorizados pelas suas classes de origem e apresentam seus atributos; 


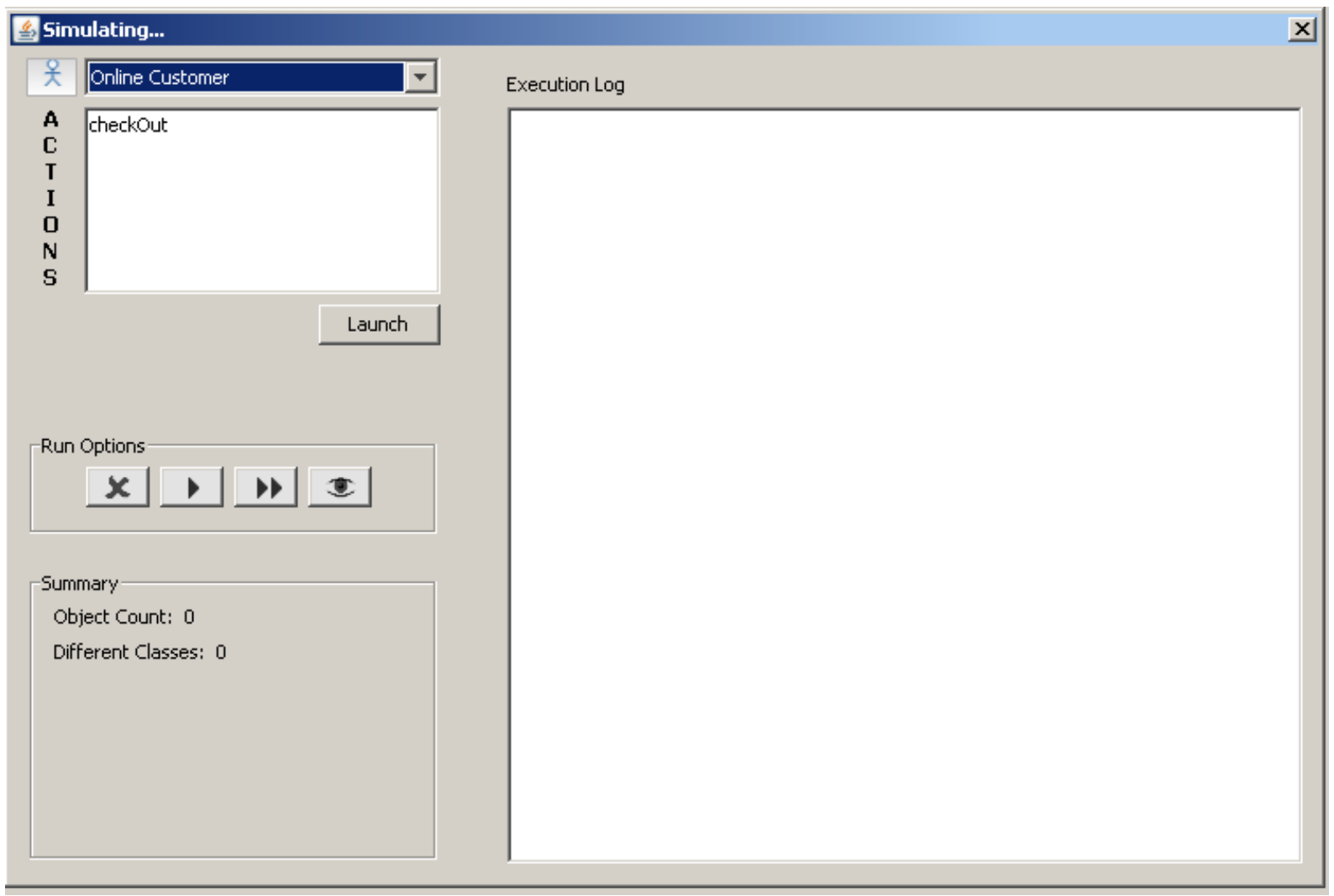

Figura 3.13: Ambiente de simulação.

2. resumo sobre o objeto selecionado, nome, classe e data de criação do objeto na memória.

\subsubsection{Ambiente de Simulação}

Com as informações do documento XMI e os dados adicionais fornecidos pelo usuário da aplicação, pode-se começar o processo de simulação.

A figura 3.13 mostra a tela principal do ambiente de simulação do ModSim.

O ambiente de simulação é composto por:

- entidades externas importadas dos diagramas de casos de uso;

- ações (eventos ou operações) disponíveis para o ator iniciar a simulação;

- $\log$ de execução onde o fluxo da simulação é efetivamente apresentado;

- resumo de informações da memória virtual; 


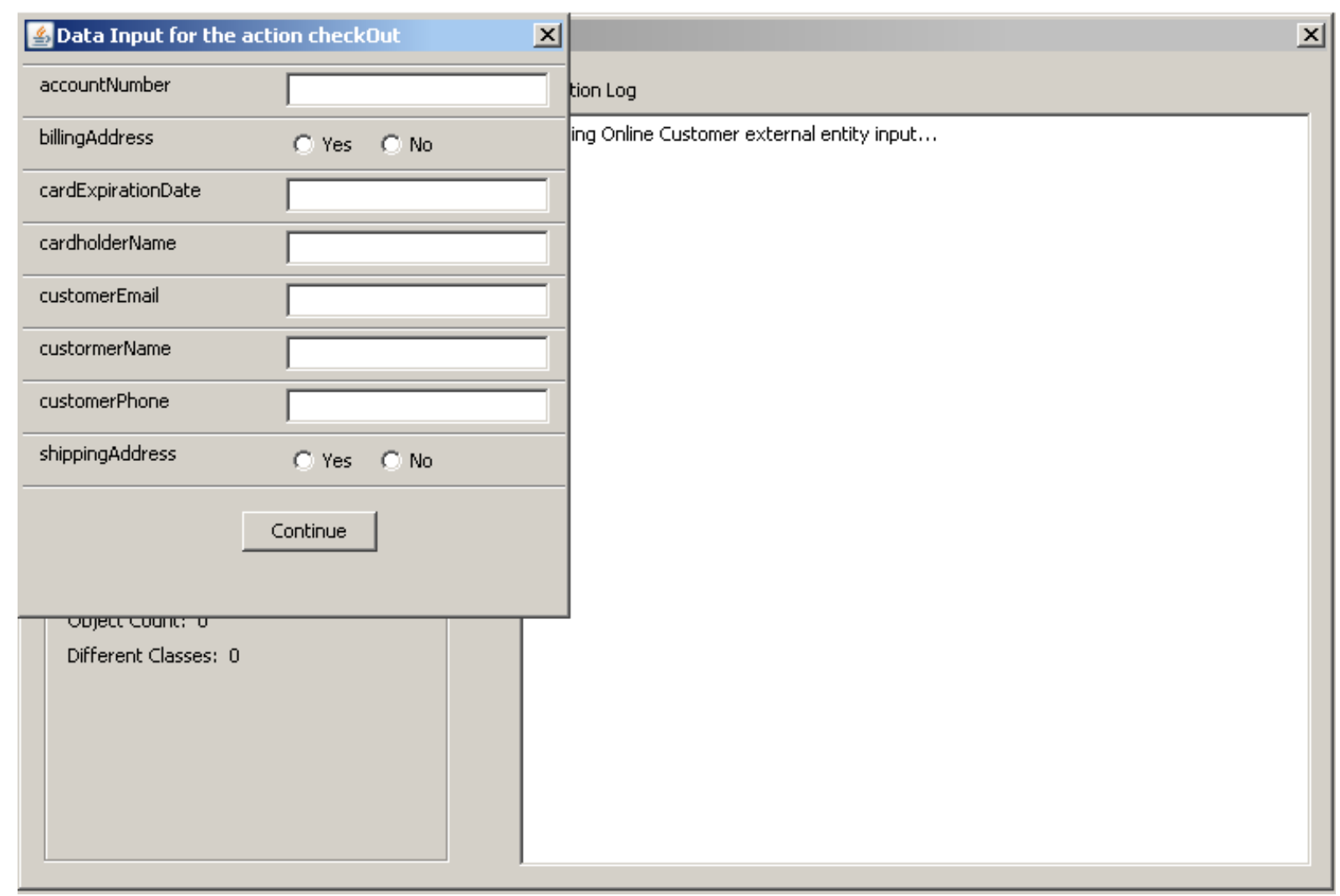

Figura 3.14: Tela de entrada de dados gerada dinamicamente.

As ações disponíveis para simulação são derivadas dos diagramas de sequência, nas trocas de mensagens entre uma entidade externa e um objeto.

Ao iniciar a simulação, baseado nos parâmetros do evento ou operação, telas dinâmicas são geradas para interação com o usuário. Um exemplo destas telas é apresentado na figura 3.14

Neste exemplo são solicitados valores de entrada para os parâmetros de um evento chamado checkOut. Observa-se que alguns parâmetros não utilizam campos texto. Esses parâmetros tiveram seus tipos de dados de negócio mapeados para o tipo computacional lógico. Assim, a máquina virtual facilita a entrada dos dados por parte do usuário.

Os outros campos, são validados de acordo com o mapeamento de dados feito na preparação para a simulação. Deve-se respeitar os tipos de dados, intervalos numéricos, máscaras etc.

Após o preenchimento dos campos desejados, o usuário deve continuar e o fluxo seguirá até o próximo passo da simulação. Se houver necessidade de nova interação com entidades externas, novas janela como a do exemplo, possivelmente com outros parâmetros, serão abertas para interação com o usuário. 


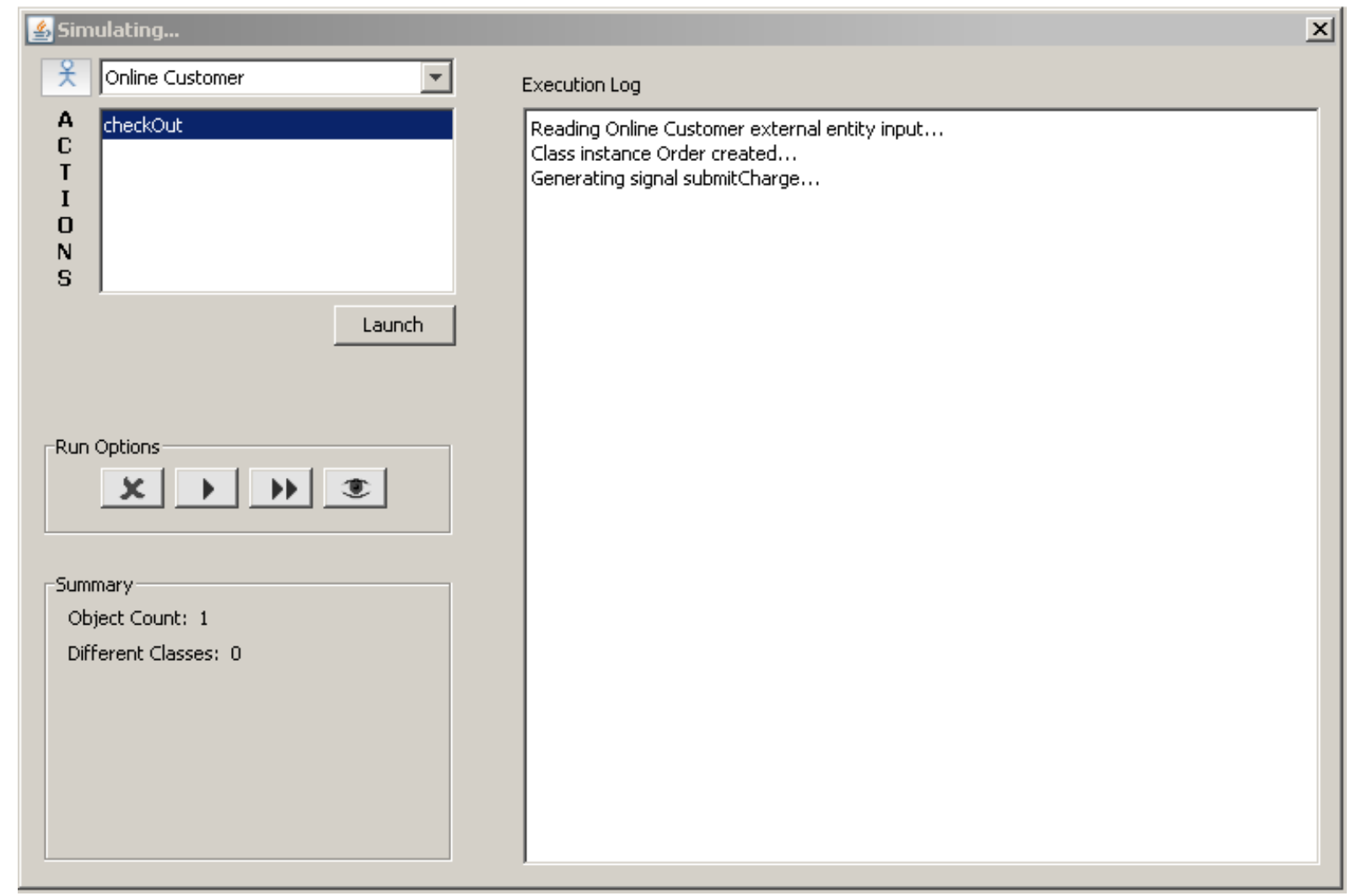

Figura 3.15: Log da simulação.

A imagem 3.15 mostra a tela exibida após a confirmação dos parâmetros de entrada, de acordo com o fluxo modelado. Note que o log de execução mostra todo o processo da simulação, permitindo que o engenheiro identifique eventuais erros de modelagem, incoerência semântica ou até a falta de alguma informação que deveria estar representada no modelo. 


\section{Resultados Obtidos em Simulações}

Neste capítulo são apresentados alguns casos de simulação de modelos para verificar o comportamento da aplicação.

A análise do comportamento do protótipo ModSim foi validado utilizando um estudo de caso baseado em Mellor e Balcer (2002). Este caso é sobre uma livraria virtual e envolve os diversos diagramas da UML. Trechos deste estudo de caso são apresentados a seguir.

Deve-se deixar claro que apenas esse caso foi utilizado para a construção da prova de conceito, porém, outros casos devem ser trabalhados no futuro para garantir que a aplicação funciona com diferentes cenários, o que hoje é apenas uma indicação. Uma possibilidade interessante seria a utilização do protótipo por uma ou mais empresas de desenvolvimento de software para validação da aplicação e sugestão de possíveis melhorias até a criação de um ferramenta completa de simulação.

\subsection{Artefatos de entrada}

Utiliza-se nesta simulação os diagrama de classes como o apresentado na figura 4.1, de sequência, apresentado na figura 4.2 e na máquina de estado da ShoppingCart representado nas figura 4.3 .

As especificações de procedimentos definidos com a OAL nos estados apresentados nos diagramas de máquina de estados também são descritos.

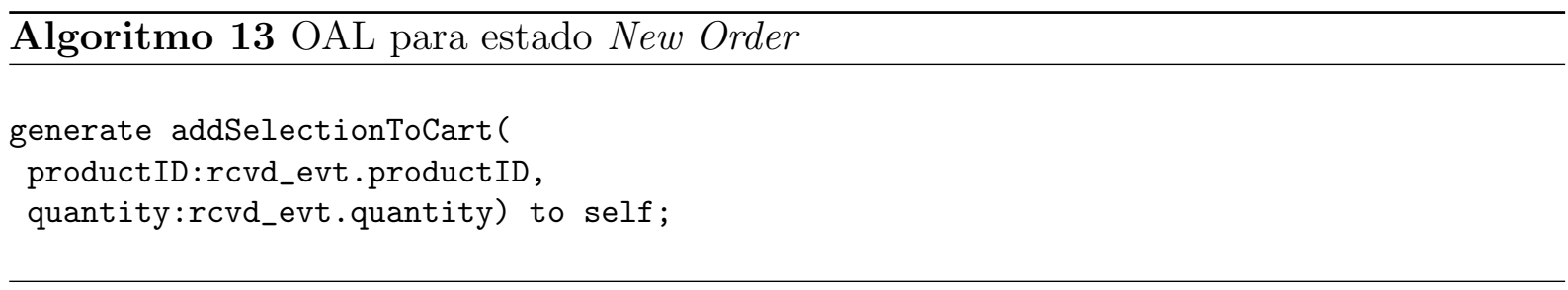




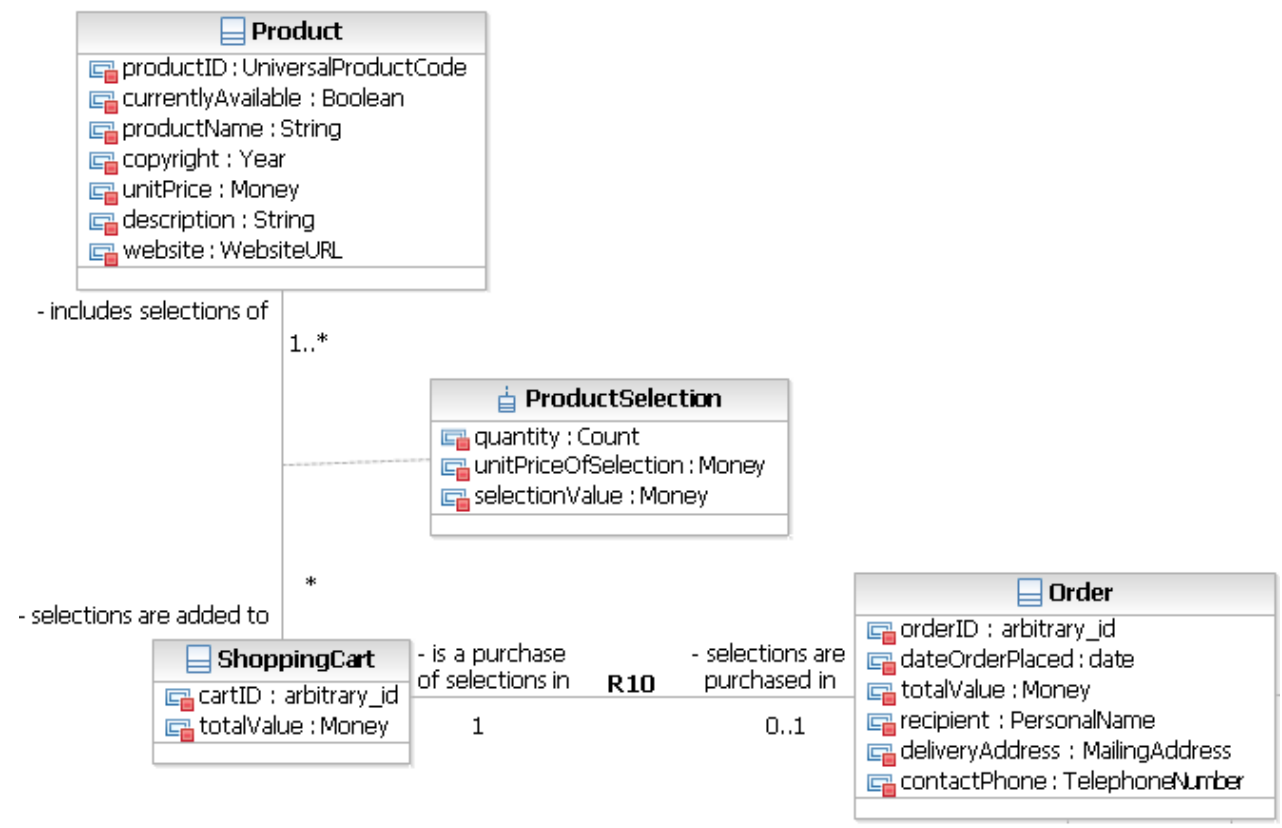

Figura 4.1: Diagrama de classes usado no experimento.

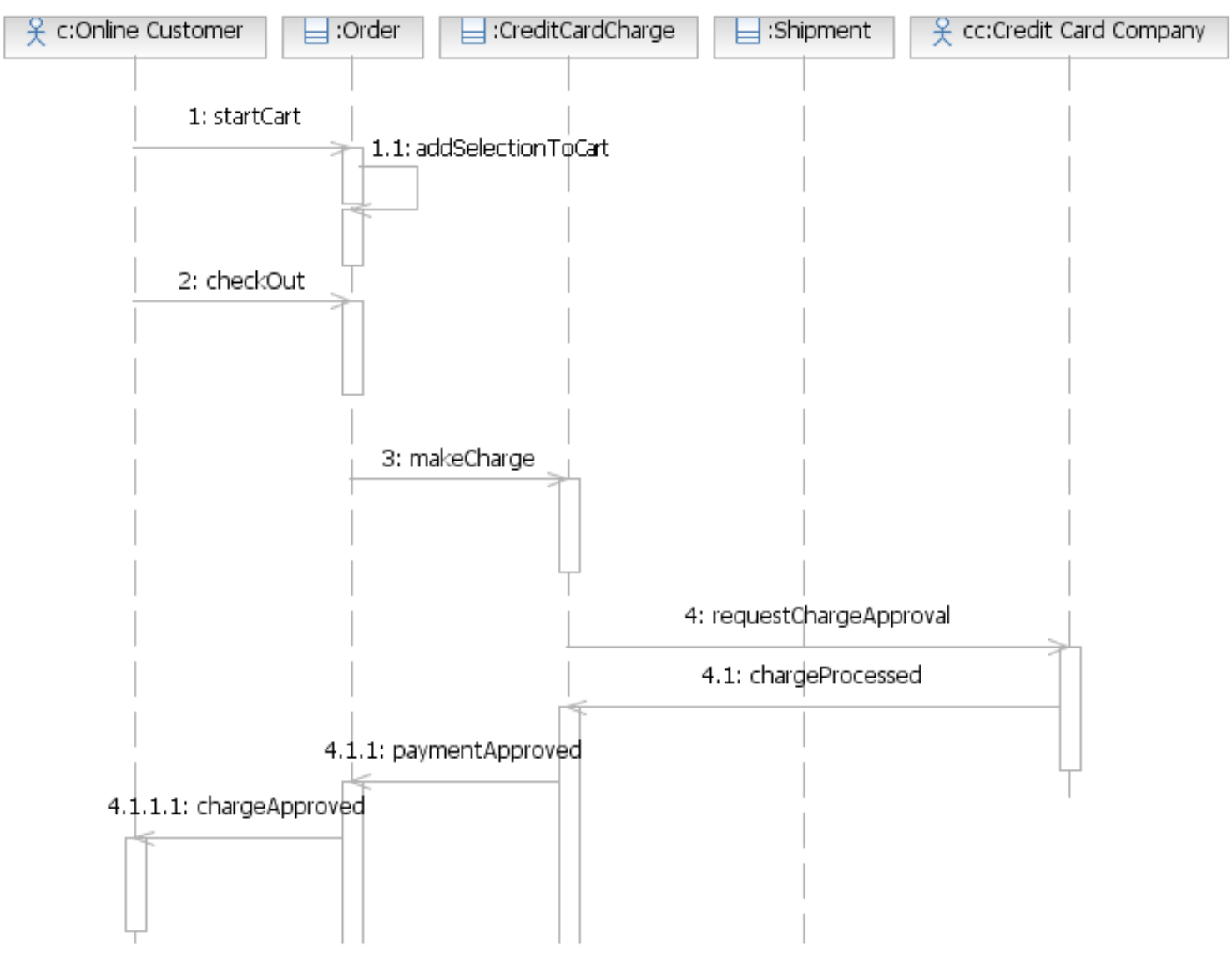

Figura 4.2: Diagrama de sequência usado no experimento. 


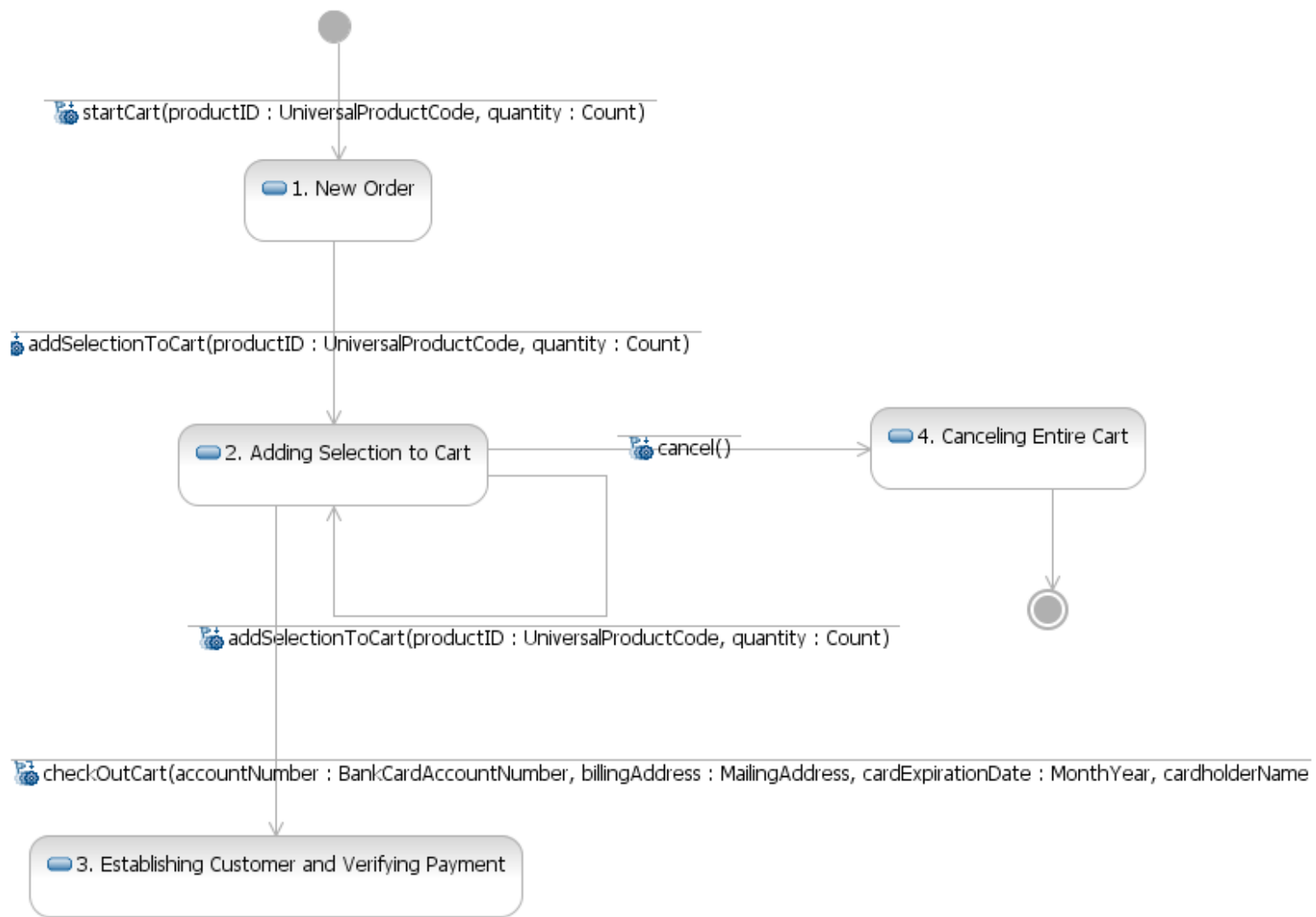

Figura 4.3: Diagrama de máquina de estado da clase ShoppingCart usado no experimento.
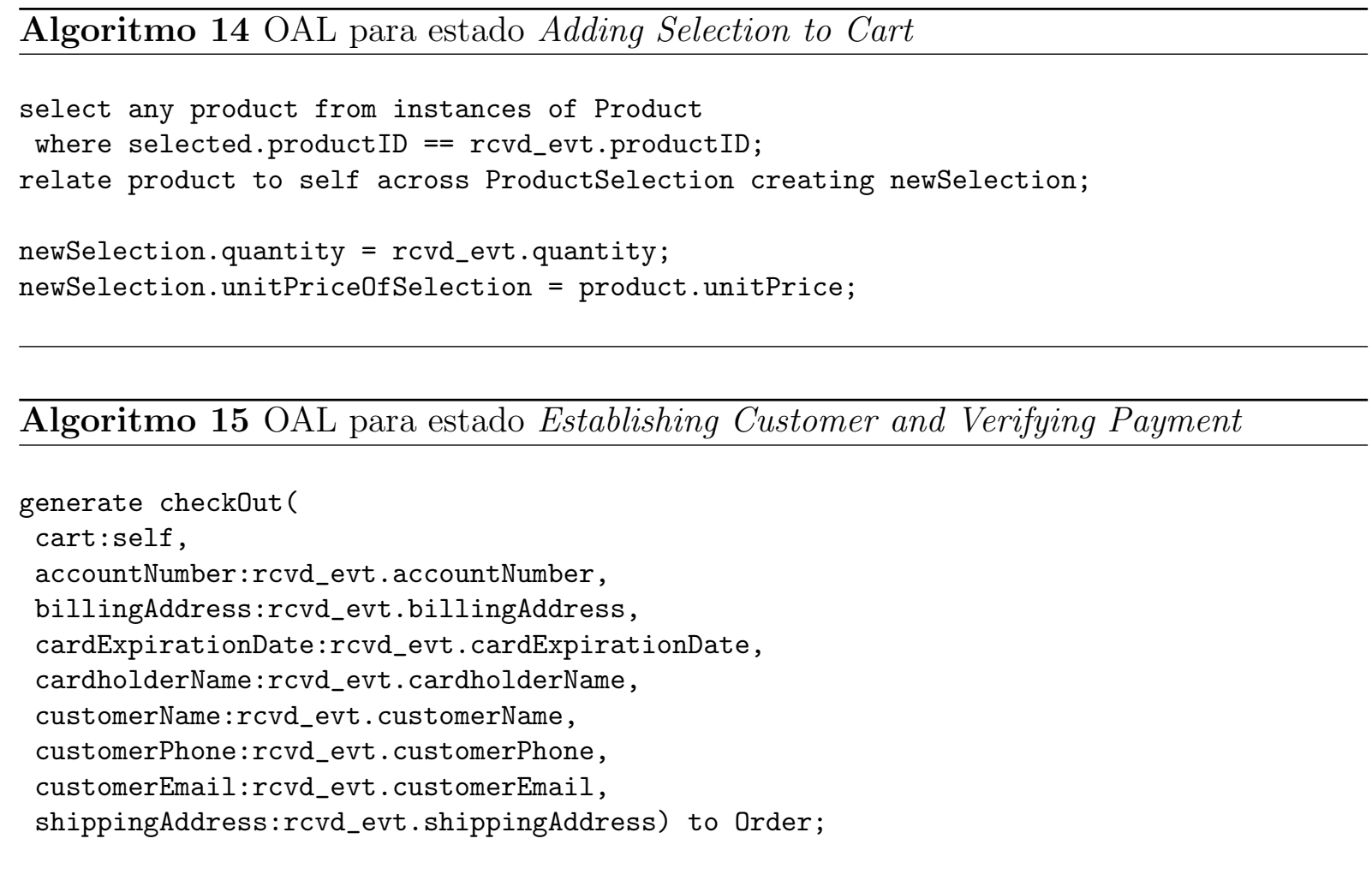


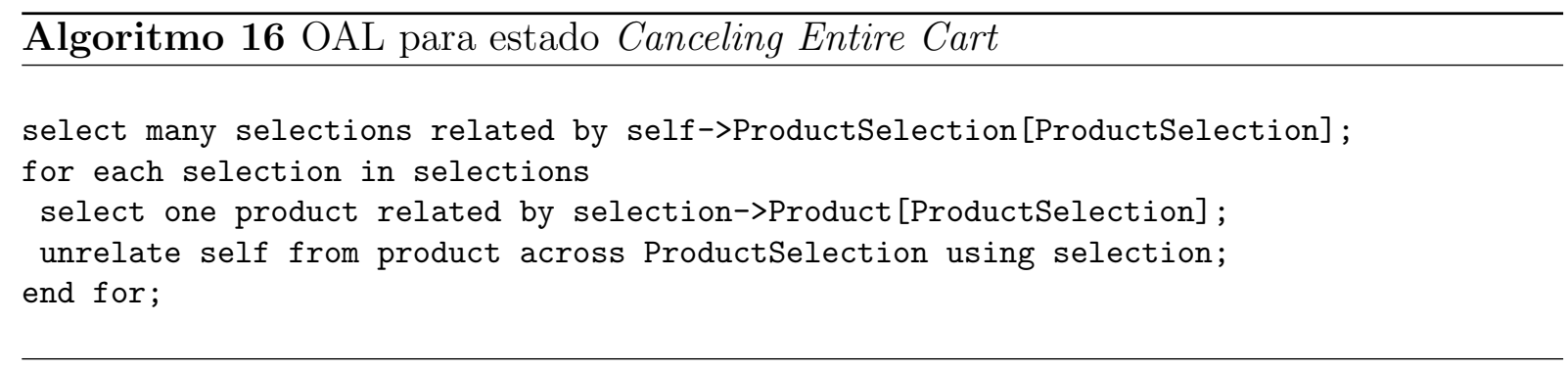

\subsection{Simulação do evento startCart}

Os resultados das simulações são apresentados em português nesta seção, dado que a aplicação ModSim foi desenvolvida apenas no idioma inglês.

A entidade externa representada pelo ator OnlineCustomer dispara o evento startCart a partir do simulador. Quando solicitado, o usuário entra com um parâmetro existente para código de produto, de acordo com os exemplos de objetos previamente criados no ambiente de simulação. Depois, o usuário dispara o evento addSelection ToCart com um código de produto válido.

\section{Log da simulação}

1. Evento startCart é disparado;

2. Objeto Shopping Cart criado;

3. Solicitando dados de entrada (productID, quantity);

4. Evento addSelection ToCart é disparado;

5. Procurando objeto da classe Product na coleção;

6. Objeto ProductSelection criado;

7. Aguardando estímulo externo.

8. Evento addSelection To Cart é disparado;

9. Procurando objeto da classe Product na coleção;

10. Objeto ProductSelection criado;

11. Aguardando estímulo externo.

No caso do usuário utilizar um código de produto inexistente:

\section{Log da simulação}


1. Evento startCart é disparado;

2. Objeto ShoppingCart criado;

3. Solicitando dados de entrada (productID, quantity);

4. Evento addSelection To Cart é disparado;

5. Procurando objeto da classe Product na coleção;

Percebe-se neste caso que o simulador não indicou o que aconteceu e simplesmente parou sua execução pois não sabe o que deve ser feito a seguir. Nem o diagrama de sequência, nem as especificações de ações indicam o que deve ser feito, apontando um possível problema de modelagem.

\subsection{Simulação do evento checkOut}

Baseado na simulação anterior, o usuário pode depois de adicionar produtos ao carrinho de compras, finalizar o pedido para pagamento.

\section{Log da simulação}

1. Evento startCart é disparado;

2. Objeto ShoppingCart criado;

3. Solicitando dados de entrada (productID, quantity);

4. Evento addSelection ToCart é disparado;

5. Procurando objeto da classe Product na coleção;

6. Objeto ProductSelection criado;

7. Aguardando estímulo externo.

8. Evento addSelection ToCart é disparado;

9. Procurando objeto da classe Product na coleção;

10. Objeto ProductSelection criado;

11. Aguardando estímulo externo; 
12. Evento checkOutCart é disparado;

13. Solicitando dados de entrada (accountNumber, billingAddress, cardExpirationDate...);

14. Evento checkOut é disparado;

15. Objeto Order é criado;

16. Procurando objeto da classe Customer na coleção;

17. Objeto Customer criado;

18. Evento submitCharge é disparado;

19. Evento makeCharge é disparado;

20. Objeto CreditCardCharge é criado;

21. Evento requestChargeApproval é disparado para entidade externa CreditCompany; 22. Aguardando estímulo externo.

O fluxo de simulação apresentado acima criou objetos de outras classes e em determinado momento, a troca de mensagens entre um objeto e uma entidade externa gerou uma atividade de interação. Assim, o fluxo só será reiniciado após a confirmação do usuário do simulador.

\subsection{Limitações}

Neste protótipo do ModSim não é possível fazer a validação sintática dos diagramas de entrada. Assim, o autor do modelo deve garantir a entrada de um modelo sintaticamente correto.

De acordo com a falha no modelo, pode-se ocorrer apenas a simples parada da execução, como no exemplo citado anteriormente. Nesse caso, o simulador não sabia como continuar. Porém, como o comportamento do simulador não é o esperado pelo usuário da aplicação naquele momento, este pode verificar seus diagramas no ponto de parada da simulação para encontrar um possível problema. 


\section{Considerações Finais}

Tema muito difundido atualmente, a arquitetura e desenvolvimento baseados em modelos ainda não atingiu um nível de maturidade corporativo esperado. Algumas ferramentas CASE apóiam levemente esse conceito com a geração de código-fonte para plataformas específica, ainda assim, de forma incompleta.

De forma geral, essas ferramentas comerciais não permitem a visualização do comportamento da aplicação modelada antes de sua implementação efetiva, o que impede a descoberta precoce de problemas ainda no modelo de negócio do sistema.

Muitas pesquisas estão sendo realizadas para aumentar o suporte das ferramentas a abordagem MDA, ainda que parcialmente, para que possam em conjunto oferecer uma solução integrada para esse tema. Para isso, é de extrema importância a utilização de padrões abertos pelas ferramentas existentes e as que estão em pesquisa.

\subsection{Cumprimento dos Objetivos Propostos}

Este trabalho teve como objetivo a especificação de um simulador para analisar a completeza e correção quanto à semântica pretendida do sistema a ser desenvolvido, utilizando a linguagem UML junto a uma proposta de extensões e restrições que permitam a simulação dos modelos.

Para isso, foi definido um conjunto de artefatos e regras semânticas necessárias para possibilitar a simulação do modelo e foi construído uma máquina virtual de execução de modelos em nível de negócio descritos em UML.

Esse modelo deve ser criado com auxílio de qualquer ferramenta CASE utilizando os diagramas tradicionais da UML, estendido com a utilização de uma ASL e respeitando a semântica definida neste estudo para cada elemento envolvido. Então, deve-se exportar o modelo como documento XMI, que será então utilizado como entrada para o simulador, objeto deste trabalho. 
Baseado nesse modelo e nos dados complementares fornecidos ao simulador, é possível verificar se a execução do sistema modelado corresponde às expectativas do seu autor em relação à correção e completeza semântica.

O ambiente de simulação oferece algumas facilidades como o mapeamento de tipos de dados de negócio para tipos de dados técnicos específicos, criação manual e automática (aleatória) de objetos de exemplo, stubs de métodos externos e interação com o usuário do simulador quando indicado pelo modelo que existe algum processo envolvendo entidades externas.

A definição da semântica para cada um dos elementos e diagramas passíveis de simulação, junto com as definições e decisões de projeto utilizadas para a criação do ambiente que pudesse auxiliar na verificação e entendimento da aplicação, foram apresentadas.

Os testes realizados indicam que o protótipo desenvolvido pode simular o comportamento de um modelo UML de negócio. A detecção de respostas incorretas ou funções inexistentes durante a simulação permitem identificar erros ou incompletezas no modelo UML, respectivamente.

\subsection{Contribuições do Trabalho}

As principais contribuições deste trabalho são dadas para as fases iniciais do ciclo de vida de desenvolvimento de software. Simular a execução de um modelo de negócio, construído utilizando a xUML, permite iniciar a verificação do sistema mais cedo e com maior facilidade, oferecida pelo ambiente de simulação.

Quanto antes são iniciados os testes de uma aplicação em relação às funcionalidades definidas na fase de levantamento de requisitos e posteriormente modeladas em nível de negócio, menor será o esforço e o custo de adequação no caso de eventuais problemas encontrados.

Assim, espera-se que, com a utilização da proposta de xUML apresentada neste estudo para auxiliar a especificação do sistema em nível de negócio e do simulador para garantir que o modelo expressa tudo o que o autor deseja, parte do tempo gasto com retrabalho relacionado aos problemas de definição do projeto possa ser eliminado nas fases posteriores.

Quantificar isso não é uma tarefa fácil e dependeria de pesquisas baseadas no uso desse simulador, porém, independente de tamanho, a maioria dos projetos pode ganhar 
com a utilização do processo apresentado.

A interação da aplicação com usuários facilita também o entendimento da solução modelada, podendo ser utilizada como ferramenta para complementar a apresentação de protótipos e validação do comportamento da solução pelos usuários finais.

Por fim, o ambiente de simulação definido nesta pesquisa visa suportar parcialmente a arquitetura MDA em relação à criação e verificação dos modelos independentes de plataforma (PIM).

\subsection{Trabalhos Futuros}

No ModSim, a verificação sintática dos diagramas não é feita em nenhum momento. Durante uma simulação porém, o comportamento da aplicação pode indicar algum problema sintático que poderia ter sido encontrado anteriormente, dado que o documento XMI de entrada tem as informações necessárias para essa validação e geração de um log de problemas. Implementar um módulo de validação da sintaxe dos diagramas logo na importação dos mesmos para o ModSim garantiria não só a completeza e correção semântica mas também sintática do modelo UML.

Além disso, o protótipo não trabalha com todas as ações de uma ASL, apenas as necessárias para demonstração da viabilidade técnica de implementação do simulador. Sugere-se como possível continuação deste trabalho o suporte a processos concorrentes e regras temporais que devem ser adicionadas para aumentar a precisão do fluxo de execução definido em um modelo UML executável.

A possibilidade de extensão da prova de conceito apresentada para a geração de códigofonte, utilizando templates de plataformas específicas para aumentar a aderência e suporte a abordagem MDA, também é uma continuação interessante para este estudo. 


\section{Referências}

AMBROGIO, A. A model transformation framework for the automated building of performance models from uml models. In: WOSP '05: Proceedings of the 5th international workshop on Software and performance. New York, NY, USA: ACM, 2005. p. 75-86. ISBN 1-59593-087-6.

BEIERLEIN, T.; FROHLICH, D.; STEINBACH, B. Model-driven compilation of uml-models for reconfigurable architectures. Second RTAS Workshop on Model-Driven Embedded Systems (MoDES), Toronto, Canada, 2004.

BIDDLE, R.; NOBLE, J.; TEMPERO, E. Teaching the evaluation of object-oriented designs. In: ACE '03: Proceedings of the fifth Australasian conference on Computing education. Darlinghurst, Australia, Australia: Australian Computer Society, Inc., 2003. p. 213-220. ISBN 0-909925-98-4.

BLANKENHORN, K. A UML Profile for GUI Layout. Dissertação (Mestrado) - University of Applied Sciences Furtwangen, 05 2004. Disponível em: $<$ http://www.bitfolge.de/pubs/thesis/Thesis_GUILayout.pdf>.

BOOCH, G.; RUMBAUGH, J.; JACOBSON, I. The Unified Modeling Language User Guide: Addison-Wesley, 1999.

BRIDGEPOINT. Object Action Language Reference Manual, 2003.

CAMPOS, R. Model Based Programming: Executable UML With Sequence Diagrams. Dissertação (Mestrado) - Faculty of Computer Science Department, California State University, Los Angeles, 2007.

CAPRETZ, L. F. A brief history of the object-oriented approach. SIGSOFT Softw. Eng. Notes, ACM, New York, NY, USA, v. 28, n. 2, p. 6, 2003. ISSN 0163-5948.

CERNOSEK, G.; NAIBURG, E. The Value of Modeling, 2004.

CZARNECKI, K.; HELSEN, S. Feature-based survey of model transformation approaches. IBM Syst. J., IBM Corp., Riverton, NJ, USA, v. 45, n. 3, p. 621-645, 2006. ISSN 0018-8670.

FLINT, S.; GARDNER, H.; BOUGHTON, C. Executable/translatable uml in computing education. In: $A C E$ '04: Proceedings of the sixth conference on Australasian computing education. Darlinghurst, Australia, Australia: Australian Computer Society, Inc., 2004. p. 69-75.

FREEMAN, E.; FREEMAN, E. Head First Design Patterns: O'Reilly, 2004. ISBN 0-59600-712-4. 
HAUSMANN, J. H.; KENT, S. Visualizing model mappings in uml. In: SoftVis '03: Proceedings of the 2003 ACM symposium on Software visualization. New York, NY, USA: ACM, 2003. p. 169-178. ISBN 1-58113-642-0.

HAUSTEIN, S.; PLEUMANN, J. Ocl as expression language in an action semantics surface language. In: Seventh International Conference on UML Modeling Languages and ApplicationsLisbon, Portugal: , 2004.

JACOBSON, I.; CHRISTERSON, M.; JONSSON, P.; G, O. Object-Oriented Software Engineering: A Use-Case Driven Approach: Addison-Wesley, 1992.

JIANG, K.; ZHANG, L.; MIYAKE, S. Using ocl in executable uml. In: MoDELS WorkshopNashville, TN, USA: , 2007.

KIELLAND, T. Consistency checking of UML models on the XMI format. Dissertação (Mestrado) - Norwegian University of Science and Technology, 2005.

MELLOR, S. J.; BALCER, M. J. Executable UML - A Foundation For Model-Driven Architecture: Addison-Wesley, 2002.

MILlER, G.; AMBLER, S.; COOK, S.; MELlOR, S.; FRANK, K.; KERN, J. Model driven architecture: The realities, a year later. In: OOPSLA, 2004. p. 138-140.

MILlER, G.; EVANS, A.; JACOBSON, I.; JONDELL, H.; KENNEDY, A.; MELLOR, S.; THOMAS, D. Model driven architecture: how far have we come, how far can we go? In: OOPSLA '03: Companion of the 18th annual ACM SIGPLAN conference on Object-oriented programming, systems, languages, and applications. New York, NY, USA: ACM, 2003. p. 273-274. ISBN 1-58113-751-6.

MILlER, J.; MUKERJI, J. Model Driven Architecture (MDA), 2001. . Mda guide version 1.0.1. Document Number: omg/2003-06-01, 2003.

MOLLA, M. K. B. An Overview of Object Oriented Design Heuristics. Dissertação (Mestrado) — Department of Computer Science, Umea University, SuÃ@cia, 2005.

MOONEY, J.; SARJOUGHIAN, H. A framework for executable uml models. In: Proceedings of the Spring Simulation Conference, 2008.

OMG. Concrete syntax for a uml action language request for proposal. OMG Document: ad/2007-08-02, 072007.

. Uml infrastructure specification, v2.1.2. OMG Document Number: formal/200\%11-04, 112007.

RIEHLE, D.; FRALEIGH, S.; BUCKA-LASSEN, D.; OMOROGBE, N. The architecture of a uml virtual machine. In: OOPSLA, 2001. p. 327-341.

RUMBAUGH, J.; BLAHA, M.; PREMERLANI, W.; EDDY, F.; LORENSEN. Object-Oriented Modeling and Design: Prentice-Hall, 1991.

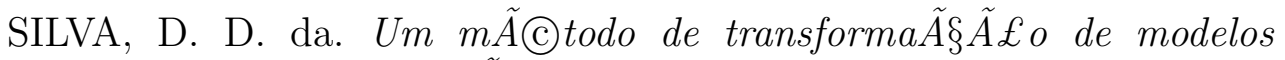
em UML e OCL para c $\tilde{A}^{3}$ digoJAVAeSQL.Tese(Doutorado) - - EscolaPolit $\tilde{A} \subset$ cnicadaUniver sidadedeS $\tilde{A} £$ oPaulo, 2005. 
TRATT, L. The mt model transformation language. In: SAC '06: Proceedings of the 2006 ACM symposium on Applied computing. New York, NY, USA: ACM, 2006. p. 1296-1303. ISBN 1-59593-108-2.

WEGNER, P. Dimensions of object-based language design. In: . New York, NY, USA: ACM, 1987. v. 22, n. 12, p. 168-182. ISSN 0362-1340.

YATAKE, K.; KATAYAMA, T. An executable semantics of object-oriented models for simulation and theorem proving. In: MSVVEIS, 2008. 